\title{
Grazing impacts on sediment production and runoff from single and mixed species grazing
}

\author{
Brittany Parks \\ West Virginia University
}

Follow this and additional works at: https://researchrepository.wvu.edu/etd

\section{Recommended Citation}

Parks, Brittany, "Grazing impacts on sediment production and runoff from single and mixed species grazing" (2013). Graduate Theses, Dissertations, and Problem Reports. 387.

https://researchrepository.wvu.edu/etd/387

This Thesis is protected by copyright and/or related rights. It has been brought to you by the The Research Repository @ WVU with permission from the rights-holder(s). You are free to use this Thesis in any way that is permitted by the copyright and related rights legislation that applies to your use. For other uses you must obtain permission from the rights-holder(s) directly, unless additional rights are indicated by a Creative Commons license in the record and/ or on the work itself. This Thesis has been accepted for inclusion in WVU Graduate Theses, Dissertations, and Problem Reports collection by an authorized administrator of The Research Repository @ WVU. For more information, please contact researchrepository@mail.wvu.edu. 


\title{
GRAZING IMPACTS ON SEDIMENT PRODUCTION AND RUNOFF FROM SINGLE AND MIXED SPECIES GRAZING
}

\author{
Brittany Parks
}

Thesis submitted to the Davis College of Agriculture, Natural Resources and Design at West Virginia University

in partial fulfillment of the requirements for the degree of

Master of Science in Plant and Soil Science

Thesis Committee:

Eugenia Pena-Yewtukhiw, Ph.D., Chair

Louis McDonald, Ph.D.

John Grove, Ph.D.

William Bryan, Ph.D.

Domingo Mata-Padrino, Ph.D.

Division of Plant and Soil Sciences

Morgantown, West Virginia

2013

Keywords: Grazing management, erosion, sediment production, mixed species grazing, land management

Copyright 2013 Brittany Parks 


\section{ABSTRACT \\ Grazing Impacts on Sediment Production and Runoff From Single and Mixed Species Grazing}

\section{Brittany Parks}

With growing human populations, we need to produce more food. Food production requires growing crops and raising livestock with existing and suitable land resources, potentially causing nutrient (phosphorus $(\mathrm{P})$ and nitrogen $(\mathrm{N})$ ) pollution. For purposes of this study, the runoff potential for the mixed and single species grassland grazing will be examined. Mixed species grazing refers to cattle and sheep grazing concurrently in the same area; while single species grazing refers to cattle grazing alone. Understanding the environmental effects of mixed grazing as compared to a single species grazing systems will help to improve farming and agricultural practices that increase sustainability and protect the environment. The goals of this study were to demonstrate how to select land management practices to maximize production while increasing environmental and farm sustainability; and to determine a direct relationship between land degradation and the two different types of grazing systems. The specific objectives of this study were to measure the effect of animal activity by monitoring selected soil characteristics/properties; and to characterize the soil properties that could be affecting water erosion and P movement in runoff water. The main hypothesis was that the single species grazing system would generate higher environmental impact (negative impact on physical and hydrologic soil properties) than the mixed species grazing system. Two experiments were developed at the WVU Animal Research farm to answer the objectives of the study. Three fields divided into six 1-ha plots were subjected to either mixed or single species grazing treatments. Two erosion plots were installed per treatment, resulting in a total of 12 erosion plots. Stratified soil samples were collected in a $10 \mathrm{~m} \mathrm{x}$ $10 \mathrm{~m}$ grid pattern, as well as within $30 \mathrm{~cm}$ of the erosion plots, on three separate sampling dates: August 2011, April 2012, and August 2012. Runoff and sediments from erosion plots were collected after every significant rain event. The measured soil properties were bulk density, penetration resistance, aggregate stability, nutrient content, $\mathrm{pH}$, organic matter content, and infiltration rate. A block ANOVA statistical analysis of the data found no statistically significant difference in bulk density between treatments; however, a significant $(\mathrm{P}=0.1)$ difference was observed in bulk density between sampling dates. Bulk density was significantly lower after winter grazing in April $2012(0.98 \pm 0.10$ $\left.\mathrm{g} / \mathrm{cm}^{3}\right)$ than after spring grazing in August 2011 and August $2012(1.03 \pm 0.09,1.09 \pm$ $0.08 \mathrm{~g} / \mathrm{cm}^{3}$, respectively). Penetration resistance was consistently higher at every depth in the single species grazing system than in the mixed species grazing system; however, this difference was not statistically significant. In general, the mixed grazing system exhibited larger dry and wet aggregate stability than the single species grazing system, however the results were not statistically significant. Overall $\mathrm{pH}$ was slightly acidic for the study area (5.15 \pm 0.45 ), which could inhibit the bioavailable nutrients; however, this effect of $\mathrm{pH}$ on the bioavailable nutrients was not observed with this study. The overall phosphorus content for the study area was $104.7 \pm 51.6 \mathrm{mg} / \mathrm{kg}$, which was well above the reported 
optimum P content for established mixed grasses (Penn State, 2012). Overall, the single species grazing exhibited higher $P$ than in the mixed species treatment. Potassium followed the same trend in that the overall $\mathrm{K}$ content for the study area was $320.8 \pm 158.6$ $\mathrm{mg} / \mathrm{kg}$; which is on the higher end of the recommended $\mathrm{K}$ contents for established mixed grasses (Penn State, 2012). Potassium also followed the same trend as P in that the single species grazing exhibited larger bioavailable $\mathrm{K}$ contents than the mixed species grazing system. Other studies have found that an increased K content at the surface increases the risk for $\mathrm{K}$ to be transported with sediments. The overall SOM $(0-5 \mathrm{~cm})$ content of the experimental area was $90.0 \pm 20.2 \mathrm{~g} / \mathrm{kg}$. The single species grazing treatment exhibited an overall average surface $(0-5 \mathrm{~cm}) \mathrm{SOM}$ of $91.7 \pm 17.7 \mathrm{~g} / \mathrm{kg}$, a value that was higher than that measured for the mixed species grazing treatment $(88.2 \pm 22.7 \mathrm{~g} / \mathrm{kg})$; the measured difference between grazing treatments was not statistically significant. Overall, the mixed species grazing treatment exhibited a faster infiltration rate than the single species grazing treatment. The average runoff volumes were separated into three periods. Average runoff volume for the mixed species was greater than the single species treatment at two of the three Periods; however the single species produced more sediment than the mixed species treatment at two of the three Periods. A split-plot ANOVA determined these differences were not significant. The average runoff volumes for the two treatments do not support the hypothesis of the study; however, all other measured variables depict trends that indicate that the single species grazing system generates a higher environmental impact than the mixed species grazing system. Since this study was only established in 2009, more research may need to be implemented to see more significant effects of the grazing treatments. 


\section{TABLE OF CONTENTS}

CHAPTER 1. INTRODUCTION AND JUSTIFICATION ................................................................... 1

CHAPTER 2. LITERATURE REVIEW ................................................................................ 5

The Erosion Process in Grazed Grasslands ....................................................................... 5

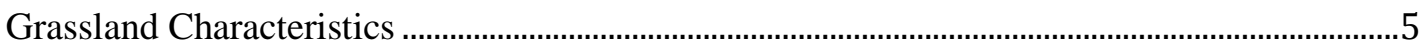

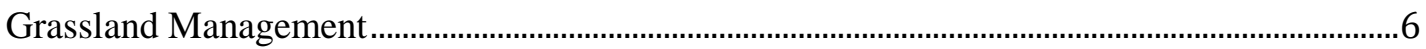

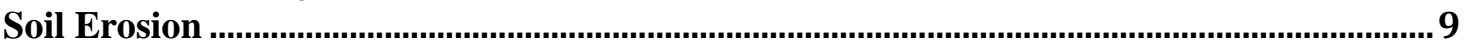

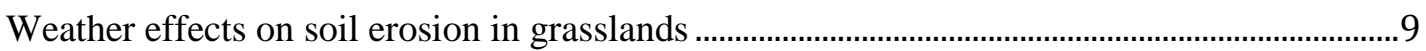

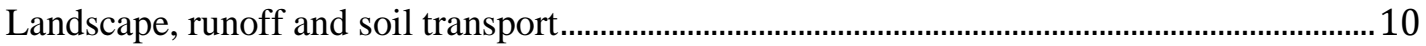

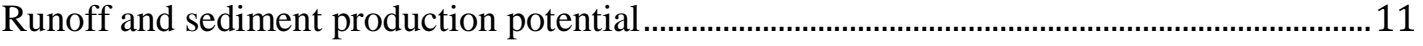

Erosion under Grazing Management ........................................................................... 16

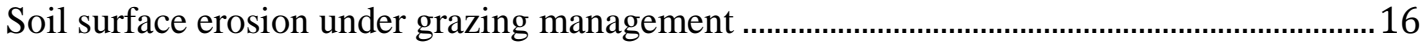

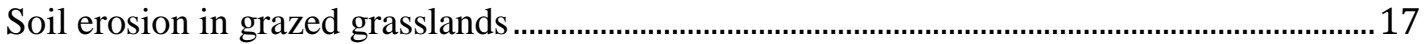

Soil phosphorus pollution from grasslands....................................................................................18

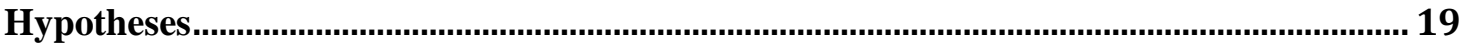

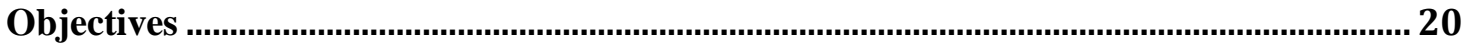

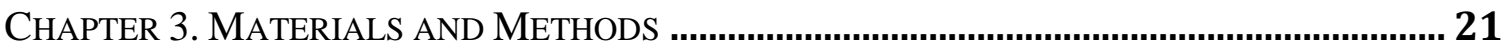

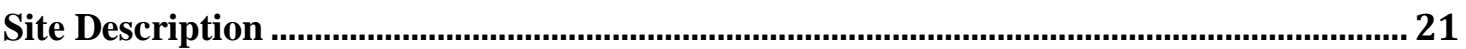

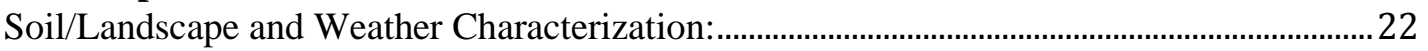

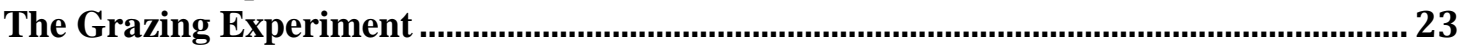

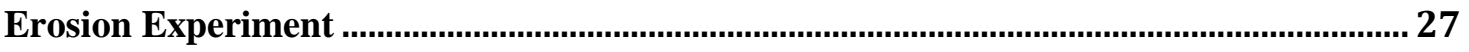

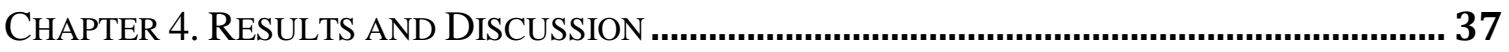

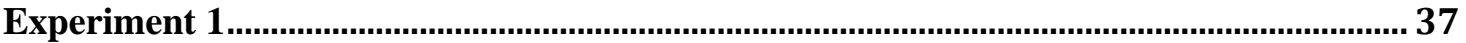

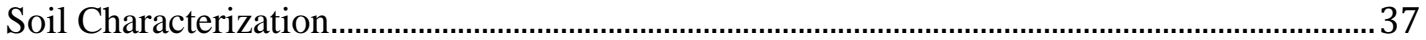

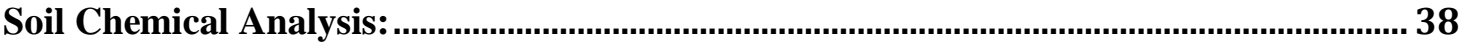

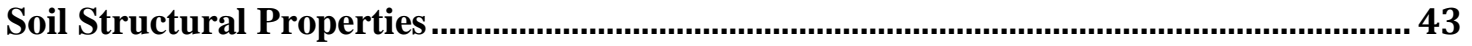

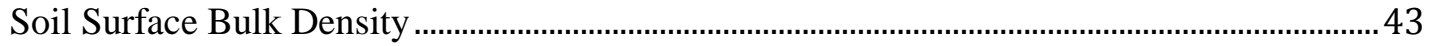

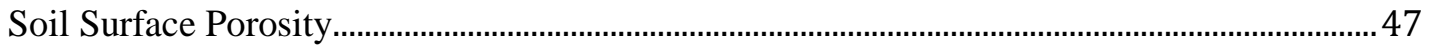

Soil Surface Dry Aggregate Stability ………................................................................................. 54

Soil Surface Wet Aggregate Stability .................................................................................. 56

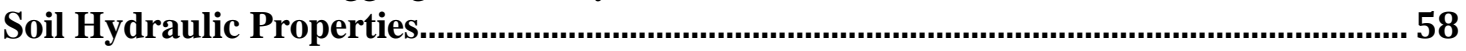

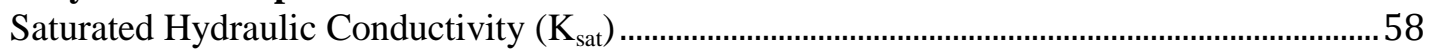

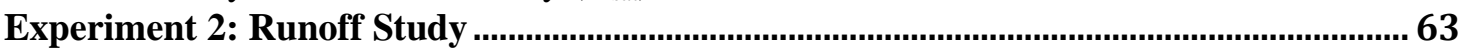

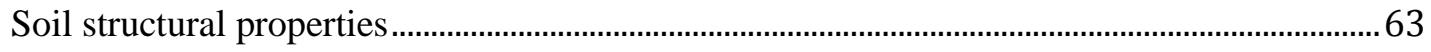

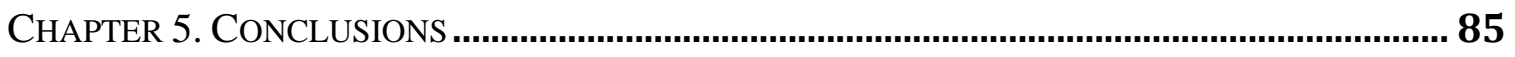

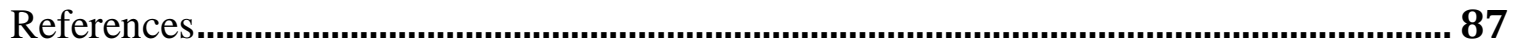

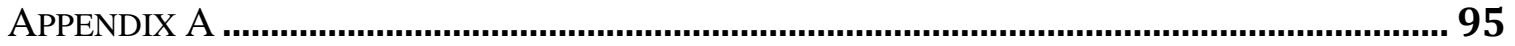

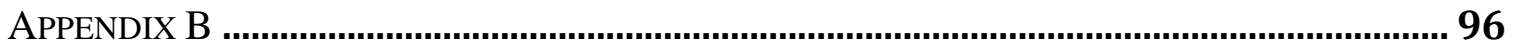

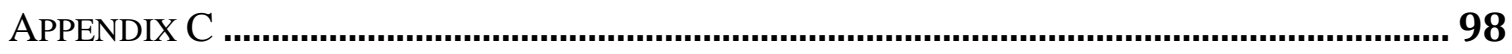

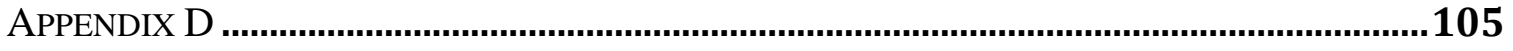

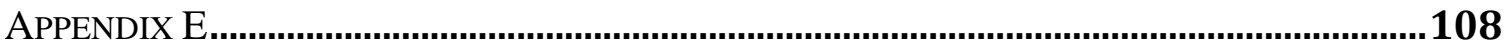

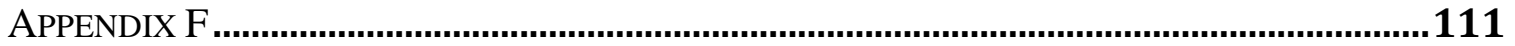




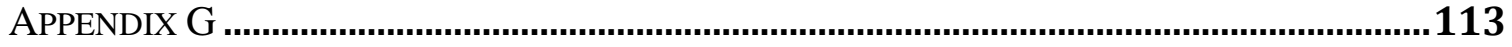

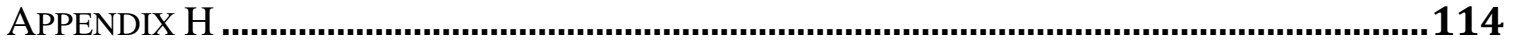

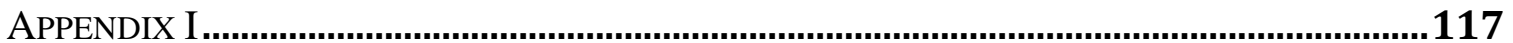




\section{LIST OF TABLES}

Table 1. Sand size fractions and sieve size identifications.

Table 2. Mean, standard deviation, and analysis of variance for soil particle size fractions measured at Date 1.

Table 3. Mean, standard deviation, and analysis of variance for $\mathrm{pH}$, SOM, STP and total $\mathrm{N}$ measured at Date 1 .

Table 4. Mean, standard deviation, and analysis of variance statistics for STK, Ca, Mg and $\mathrm{Zn}$ measured at Date 1.

Table 5. Mean, standard deviation, and analysis of variance statistics for bulk density, by date.

Table 6. Mean, standard deviation, and analysis of variance for porosity by date.

Table 7. Mean, standard deviation, and analysis of variance for penetration resistance measured at Date 1.

Table 8. Mean, standard deviation, and analysis of variance for penetration resistance at measured Date 2

Table 9. Mean, standard deviation, and analysis of variance for penetration resistance measured at Date 3.

Table 10. Mean, standard deviation, and analysis of variance for dry aggregate stability (MWD) by date.

Table 11. Mean, standard deviation, and analysis of variance for wet aggregate stability (MWD).

Table 12. Overall statistics for soil saturated hydraulic conductivity.....

Table 13. Mean, standard deviation, and analysis of variance for bulk density in the runoff study.

Table 14. Mean, standard deviation and analysis of variance for erosion plot porosity. . 66

Table 15. Erosion plot penetration resistance at Date 3 .

Table 16. Mean, standard deviation and analysis of variance for the erosion plot dry aggregate stability for Dates 1 and 3 .

Table 17. Mean, standard deviation and analysis of variance for the erosion plot wet aggregate stability determined at Date 1)...

Table 18. Soil surface $(0-5 \mathrm{~cm}) \mathrm{K}$ factor, by erosion plot.

Table 19. Mean, standard deviation, and analysis of variance for saturated hydraulic conductivity near the erosion plots at Dates 1 and 3

Table 20. Cumulative precipitation data for the three Periods. Data obtained from the weather station at the WVU Reedsville Farm.

Table 21. Mean, standard deviation, and analysis of variance for runoff by period, treatment, field, and enclosure. 
Table 22. Mean, standard deviation, and analysis of variance for sediment production, by period, according to treatment, field, and erosion plot enclosure. .................................. 83 


\section{LIST OF FIGURES}

Figure 1. Flow chart showing the interconnectedness of soil properties and the physical degradation associated with overgrazing. From Bilotta et al. (2007)...................................... 3

Figure 2. Soil map of the experimental area at the West Virginia University Reedsville Animal Research Farm. Taken from USDA (2011). ............................................................... 22

Figure 3. Soil map indicating spatial arrangement of fields and treatments in the experimental area (West Virginia University Reedsville Animal Research Farm).......... 24

Figure 4. Experimental grazing management schedule. ....................................................... 25

Figure 5. a) Sampling schedule for Experiment 1; b) Sampling schedule for Experiment

2. Stars indicate soil samples taken (Dates 1 and 3).............................................................. 25

Figure 6. Schematic Diagram of Erosion Plot ........................................................................... 29

Figure 7. a) Open Erosion Plot; b) Enclosed Erosion Plot ....................................................... 30

Figure 8. Average soil organic matter (SOM, g/kg) with soil depth. ................................... 41

Figure 9. Relationship between surface $(0-5 \mathrm{~cm})$ bulk density (BD) and clay content across the study area at Date 1 ................................................................................................ 46

Figure 10. Relationship between surface $(0-5 \mathrm{~cm})$ bulk density $(\mathrm{BD})$ and soil organic matter (SOM) across the study area at Date 1 ......................................................................... 46

Figure 11. Average penetration resistance by depth increment, across all dates, fields and

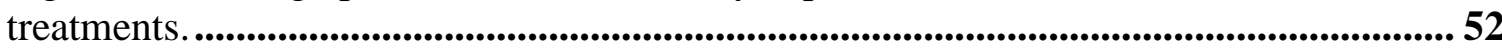

Figure 12. Relationship between wet aggregate size and soil organic matter (SOM) for the study site at Date 1 .................................................................................................................5 57

Figure 13. Relationship between bulk density and saturated hydraulic conductivity (single ring standard method) at Date 2.............................................................................................61

Figure 14. Relationship between wet aggregate diameter and saturated hydraulic conductivity (Wooding infiltrometer) at sampling Date 1..................................................... 61

Figure 15. Monthly rainfall and runoff, by treatment, during the study period................. 75

Figure 16. Runoff water visual characteristics: Breaker 1 is from an open erosion plot under single species grazing, Beaker 2 represents is from an enclosed erosion plot under single species grazing; Beaker 3 is from an open erosion plot under mixed species grazing; and Beaker 4 is from an enclosed plot under mixed species grazing. All samples came from Block/Field 1. ......................................................................................................... 80

Figure 17. Total rainfall and total runoff by period and treatment recorded during the study.

Figure 18. Relationship between surface $(0-5 \mathrm{~cm})$ dry aggregate stability (MWD) at Date 3 and sediment production $(\mathrm{Mg} / \mathrm{ha})$ during Period 3 . 84 


\section{CHAPTER 1. INTRODUCTION AND JUSTIFICATION}

Human activities like road building, crop production and mining will impact the environment, causing pollution and productivity decline. With growing human populations, there is a need to produce more food. Food production requires growing crops and raising livestock with existing suitable land resources, potentially causing nutrient (phosphorus and nitrogen) pollution. Different management systems are used

when raising livestock, e.g. confinement feeding, free range grazing, and pasture grazing. Within these systems, land-owners are encouraged to use best management practices to maintain, even increase, the sustainability and productivity of the system. Raising livestock in grassland ecosystems requires management that is in harmony with the environment.

Sustainability consists of developing and establishing management practices that enhance the ability of the land resource to support the productivity of a specific land use for an extended time. Soil is one of the most important components of a productive landscape; and is considered renewable because soil can be managed so as to restore, maintain, or increase its productivity; which may be "replenished" or recovered over a long period of time (e.g. human life span).

Different management systems exist, but specific goals need to be met. The environmental goal is to find the most sustainable way to produce livestock, and the production goal is to manage the agricultural system to optimize economic return. What the landowner decides for his/her land tends to have a specialized focus, based on the 
utilization of local resources (climate, markets, socioeconomics) to produce the best economic return (Franzluebbers, 2006). This economic optimization has led the agricultural community towards more technologically based systems, such as confinement feeding. Although confinement feeding may increase productivity and economic returns (Franzluebbers, 2006), there are environmental risks resulting from this land-use and associated management practices (i.e. animal waste management) that could reduce farm sustainability.

Grazing is considered an economical and sustainable way to raise livestock, but when the wrong management system is implemented, the consequences can be detrimental. Grazing can impact soil properties such as structure and bulk density; herbage plant species and biomass; and surface infiltration, runoff, and associated nutrient losses. If grazing is managed incorrectly, the presence of animals can damage soil quality, making this production system less sustainable. Bilotta et al. (2007) showed the interconnectedness of soil properties and their physical degradation, as caused by grazing (Fig. 1). The magnitude of physical degradation varies with the species, age, and stocking density of the grazing animal. Animals deform soil by treading and expose soil with plant defoliation. When animals graze there is forage defoliation, which leads to a decrease in herbage yield, percent cover, and biodiversity in the sward. As a consequence, the overall protection of the soil surface is reduced.

Trampling can affect both the surface soil and the vegetation. Direct trampling of the vegetation leads to decreased protection at the soil surface and, as a consequence, increases runoff and water quality degradation (Fig. 1). As soil moisture increases, the magnitude of soil property degradation tends to increase. Trampling of drier soils 
produces minimal deformation, while trampling of wetter soils creates compaction, pugging and poaching effects. Soil deformation by compaction, pugging and poaching leads to increased bulk density and decreased porosity, infiltration, and hydraulic conductivity. Additionally, soil deformation leads to increased overland flow, erosion, and water quality deterioration (Fig.1).

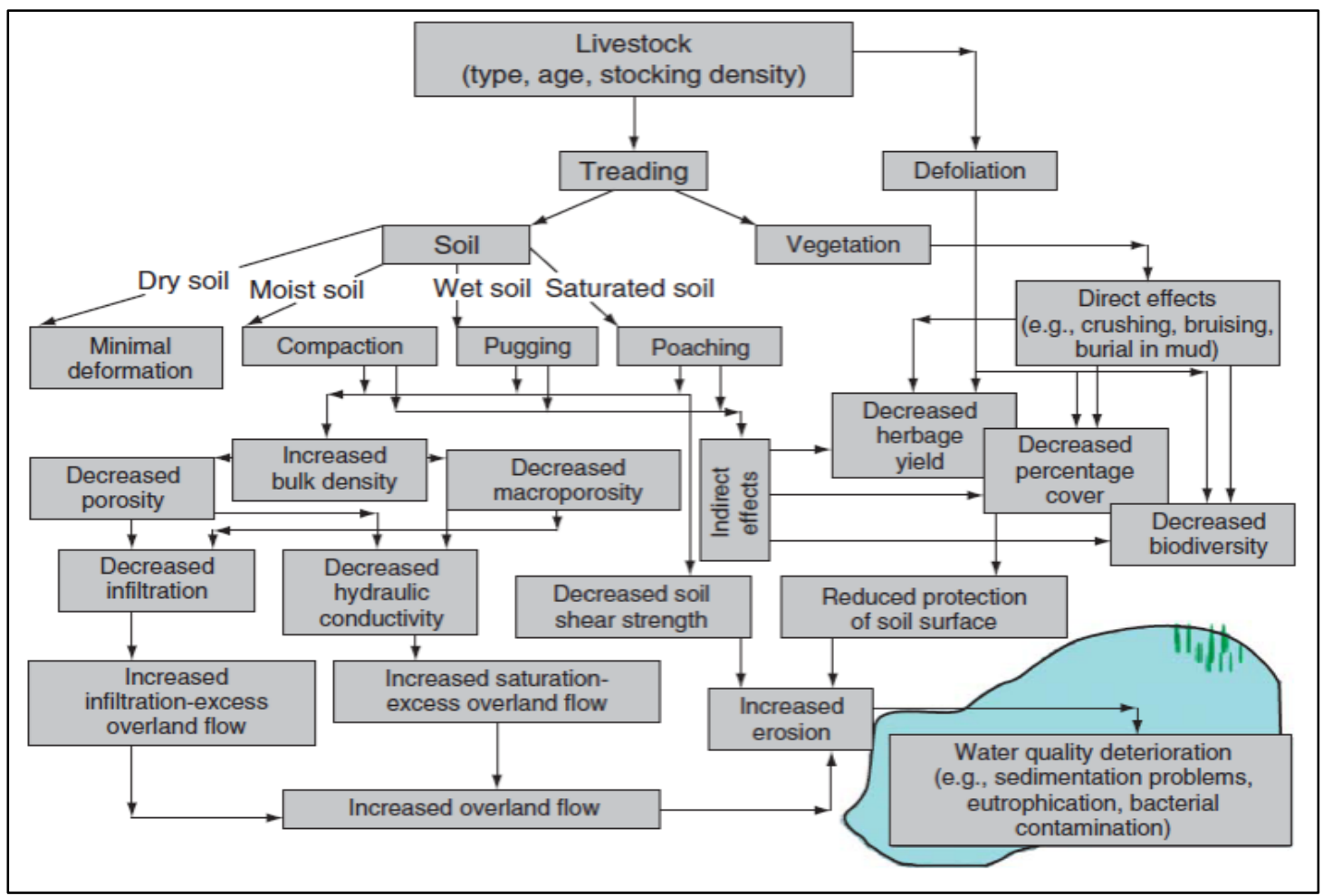

Figure 1. Flow chart showing the interconnectedness of soil properties and the physical degradation associated with overgrazing. From Bilotta et al. (2007).

Healthy grassland is defined by the National Resources Conservation Service (NRCS) as a grassland ecosystem that exhibits beneficial values and functions. Grassland environments aid in nutrient cycling, raise soil organic matter levels, provide forage for livestock, and can give recreational and aesthetic benefits (Atkin, 2006). 
Mixed and single species grazing are two management systems used when raising livestock on grasslands. A single species grazing system consists of one animal species grazing an area, while a mixed species grazing system consists of two or more species concurrently grazing the same area. Each animal species has their particular feeding behavior and requirement and, as a consequence, the single and mixed animal species activity will impact the environment differently.

In 2009, at the West Virginia University Reedsville Animal Research Farm, a project examining the differences in animal productivity due to mixed or single species grazing was started. The project opened an opportunity to study changes in soil chemical, physical and biological properties that might result from the two grazing systems. This study could provide landowners with information on grazing management systems that may increase productivity and sustainability. Understanding the effect of different grazing management systems on soil properties will aid in finding production alternatives that may reduce phosphorus losses, maintain and improve the quality of grassland soils, and sustain food production for growing human populations.

The long-term goal of this research is to deepen our understanding on how to select land management practices to maximize production while increasing environmental and farm sustainability. The goal was to determine whether there were differences in land degradation due to the two different types of grazing systems (single versus mixed species). Though the two different species grazing treatments may eventually result in differences in physical and hydrologic soil properties, the working hypothesis for this study, with measurements after only three years of treatment imposition, was that no difference due to the single and mixed species grazing treatments would be observed. 


\section{CHAPTER 2. LITERATURE REVIEW}

\section{The Erosion Process in Grazed Grasslands}

\section{Grassland Characteristics}

Grasslands are ecosystems in which the dominant plant species are grasses, lacking trees and shrubs (Wedin and Fales, 2009). Grasslands fulfill many ecosystem services while supporting unique plant and animal species. Grasslands are used for raising livestock, rural residences, oil and gas production, urban development, mining, Conservation Reserve Program (CRP) “protected areas”, and high-intensity recreation (The Heinz Center, 2002). Cold winters, hot summers, and moderate amounts of rainfall characterize grasslands found in temperate regions of the world.

The grass species found in grasslands can be characterized as native or managed. Native grasslands rely on natural evolutionary traits to help sustain the environment. Wildfires and drought help eradicate invasive, unadapted plant species (Peiper and Heitschmidt, 1988). In arid grasslands, rainfall is the most limiting factor, determining ecosystem services, such as herbage production (Cherwin and Knapp, 2012). In this study, the research focus was on managed grasslands. The predominant grass species in managed grasslands are usually not naturally found in the study area.

Different potential environmental problems can arise from grassland utilization and management practices. The vegetation in grasslands supports many ecosystem services, helping to prevent erosion by providing cover to protect the soil surface from raindrop impact, and an increasing root mass that helps hold surface aggregates together. Hofmann 
and Reis (1991) observed significant relationships between height of ground cover and soil loss. The authors reported that as ground cover decreased, soil losses increased.

Grassland soils tend to exhibit granular structure and high porosity (Brady and Weil, 2002). Infiltration rates can increase when dense vegetation and large pores (macropores) are present, reducing overland flow (Kemper and Rosenau, 1986). Senescence of roots and the burrowing of macro-invertebrates (e.g. earthworms) can create additional macropores (Drewry, 2006). Plant parts that die and fall off are incorporated into the soil, adding organic matter that can degrade from exposure to the elements (rain, snow, sun, and wind), trampling, or digestion by soil macro-invertebrates. When organic matter is added to the soil, bioavailable nutrients (available to plants) and soil stability increase (Brady and Weil, 2002).

\section{Grassland Management}

Grassland management for invasive species includes burning, grazing and chemical control (Pearson and Ison, 2004; FAO, 2012), and these are beneficial to prevent growth of undesirable plants (weeds, brush, etc.). Brush species can harbor unwanted pests, compete for nutrients and water, and can interfere with the availability of forage for animals. Managed grasslands are the result of sowing desirable plant species on cultivated land. The plant species are selected according to external factors (ability of the grass/legume species to grow in a given environment) and animal preference (FAO, 2012). In cases where managed grassland has been abandoned, researchers have observed that succession back to the natural ecosystem occurs (generally woodland). 


\section{$\underline{\text { Grazing }}$}

Bilotta et al. (2007) discuss three ways by which the presence of grazing animals can cause environmental degradation in an ecosystem; loss of vegetative matter from defoliation, deformation of soil structure from animal treading, and increased nutrient deposition from animal wastes. Preventing environmental degradation caused by animals is essential to ensuring sustainability in the production system, starting with the establishment of vegetative cover.

Vegetative matter is an essential component of grazing that acts as forage for grazing livestock, aids in protecting the soil from physical deformation, and adds organic matter to the soil. With forage management, a grazier has many things to consider. Animal species graze differently, according to quality (selectivity/preference) and quantity of herbage mass (forage availability) (Bilotta et al., 2007). Compared to cattle, sheep can be more selective while consuming forages, mainly focusing on clover and eating less dead material, due to smaller mouths/bite size (Bilotta et al., 2007). Animals also consume different amounts of forage, according to their life cycle and body weight (Bilotta et al., 2007; Pieper and Heitschmidt, 1988).

Biodiversity is an important forage characteristic to consider when selecting a grazing management system. Ensuring biodiversity in a grazing system increases the sustainability of the sward by eliminating risks associated with monocultures (e.g. plant diseases, invasive pests, decreased plant selectivity with both grazing species) (Olff and Ritchie, 1998). In a mixed grazing system, cattle and sheep selectively graze the plant species that are desirable to each of them. This suggests that having a dense sward, full of

plant species desirable to both cattle and sheep, will optimize production while increasing 
sustainability. Olff and Ritchie (1998) discussed different management practices that alter plant species diversity and richness, and found conflicting reports in the literature.

Factors such as stocking rate, grazing animal species, environment (weather, temperature, etc.) can impact plant diversity. Olff and Ritchie (1998) stated that depending on soil quality, rich or poor, herbivory in North America will increase or decrease plant diversity, respectively. When soil quality is poor, the effects of grazing will be intensified, and biodiversity within the sward will decline (Olff and Ritchie, 1998).

Forages also protect the soil from animal trampling. The above-ground plant parts act as a boundary between the hoof and the soil, while the below-ground plant parts aid in holding surface soil aggregates together, increasing shear strength and load bearing capacity (Bilotta et al., 2007). Roots aid in stabilizing the soil while reduced plant cover increases the risk of soil being separated and transported by water (Hofmann and Reis, 1991). To reduce runoff and erosion, a foundation of vegetative cover is necessary (Carroll et al., 2000).

Animals tread on soil differently; depending on hoof placement, body weight, the amount of daily movement, and hoof phenotype. Additionally, depending on soil moisture, animals can produce different degrees of soil physical deformation. When soil moisture is high soil deformation increases and, as a consequence, soil physical degradation tends to be accelerated (Drewry, 2006; Greenwood and McKenzie, 2001).

Grassland animals excrete nutrients back onto the soil. This activity is beneficial to the vegetative material because the animals are returning removed nutrients. Urine is generally rich in nitrogen $(\mathrm{N})$ and potassium $(\mathrm{K})$ and fecal matter is generally rich in nitrogen $(\mathrm{N})$ and phosphorus (P) (Bilotta et al., 2007). Added $\mathrm{N}$ tends to aid grass 
development, while P tends to support legume species. Nutrient deposition due to animal activity can alter the botanical composition of the sward. Nolan et al. (2001) studied white clover pasture density after cattle, cattle and sheep, or sheep, had grazed. The authors noticed that sheep preference for white clover surpassed cattle preference for white clover. Sheep-grazed pastures exhibited lower white clover density than those where cattle grazed alone or where cattle and sheep grazed together (Nolan et al., 2001).

\section{Soil Erosion}

Non-grazed grasslands are though to exhibit lower erosion risk than other land management systems, such as cropland. Unlike cropland management systems that include tillage, grasslands are covered with permanent vegetation. Cerdan et al. (2010) demonstrated that land management systems without permanent vegetation exhibit soil losses at least an entire magnitude greater than those that include permanent vegetation. The authors reported that European grasslands have an average erosion rate of $0.4 \mathrm{tha}^{-1}$

$\mathrm{yr}^{-1}$. Cropping systems that lack vegetative cover for prolonged periods of time will exhibit increased erosion (McCauley, 2005).

\section{Weather effects on soil erosion in grasslands}

Weather characteristics affecting soil erosion can be assessed through the measurement of the duration, intensity and amount of rain, as well as air temperature fluctuations. Some runoff and erosion studies use simulated rainfall to determine erosion rates with various land-uses (Hofmann and Reis, 1991; Thurow et al., 1988). Using simulated rainfall to mimic in-situ rain conditions can produce results that are not comparable to erosion studies performed under different experimental conditions (e.g. under natural 
conditions). Field runoff studies with natural rainfall use rain gauges near the experimental plots to determine rainfall amounts and, in some cases, intensity. However, this practice may not be entirely accurate. Rodda (1967) determined that rain gauges placed above the ground, instead of ground level, underestimate the amount of rain hitting the soil surface. Rain duration (e.g. days, hours, or minutes), jointly with rain intensity, determines the amount of precipitation received. Rain intensity, generally expressed in $\mathrm{mm} / \mathrm{hr}$, determines how much rain is deposited within a specific time frame (rate). High-intensity rains have a larger raindrop size and greater terminal energy. When a raindrop impacts the soil, the "splash" disrupts soil aggregates, breaking them into individual particles, and transporting particles and smaller aggregates. Long duration, low intensity rains may or may not produce as much runoff as short duration, high intensity rains. Short and highly intensive rains will often produce larger amounts of water/overland flow which will not be able to infiltrate the soil surface, thus creating higher amounts of runoff. Weather stations measure precipitation, temperature, and wind speed, and these data are available to perform weather analysis. Gonzalez-Pelayo et al. (2006) performed an analysis of variance (ANOVA) on rainfall data to determine periods of significant rainfall events, indicating the importance of weather records in experimental settings. The results were used to delineate four time periods, based on rainfall intensity and duration, and these authors found that after fire more intensive rains produced more erosion.

\section{Landscape, runoff and soil transport}

Landscape determines the location and magnitude of sediment transport through the ecosystem. Landscape characteristics such as slope, aspect, curvature and cover are 
essential information so as to understand overland flow and erosion. In cases where water cannot infiltrate into the soil, overland flow, driven by gravity, will cause detached soil (sediment) to move down slope. Slope and aspect determine the soil moisture level at the beginning of a rain event and the side of the field facing the direction of the weather event is often more moist (Bennie et al., 2006; Casanova et al., 2000). Topographical aspect affects soil temperature. North of the equator, north-facing slopes tend to have cooler temperatures than south-facing slopes (Brady and Weil, 2002). Relationships between soil properties and slope and aspect have been studied. Casanova et al. (2000) used tension infiltrometers to measure differences in infiltration as affected by slope and aspect, and observed that south-facing slopes exhibited higher clay and organic matter contents than north-facing slopes. Carroll et al. (2000) showed that erosion rates were negligible in dense swards, but when vegetation cover was poor erosion risk was greatest. Nearing et al. (2005) found no correlation between curvature and hillslope erosion rates, but curvature may give more information on the direction of the runoff, and compound topographic indices (e.g. moisture index) can aid in the determination of preexisting soil moisture contents within the landscape.

\section{Runoff and sediment production potential}

The Revised Universal Soil Loss Equation (RUSLE) has been used by many researchers to describe the components of the soil erosion process under a specific land management system, at a specific site. The RUSLE model is composed of factors such as rainfall erosivity, soil erodibility, topographic features, and management. Using this model, runoff and sediment production potential may be estimated. Soil erodibility is defined as the susceptibility of a soil/site to be eroded, and is estimated as the soil loss when all 
other erosion factors (i.e. infiltration rate, porosity, rainfall intensity) are equal. Soil structure, texture, and organic matter content are a few of the major soil properties that define and characterize soil erodibility. Soil structure is assessed by determining aggregate size distribution, organic matter content, and porosity (Troeh et al., 2004). Many factors, such as parent material, bulk density, texture, and cation exchange capacity (CEC) will influence soil erodibility (Troeh et al., 2004). A well-structured soil with a well-distributed aggregate size distribution, high organic matter content, low bulk density, and high CEC is less likely to degrade in the face of environmental forces such as wind or water erosion.

Mineralogy can influence soil structure, describing the clay types found in the soil matrix (Wilson, 1999). Soils higher in kaolinite (1:1-type clay with one tetrahedral sheet and one octahedral sheet) will produce less stable aggregates than those with smectite, (2:1-type clay with one octahedral sheet between two tetrahedral sheets). Smectite is 'sticky', binding with other soil particles to form soil aggregates (Troeh et al., 2004).

Bulk density is calculated by dividing the mass of soil particles by the total volume of the soil. High bulk density soils have a higher specific weight and less pore space than low bulk density soils. Soils with high bulk densities exhibit reduced macroporosity, and as soil moisture content increases, infiltration rates will decrease and overland flow will increase on these soils. Bulk density and penetration resistance are used to determine the degree of compaction. In ungrazed pastures, bulk density is low, while in grazed pastures bulk density is higher, due to increased trampling (Zhou et al., 2010).

Soil aggregate stability is determined by quantifying whether soil cohesive forces (forces which hold the aggregate together) can withstand an applied disruptive force (Kemper 
and Rosenau, 1986). Aggregate stability is important in grazing operations because stability promotes plant health and biomass production. When a soil is dominated by large aggregates of the same size (not well graded), that soil is not easily compacted because aggregates cannot move more closely together as opposed to a well-graded soil in which aggregates can move more closely together, fitting smaller aggregates amongst the larger aggregates. As a consequence, soils dominated by small or both small and large aggregates will not contain the macropores needed for plant roots to penetrate, grow, and absorb nutrients. A reduction in soil macroporosity is traditionally seen with soil tillage, but animal activity may also cause soil compaction (Brady and Weil, 2002). Soil structure and stability are determined by the aggregate size distribution after the soil has been subjected to a stress. The larger the aggregates, the higher the soil porosity and expected infiltration rate (Troeh et al., 2004).

The infiltration rate is also related to permeability, and determines the rate at which water is absorbed by the soil surface. The process of soil water infiltration allows precipitation to move into the soil. Soils with high porosity tend to conduct water faster than soils with low porosity. However, not all soils with high porosity will conduct water quickly. Pore continuity/tortuosity is important to the rate of infiltration and water movement. The more continuous/less tortuous the pores, the faster water will infiltrate and move through the soil. Understanding soil hydraulic conductivity and infiltration rate is important to following how water moves through the soil profile. Hydraulic conductivity, which is related to the permeability of a soil system, indicates the ease of water movement through the system. Pietola et al. (2004) showed that even low intensity grazing decreases infiltration rate to about $20 \%$ of that observed in non-grazed systems. Trampling causes a 
decrease in hydraulic conductivity due to destruction of macropores (Pietola et al., 2004; Reszkowska et al., 2010).

A higher soil organic matter (SOM) content increases soil stability by improving the ability of soil aggregates to resist deformation due to a physical force (Troeh et al., 2004; Lado et al., 2005). Lado et al. (2005) assessed SOM and aggregate size effects on surface seal formation, and found that soils with higher SOM exhibited significantly higher aggregate stabilities and lower seal formation. Lado et al. (2005) determined that the SOM acted as cement, holding soil particles together in aggregates. Particle cementation increases soil aggregate stability and improves soil structure, therefore decreasing soil erodibility. Vegetation-derived extracellular polysaccharide coatings and root exudates are water repellant, promote overland flow (Hallett et. al, 2001), and can strengthen an aggregate by gluing particles together (Six et al., 2002a). Organic matter offers habitat for microbial activity, and microbial exudate increases soil stability.

As SOC increases, soil aggregate stability and infiltration rate increase, and soil transportability decreases. When measuring SOC in non-grazed, light continuous and heavy continuous grazing, concentrations were observed to be highest with light continuous grazing or rotational grazing and lowest in heavy continuous grazing (Ingram et al., 2008; Teague et al., 2011).

Texture is defined as the primary particle (sand, silt and clay) size distribution. As was discussed previously, the clay fraction helps to hold aggregates together, while higher contents of sand and silt indicate a less stable structure. Infiltration rates are likely lower in soils with high clay and silt contents, decreasing permeability and causing ponding/accumulation of water at the soil surface (Troeh et al., 2004). Raindrop energy at 
the surface of the soil can be decreased and dispersed by coarse particles, such as rocks (Epstein et al., 1966). Rocks at the surface can increase infiltration and decrease compaction (Epstein et al., 1966).

Cation exchange capacity also plays a role in controlling soil erodibility. A high CEC is related to greater clay "specific surface", with more sites that can hold and exchange cations and attract other clay particles and organic matter. However, when colloids have a high level of exchangeable $\mathrm{Na}^{+}$(occupying more than $10 \%$ of the CEC), colloids will be dispersed, preventing aggregation, and erodibility will be enhanced (Troeh et al., 2004). Another important factor that affects soil erodibility is previous land use. A cultivated soil will erode differently than a soil that has been under rotational grazing. Past erosion studies have focused on runoff from cropland under conventional (Tiessen et al., 2009) or reduced tillage production systems (McCool et al., 2008). Tiessen et al. (2009) used modeling to assess water erosion and tillage practices within potato production. In this study, reduced tillage was found to reduce water erosion and soil degradation on hillslopes (Tiessen et al., 2009). McCool et al. (2008) compared the amount of soil erosion produced under reduced tillage winter wheat, with burning for weed control, to conventionally managed winter wheat. The amount of soil loss from both management systems was not significantly different (McCool et al., 2008).

Runoff from grasslands has always been considered to contribute small amounts of sediment, making the environmental impact negligible. Some erosion studies have been performed to evaluate the impact of grazing animals on infiltration rates and interrill erosion, and have found evidence that runoff from livestock production in grasslands should not be disregarded (Thurow et al., 1988; Evans, 1997; Hofmann and Ries, 1991). 
Evans (1997) assessed sheep production in the UK, and reported that after the 1946 Agriculture Act and headage payments (payment per head of sheep), sheep populations dramatically increased. Evans (1997) observed that increased sheep populations led to overgrazing and higher erosion rates. Thurow et al. (1988) observed seasonal differences among infiltration rates for both short duration and heavily stocked grazing management, but no seasonal differences in moderately stocked continuously grazed treatments.

Hofmann and Ries (1991) determined that vegetation and cover, not soil properties, determined erodibility of a rangeland in the northern Great Plains (USA). However, little research has been done to determine the impact of mixed grazing systems on soil physical properties, and no published research determining erosion rates in these grazing systems has been found.

\section{Erosion under Grazing Management}

\section{Soil surface erosion under grazing management}

When animals are included in grassland production systems, whether the system is a concentrated animal feeding operation (CAFO) or grazed grassland, soil erosion is positively related to the stocking rate/intensity (Bilotta et al., 2007; EPA, 2012). Concentrated animal feeding operations provide feed to many animals in a small land area, and are listed as a potential pollutant point source in the 1972 Clean Water Act (Hribar, 2010). The concentration of animals in small areas can create dramatic trampling effects, destroy vegetative material (increasing soil susceptibility to erosion), increase surface concentrations of urine and feces and, as a consequence, increase runoff that may enhance transport of sediments, nutrient concentrations, and organic matter to waterways 
(EPA, 2012). Compared to CAFOs, grasslands provide more land area such that the effect of the animals on soil and vegetation is dispersed throughout the landscape.

\section{Soil erosion in grazed grasslands}

Grazing imposes stress on the soil system. The surface pressure imposed by the grazing animals may degrade the soil by producing soil compaction. As discussed earlier, Bilotta et al. (2007) described three types of surface degradation in grazing management systems; compaction, pugging and poaching. Cattle cause different soil disturbance effects than sheep; cattle result in greater surface disturbance and less compaction. Sheep, on the other hand, cause little surface disturbance and greater compaction (Betteridge et al., 1999).

Compaction in grazing systems occurs when a force, such as the impact of animal hooves, is applied to the soil surface. Compaction can reduce soil pore size (amount of porosity) and, as a consequence, reduce the soil air and water volume. This type of soil degradation reduces vegetative growth and soil permeability (Bilotta et al., 2007).

Pugging is defined as the plastic deformation of soil materials due to animal activity. Because the soil has plastic properties, once soil materials are deformed, the materials tend to stay in that state. Drewry (2006) described pugging as trampling that causes "deep hoof imprints" that can inhibit vegetative growth and create a non-uniform pasture surface. Pugging occurs when the soil is moderately saturated (high moisture content) (Bilotta et al., 2007; Drewry, 2006). Poaching is an elastic deformation of the soil materials. After a force has been applied, deformation occurs, and once the force is removed, the soil returns to the original shape. Poaching occurs under saturated 
conditions, and is characterized by lateral deformations, without a change in soil volume (Bilotta et al., 2007). Soil moisture content determines soil susceptibility to structural alterations. Soil moisture dynamics during different seasons or rainy periods will determine the susceptibility of a soil to deformation in the field.

\section{Soil phosphorus pollution from grasslands}

During grazing events animals recycle, redistribute, and may introduce more nutrients into their pasture with their excretions. Only a small percentage of the nutrients ingested by cattle are assimilated and utilized by the animal and, as a consequence, animals excrete unutilized nutrients back to the soil surface (Bilotta et al., 2007). Since each animal species has different grazing habits and forage preferences, excretions of individual species may have different nutrient concentrations.

Phosphorus is essential for plant and animal nutrition. Phosphorus is easily bound to soil particles, sometimes becoming unavailable for plants. Since P is a non-renewable resource, landowner management practices must be designed to minimize losses. One $\mathrm{P}$ management practice involves adding inorganic $\mathrm{P}$ to the soil. The negatively charged inorganic phosphate ions react with positively charged cations held on soil particles, such as calcium, iron and aluminum, forming compounds increasingly insoluble with time (Mississippi State University Extension Service, 2010). Soil pH is somewhat indicative of whether soil bound $\mathrm{P}$ is relatively available or unavailable to plants ( $\mathrm{pH}$ values around 6 to 7 indicate higher $\mathrm{P}$ availability). In an agricultural setting, most of the $\mathrm{P}$ lost from the soil is bound to soil particles (Elrashidi, 2010). Sharpley (1995) found that P losses from pastures/hayfields were significantly less than those from a more soil disturbing land management system, such as conventionally tilled cropland. Soil-bound P and soluble P 
are found at the soil surface, and both can be lost by transport in runoff. Most of the $\mathrm{P}$ found in streams is bound to, and carried by, eroded soil sediment (Troeh et al., 2004). Recent $\mathrm{P}$ isotope studies have determined that $\mathrm{P}$ is eroded from a thin surface soil layer (Sharpley, 1995).

An increase in sediment production due to erosion can cause water turbidity problems, reducing water quality. Certain forms of $\mathrm{P}$ (and $\mathrm{N}$ ) lost by erosion can cause eutrophication in water bodies. Phosphorus losses from intensively grazed fields have been shown to be high enough to cause eutrophication (Haygarth and Jarvis, 1996). Grazing systems may differ in their ability to prevent erosion. Understanding the erosion process, under different grazing systems, is important in preventing $\mathrm{P}$ from becoming a surface water pollutant. Specifically, understanding the effect of different grazing management systems on soil properties will aid in finding production alternatives that may reduce $\mathrm{P}$ losses, maintain and improve quality of grassland soils, and sustain food production for growing human populations.

\section{Hypotheses}

Though the two different species grazing treatments may eventually result in differences in physical and hydrologic soil properties, the working hypothesis for this study, with measurements after only three years of treatment imposition, was that no difference due to the single and mixed species grazing treatments would be observed. Over time, the hypothesis for this study would be that the single species grazing system would generate higher environmental impact (negative impact on physical and hydrologic soil properties) than the mixed species grazing system. 
Eventually, a single species grazing system will reduce soil quality, defined by soil physical and chemical characteristics (soil structure, soil texture, bulk density, infiltration rate, nutrient content, $\mathrm{pH}$, and organic matter content) when compared to the mixed grazing system. This means that we would find that soils under the single species grazing system will have high bulk densities, lower infiltration rates and hydraulic conductivity, impaired soil structure and reduced levels of plant available nutrients, all indicative of reduced soil quality.

\section{Objectives}

The research objectives were to:

1.) Measure the effect of single and mixed species grazing on soil structure, texture, bulk density, infiltration rate, $\mathrm{pH}$ and nutrient and organic matter contents.

2.) Characterize soil properties (soil organic matter, bulk density, texture, penetration resistance, aggregate stability, surface hydraulic conductivity, infiltration rate) affecting runoff volume and sediment production during water erosion.

After fulfilling the objectives described for this project, it will be possible to make inferences about the erosion process occurring in paddocks with mixed and single species grazing. From these inferences the environmental impact of runoff, nutrient losses, and sediment production from these grazing systems may be assessed. 


\section{CHAPTER 3. MATERIALS AND METHODS}

\section{Site Description}

The West Virginia University Reedsville Farm $\left(79^{\circ} 47^{\prime} \mathrm{W}\right.$ and $\left.39^{\circ} 30^{\prime} \mathrm{N}\right)$ is located in Preston County, West Virginia. The area is characterized by long winters and short growing seasons. During the winter months, the ground is mostly snow covered, accumulating $190 \mathrm{~cm}$, on average. Extreme temperatures range from $35^{\circ} \mathrm{C}$ to $-31^{\circ} \mathrm{C}$ and the average annual precipitation is 127 centimeters. Preston County was carved out by the Cheat River, resulting in a high, dissected plateau.

The soil series found within the selected experimental area are the Ernest silt loam, with 3-8 percent slopes $(\mathrm{ErB})$; and Rayne silt loams, with 3-8 $(\mathrm{RaB})$ and 8-15 $(\mathrm{RaC})$ percent slopes (Fig. 2). The Rayne silt loams are fine-loamy, mixed, Typic Hapludults and the Ernest silt loam is a fine-loamy, mixed Aquic Fragiudult (USDA, 2011).

This study took place within an existing grazing experiment established in 2009 to assess grazing animal performance and soil and forage plant community differences resulting from mixed or single species grazing. Two experiments were used in this study. The first experiment used the grazing experiment to generate information to assess mixed and single species grazing impacts on soil properties, and the second, an erosion/runoff experiment within the grazing experiment that assessed the overland flow and sediment production resulting from the grazing treatments. 


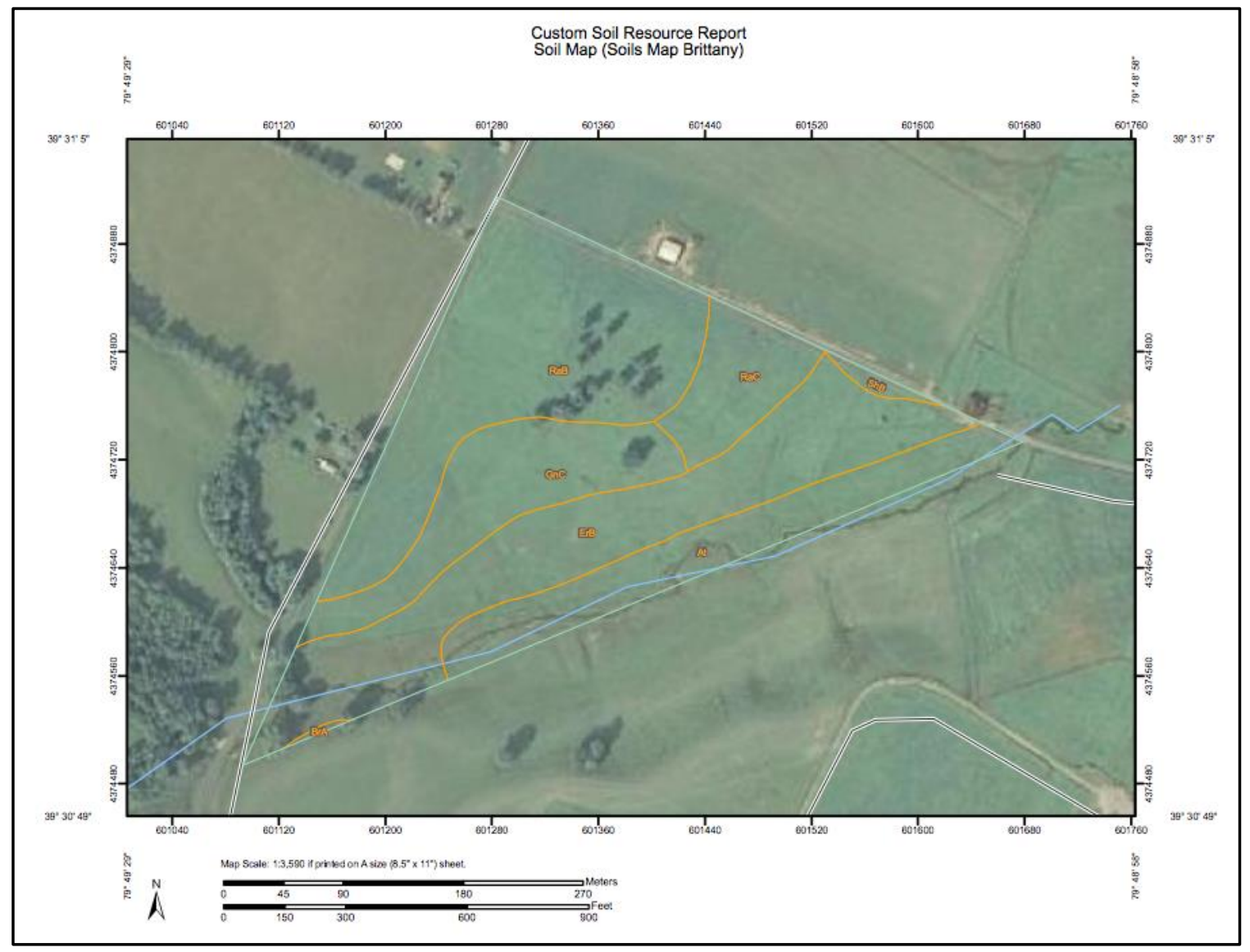

Figure 2. Soil map of the experimental area at the West Virginia University Reedsville Animal Research Farm. Taken from USDA (2011).

Soil/Landscape and Weather Characterization:

Soil texture, slope, and weather variables were measured at the research site. Overall slope of each grazing treatment, in each field, was determined with an Abney level at the beginning of the experiment (August 2011). Weather (total precipitation, maximum, minimum, and average air temperature) was recorded manually and daily from a weather station located at the WVU Reedsville Farm. The variables used in this experiment were total rainfall, average rainfall per event, the number of rain events above the average, and the percentage of the total number of rain events that were above average. 


\section{The Grazing Experiment}

This experiment was designed to test the hypothesis that the single species grazing treatment would generate higher environmental impact (negative impact on physical and hydrologic soil properties) than the mixed species grazing system. The objective of this experiment (Objective 1) was to measure the effect of animal activity on selected soil characteristics and properties.

The grazing experiment was established in 2009 , in a 2.4 ha (six acre) area. The experimental area was composed of three fields/replicate blocks, each divided into two paddocks. Field 1 was in the western portion of the area, Field 2 was in the center, and Field 3 occupied the eastern part of the experimental area (Fig. 3). The single and mixed grazing treatments each were randomly assigned to one of the two paddocks in each field/replicate block, resulting in a randomized complete block design. The paddock assignments for the treatments were kept constant for the duration of the study (Fig. 3).

Single species grazing consisted of two bovine present in the paddock at the same time; mixed species grazing consisted of one bovine and six sheep. The animal ratio (calculated by the researcher who established the grazing study) was established on the assumption that six sheep would remove the same amount of forage as one bovine. At the end of August 2011, and again in August 2012, the animals were removed from all paddocks, and forage was stockpiled for three months. During the winter season, steers were grazed in all six paddocks (Fig. 4). The steers (Bos taurus) used in the experiment were Angus by Hereford crossbreds (initial weight $=300 \mathrm{~kg}$ ). The sheep (Ovis aries) used in the experiment were suffolk by dorset crossbreds (initial weight $=25 \mathrm{~kg}$ ). 
A mixture of grasses and legumes prevailed in the paddocks, including orchardgrass (Dactylis glomerat), Kentucky bluegrass (Poa pratensis), tall fescue (Schendonorus phoenix), velvetgrass (Holcus lanatus), white clover (Trifolium repens), and red clover (Trifolium pretense). All other plants were categorized as forbs.

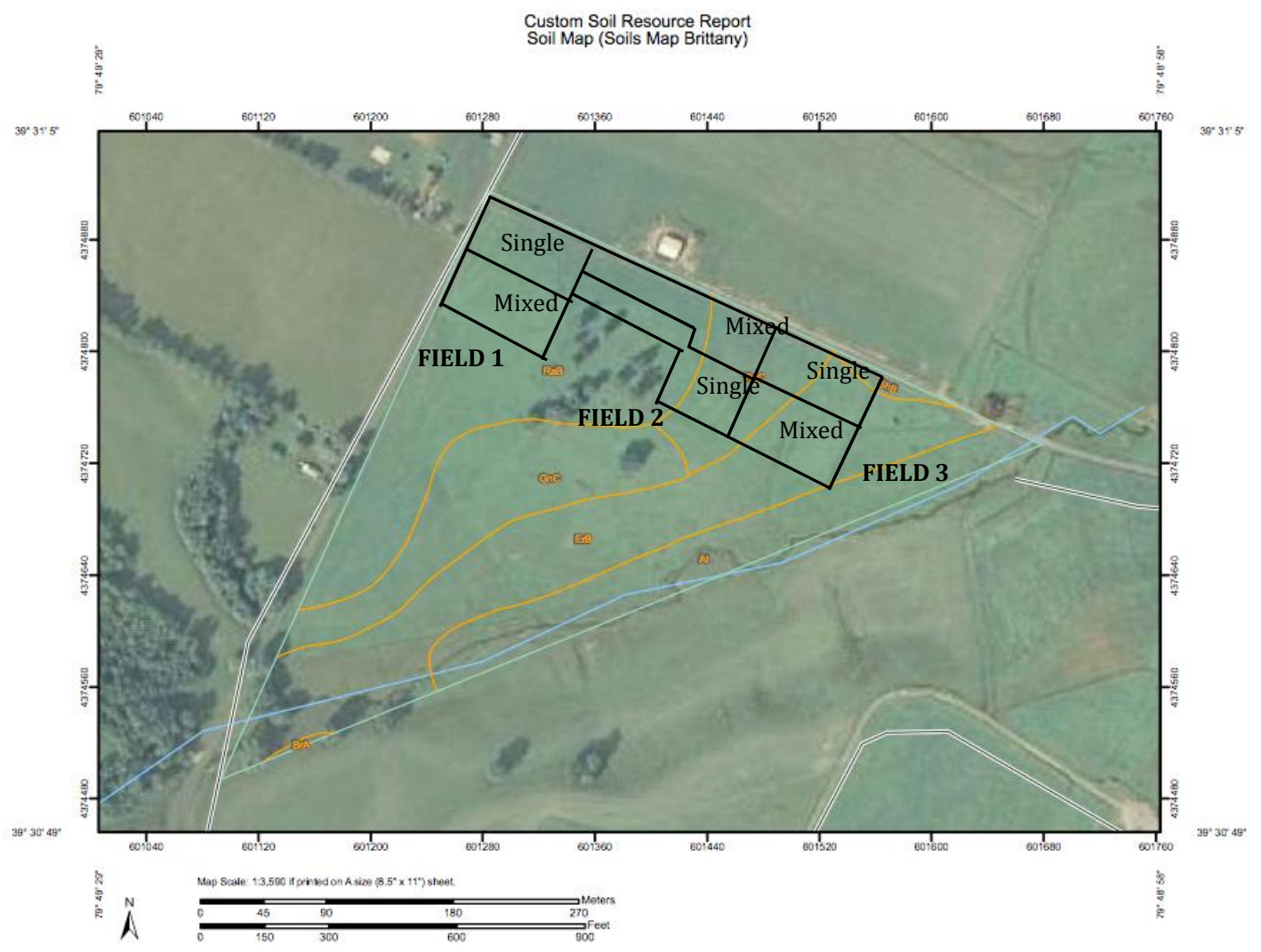

Figure 3. Soil map indicating spatial arrangement of fields and treatments in the experimental area (West Virginia University Reedsville Animal Research Farm). 


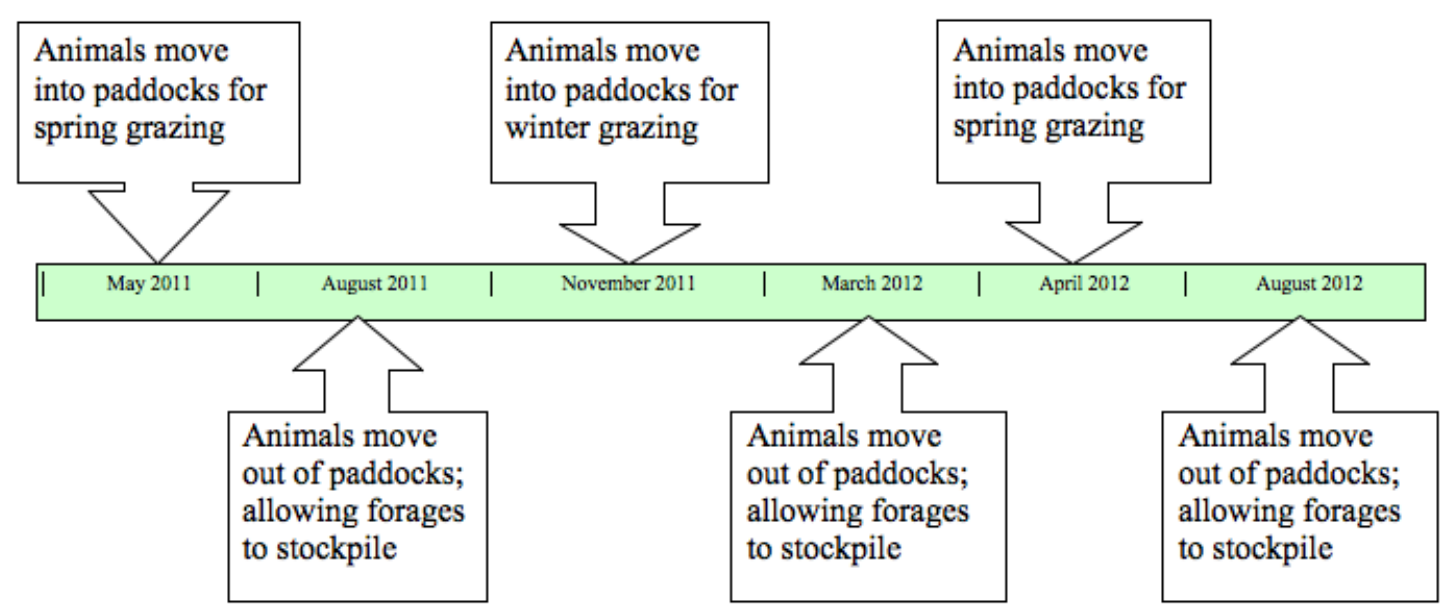

Figure 4. Experimental grazing management schedule.

a)

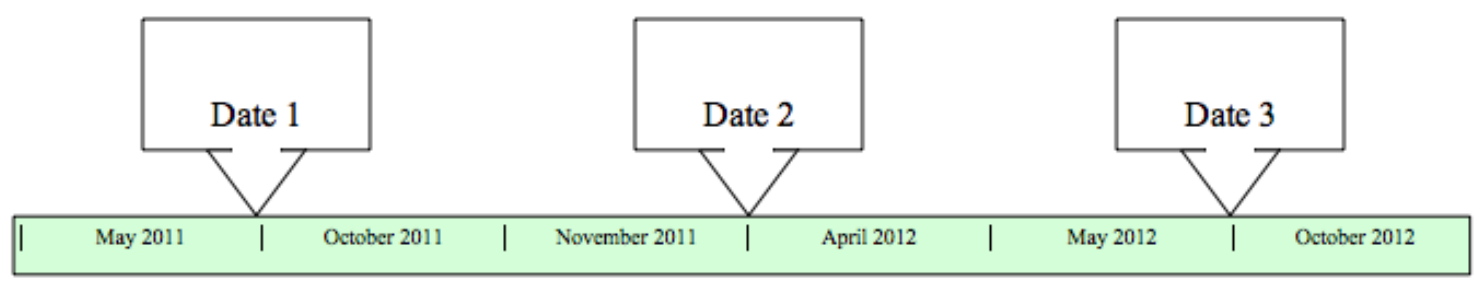

b)

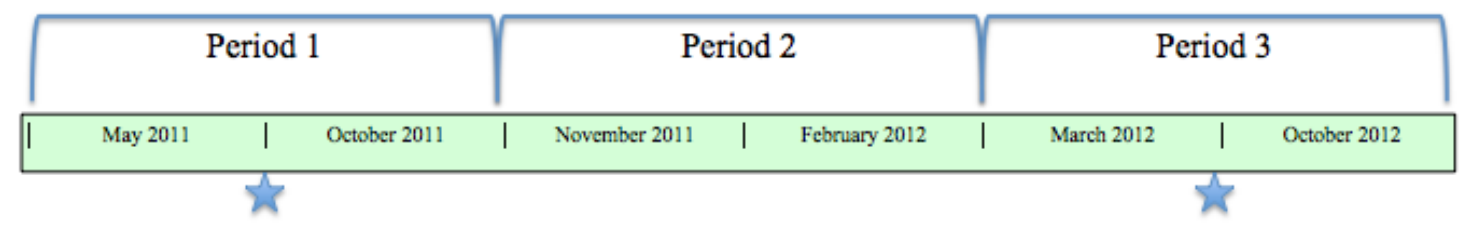

Figure 5. a) Sampling schedule for Experiment 1; b) Sampling schedule for Experiment 2. Stars indicate soil samples taken (Dates 1 and 3). 


\section{Soil Sampling}

In each paddock, soil sampling was performed on a $10 \mathrm{~m}$ by $10 \mathrm{~m}$ grid. A total of 77 individually geo-referenced points were sampled. At each of the 77 geo-referenced points, bulk density, texture, single ring infiltration, penetration resistance, aggregate stability, and stratified soil cores $(0-5,5-10,10-15,15-20 \mathrm{~cm}$ depth) were determined/taken. There were three soil sampling events: After spring grazing in August 2011 (Date 1), after winter grazing in April 2011 (Date 2), and after spring grazing in August 2012 (Date 3) (Fig. 5a). However, not all variables were measured at each event. The following variables were only determined from the stratified soil samples taken at Date 1 (August 2011): texture, bioavailable nutrients (P, K, Ca, and Mg), soil organic carbon (SOC) and total nitrogen. Other variables measured at Date 1 were bulk density, porosity, aggregate stability, penetration resistance and saturated hydraulic conductivity (Wooding infiltrometer). The variables measured at Date 2 (April 2012) were bulk density, porosity, aggregate stability, penetration resistance, and saturated hydraulic conductivity (single ring infiltrometer). The variables measured at Date 3 (August 2012) were bulk density, porosity, aggregate stability, penetration resistance, and saturated hydraulic conductivity (single ring infiltrometer).

\section{Statistical Analysis}

For the variables measured in this experiment, descriptive statistics and Pearson correlation coefficients were calculated using SAS software (SAS Institute Inc., 2009). Soil data were analyzed using a one-way treatment classification (grazing treatments) in a randomized complete block design using PROC GLM of SAS (SAS Institute Inc., 2009). 
Because the measured variables define unstructured populations, differences were determined using the Least Significant Difference (LSD) procedure.

At the end of the experiment the effect of date and the interactions between treatment and date was analyzed using a two-way treatment classification (date and grazing treatments) analysis of variance in a randomized complete block design using PROC GLM of SAS software (SAS Institute Inc., 2009).

\section{Erosion Experiment}

This experiment was designed to test the hypothesis that the single species grazing system would generate higher environmental impact (negative impact on hydrologic soil properties) than the mixed species grazing system. The objectives of this experiment were to characterize soil properties affecting water erosion and sediment transport (Objective 2). Two erosion plots were installed in each paddock. The erosion plots were designed to catch sediment and runoff from a $1.5 \mathrm{~m}^{2}$ area of the paddock (Fig. 6). The slope within each erosion plot was between 9 and 11\%, and was measured with carpenter levels and a combination of rulers. The slopes around the plots were measured using an Abney level.

One of the two erosion plots installed in each paddock was open to animal grazing (Fig. 7a) and the other was enclosed or protected from grazing activity (Fig. 7b). The plot design was similar to the design used in Willard (2010) (Fig. 6). Specific modifications were made to accommodate for grazing activity. These modifications included the use of flexible and durable materials for plot boundaries, so that animals would not suffer leg 
injuries during the experiment. The erosion plots did not collect the totality of runoff and sediment produced in a paddock. However, they were placed in the field to represent the general paddock conditions.

\section{Soil, Sediment and Runoff Water Sampling}

Soil variables related to the erosion potential were measured within $30 \mathrm{~cm}$ of the erosion plot; two sampling points per plot. Variables measured at each sampling point were insitu water infiltration, bulk density, texture, penetration resistance, aggregate stability, and stratified soil cores $(0-5,5-10,10-15,15-20 \mathrm{~cm}$ depth). Two soil sampling events were performed: After spring grazing in August 2011 (Date 1) and August 2012 (Date 3) (Fig. 5). However, due to the nature of some of the measured soil variables, not all variables were measured at each event. Soil texture and sand fractionation analyses were only determined on the stratified soil samples taken at Date 1. Other variables measured at Date 1 were bulk density, porosity, aggregate stability, and saturated hydraulic conductivity (Wooding infiltrometer). Runoff water and sediment samples were gathered from the erosion plots depending on weather conditions, whenever rain events produced appreciable runoff. 


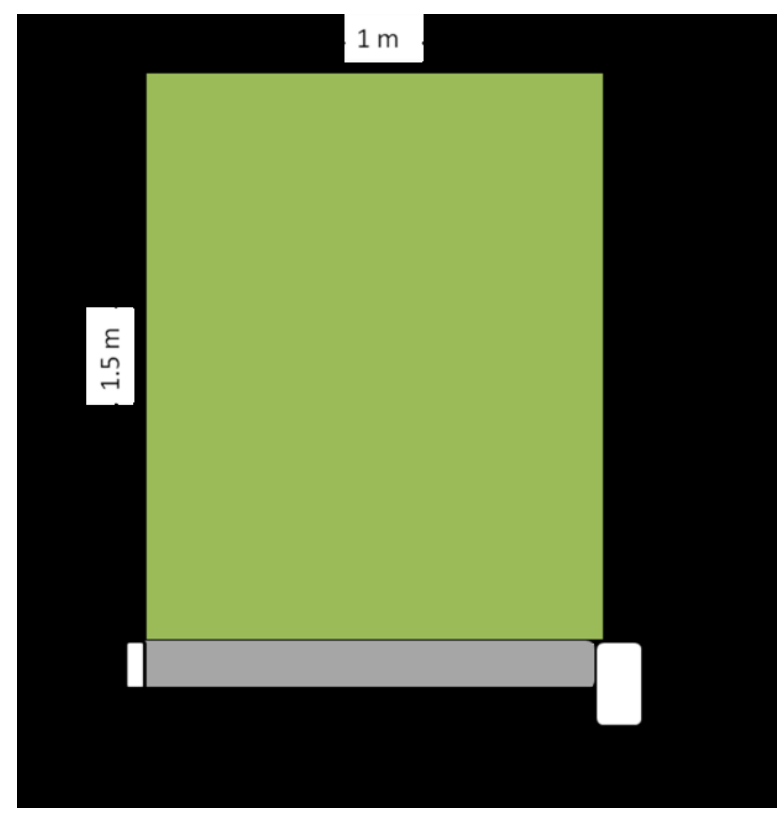

Figure 6. Schematic Diagram of Erosion Plot

a)

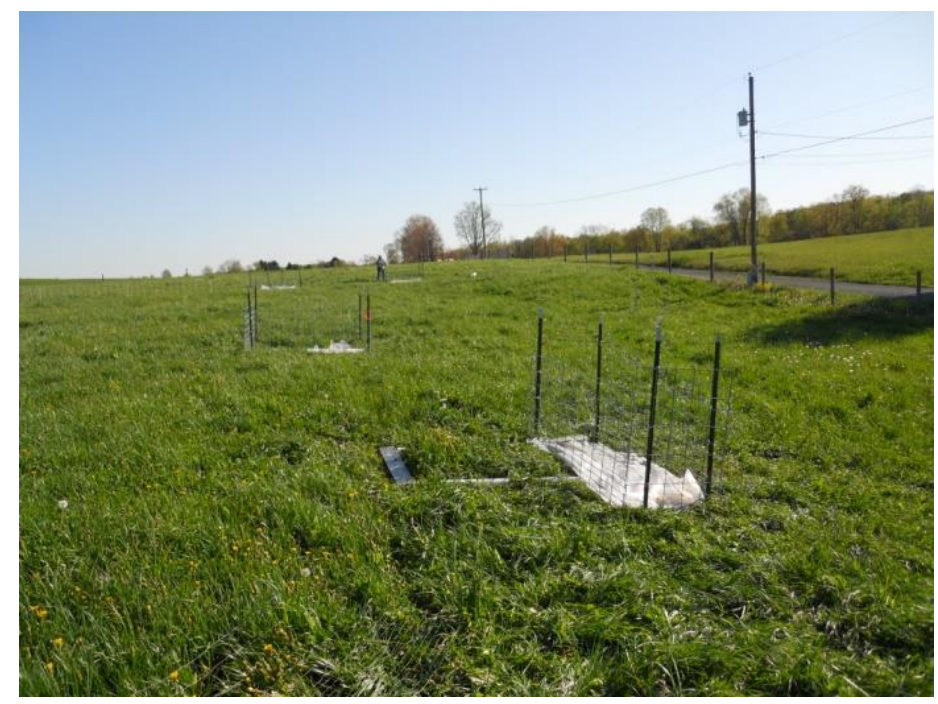


b)

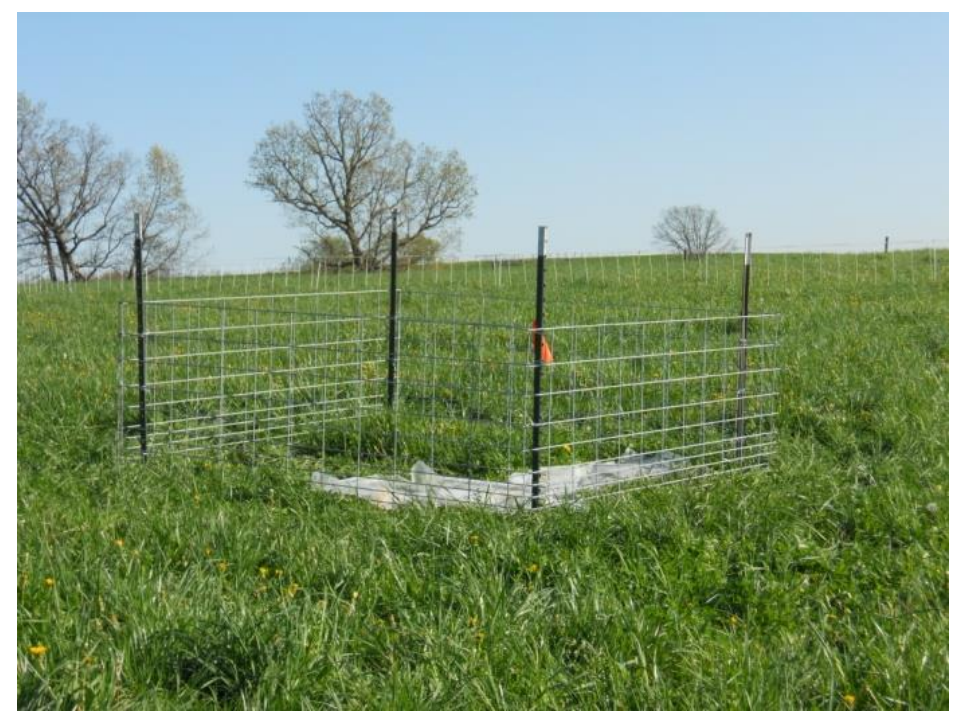

Figure 7. a) Open Erosion Plot; b) Enclosed Erosion Plot

Based on grazing management and season, runoff water and sediment production data were divided into three periods: Period 1 was from May 2011 to October 2011, Period 2 was from November 2011 to February 2012, and Period 3 was from March 2012 to October 2012.

\section{Experimental Design}

To test the hypothesis and answer the runoff/erosion research questions, the experiment was analyzed as a completely randomized split-plot design with three reps (Fig. 3). The whole plot treatments consisted of two grazing systems (single and mixed grazing), and the sub-plot treatments consisted of two grazing levels over the erosion plots (grazed/animals included and non-grazed/animals excluded). 


\section{Statistical Analysis}

For the variables measured in this experiment, descriptive statistics and Pearson correlation coefficients were calculated using SAS software (SAS Institute Inc., 2009). The data obtained in this experiment were analyzed as a completely randomized, splitplot design using PROC GLM of SAS software (SAS Institute Inc., 2009). The whole plot grazing treatments, and the sub-plot treatments (grazed/animals included and nongrazed/animals excluded) were assumed to be normally and independently distributed. At the end of the experiment the effect of period and the interactions between treatment and period were analyzed as a split-plot design with three replications, where the whole plot was grazing system and the sub-plot was period, using PROC GLM of SAS software (SAS Institute Inc., 2009).

\section{General Methods}

\section{Soil Texture and Bioavailable Nutrients}

Soil texture was determined on all samples using the pipette method (Gee and Or, 2002). A vibratory sieve was used for sand fractionation analysis, to determine the distribution of different sized particles within the sand fraction (Table 1) (Gee and Or, 2002). Bioavailable soil nutrients $(\mathrm{P}, \mathrm{K}, \mathrm{Ca}$, and $\mathrm{Mg}$ ) were extracted from all stratified samples using the Mehlich 3 extraction procedure (Mehlich, 1984), and measured using an inductively coupled plasma emission spectrophotometer. Soil organic carbon (SOC) and total nitrogen were measured by dry combustion at the Regulatory Services Laboratory (University of Kentucky, Lexington, KY) for the $0-5 \mathrm{~cm}$ soil depth increment. 
Table 1. Sand size fractions and sieve size identifications. ${ }^{1}$

\begin{tabular}{cccc}
\multicolumn{2}{c}{ Sieve Sizes } & \multicolumn{2}{c}{ Sand Size Fractions } \\
Number & Opening $(\mathrm{mm})$ & & Size $(\mathrm{mm})$ \\
\hline & & & \\
18 & 1.000 & Very Coarse & $2.0-1.0$ \\
35 & 0.500 & Coarse & $1.0-0.50$ \\
60 & 0.250 & Medium & $0.50-0.25$ \\
140 & 0.106 & Fine & $0.25-0.10$ \\
270 & 0.053 & Very Fine & $0.10-0.05$ \\
300 & 0.047 & & \\
& & &
\end{tabular}

${ }^{1}$ Taken from Gee and Or, 2002.

\section{Measures of Soil Structure}

Bulk density was determined by extracting intact cores with a Uhland sampler.

Penetration resistance was obtained using a RIMIK Penetrologger at all sampling points (3 replications per point). A composite sample (five cores per point) was obtained for the stratified soil sample; the samples were dried for moisture determination, crushed, and passed through a $2 \mathrm{~mm}$ sieve for laboratory analysis. Moisture content was obtained at the same time as penetration resistance to ensure that moisture content did not overly influence the penetration resistance measurements.

Dry aggregate stability was determined using the drop-shatter method (Diaz-Zorita et al., 2007). After dropping an intact soil core sample at with moisture content at field capacity, the shattered soil was air dried and then placed on a vibratory sieve shaker to determine the resulting aggregate size distribution. Wet aggregate stability was determined using the Yoder machine (Yoder, 1936). A 4-8mm aggregate sub-sample obtained from the previously described drop-shatter method was placed in the Yoder machine and subjected to water dispersion for five minutes. Both wet and dry aggregate 
size distributions were characterized/calculated using the geometric-mean diameter (GMD) (Eqn 1.) and mean weight diameter (MWD) (Eqn 2.) equations, as follows:

$$
\mathrm{GMD}=\exp \left(\frac{\sum_{\mathrm{i}=1}^{\mathrm{n}} w \mathrm{i} \log \mathrm{xi}}{\sum_{\mathrm{i}=1}^{\mathrm{n}} \mathrm{wi}}\right) \quad \text { Eqn } 1 .
$$

$$
\mathrm{MWD}=\sum_{i=1}^{n} x i w i \quad \text { Eqn } 2 .
$$

where $\mathrm{w}_{\mathrm{i}}$ is the weight of aggregates of a certain size as a fraction of the total dry weight of the sample, and $\mathrm{x}_{\mathrm{i}}$ is the diameter size of the same-size fraction.

Weather, Soil Hydrology and Water Erosion Variables:

Weather variables were obtained from the weather station located at the WVU Reedsville Farm. Daily rainfall totals were collected from April 2011 to July 2012. Total precipitation per period was calculated by summing the daily rainfall totals for the days within that period. Average precipitation per rainy day was calculated by dividing the total precipitation per period by the number of rainy days within that period. Daily rainfall totals were then compared to the average precipitation per rainy day; rainfalls above this average were tallied. The percentage of rainy days above average was calculated by dividing the number of rainy days above average by the total number of rainy days in a period.

In this study, saturated hydraulic conductivity was measured with two different instruments, the Wooding and single-ring infiltrometers. The Wooding infiltrometer measured the rate at which water infiltrated into the soil at saturation (Wooding, 1968). 
The Wooding infiltrometer consisted of a water-filled tower and a $15 \mathrm{~cm}$ diameter ring. The tower was placed on top of the ring and the area between the infiltrometer, ring and soil was always filled with water (saturated soil). As water infiltrated, the water drained from the tower into the soil, and readings were taken over 60 to 120 minutes, at $0.5,1,5$ and 10 minutes intervals. Using the Wooding equation, saturated hydraulic conductivity was derived from the data. For both Experiment 1 and 2, the Wooding infiltrometer was used only at Date 1 . The single-ring infiltrometer consisted of a $15 \mathrm{~cm}$ diameter ring placed firmly into the soil, which was filled twice with $2.5 \mathrm{~cm}$ of water (Smith and Doran, 1996; Soil Quality Test Kit Guide, 2001). Soil moisture content may affect water infiltration, therefore, based on the assumption that total saturation of the soil surface was achieved after infiltration of the first $2.5 \mathrm{~cm}$ of water, only the time for the second $2.5 \mathrm{~cm}$ of water infiltration was recorded. Soil moisture was determined before (no water added to the ring) and after each infiltration measurement (after infiltration of $5 \mathrm{~cm}$ of water) to determine antecedent and final soil moisture.

The Wooding and single-ring infiltrometer measurements were made at four representative, but randomly selected, geo-referenced grid points in each of all six paddocks. The Wooding infiltrometer was used to measure saturated hydraulic conductivity, in duplicate, within $30 \mathrm{~cm}$ of each erosion plot. A total of 48 saturated hydraulic conductivity measurements were obtained using the Wooding infiltrometer at Date 1. Single-ring infiltrometers were used to measure saturated hydraulic conductivity at two sampling dates (Date 2 and Date3). At Date 2, after winter grazing in 2012, a total 122 single-ring infiltrometer measurements were taken: 41 in Field 1, 43 in Field 2, and 38 in Field 3. From those 122 samples, 63 single-ring infiltrometer measurements were 
taken in the single species grazing treatment and 59 in the mixed species grazing treatment. At Date 3, after spring grazing in August 2012, a total of 80, 86, and 76 singlering infiltrometers measurements were taken in Fields 1, 2, and 3, respectively. From those measurements (242 in total) 137 single-ring infiltrometers were taken in the single species grazing treatment and 105 in the mixed species grazing treatment. The number of single-ring infiltration measurements made at Date 3 was increased with respect to Date 2 with the objective of reducing the variability relative to that observed in earlier measurements. At sampling Date 3, the original method was changed by increasing the standard initial amount of infiltrating water from 2.5 to $5 \mathrm{~cm}$; the third $2.5 \mathrm{~cm}$ was timed.

Runoff and sediment samples were collected from the erosion plots when weather permitted (after each runoff producing rainfall). The runoff water and sediment were transferred from the collection bag located at the end of the collection tube in the erosion plot into a separate plastic container. The sample was then transported to the WVU Soil Physics Laboratory for further analysis. Runoff water volume was measured with graduated cylinders. The runoff water volume was recorded. To obtain the sediment weight, the mixed water and sediment sample was allowed to settle for 48 hours in a beaker, and the excess clear supernatant water was decanted. The beaker was placed in the oven for 72 hours (or until completely dry) at $85^{\circ} \mathrm{C}$. Dried beakers were weighed and sediment production was determined. The total sediment weight was recorded. Recorded runoff water volumes and sediment weights were averaged by plot for each period.

The soil erodibility ( $\mathrm{K}$ factor) for the $0-5 \mathrm{~cm}$ surface soil was determined for each erosion plot using the following equation:

$$
\mathrm{K}=2.8 \times 10^{-7} \mathrm{M}^{1.14}(12-\mathrm{a})+4.3 \times 10^{-3}(\mathrm{~b}-2)+3.3 \times 10^{-3}(\mathrm{c}-3)
$$


where $\mathrm{M}$ is the particle size parameter, $\mathrm{a}$ is the organic matter content, $\mathrm{b}$ is the soil structure and c is the permeability class (Fangmeier et al., 2006). Due to very high organic matter contents, a nomogram could not be used to determine the $\mathrm{K}$ factor of the soils in the study area. 


\section{CHAPTER 4. RESULTS AND DISCUSSION}

\section{Experiment 1}

\section{Soil Characterization}

Soil Particle Size and Sand Fractionation Analysis

The overall average soil texture (0-5 cm depth) for the research area was 242,241 , and $517 \mathrm{~g} / \mathrm{kg}$ clay, sand and silt, respectively, resulting in a silt loam textural class (Table 2).

The silt loam texture measured in this study is consistent with the soil type reported in the NRCS Soil Resource Report for the specific area (USDA, 2011). Based on the NRCS Soil Resource Report, small texture variations should be expected between the experimental fields. Small variations in average sand, silt, and clay contents between fields (Fig. 3) were measured (Table 2).

Table 2. Mean, standard deviation, and analysis of variance for soil particle size fractions measured at Date 1.

\begin{tabular}{|c|c|c|c|}
\hline & Sand & $\begin{array}{r}\text { Silt } \\
\mathrm{g} / \mathrm{kg}\end{array}$ & Clay \\
\hline \multicolumn{4}{|l|}{ Treatments } \\
\hline Single & $238 \pm 44^{\mathrm{a}^{*}}$ & $519 \pm 38^{\mathrm{a}}$ & $243 \pm 28^{\mathrm{a}}$ \\
\hline Mixed & $244 \pm 57^{\mathrm{a}}$ & $515 \pm 44^{\mathrm{a}}$ & $241 \pm 34^{\mathrm{a}}$ \\
\hline \multicolumn{4}{|l|}{ Block/Field } \\
\hline Field 1 & $246 \pm 49^{a}$ & $532 \pm 38^{\mathrm{a}}$ & $223 \pm 35^{c}$ \\
\hline Field 2 & $266 \pm 42^{\mathrm{a}}$ & $498 \pm 35^{\mathrm{b}}$ & $236 \pm 28^{b}$ \\
\hline Field 3 & $205 \pm 42^{b}$ & $524 \pm 43^{\mathrm{a}}$ & $271 \pm 77^{\mathrm{a}}$ \\
\hline \multirow[t]{2}{*}{ Grand Mean } & $241 \pm 51$ & $517 \pm 41$ & $242 \pm 31$ \\
\hline & -- & $-\mathrm{Pr}>\mathrm{F}--$ & ---- \\
\hline Treatment & 0.61 & 0.63 & 0.83 \\
\hline Block/Field & $<0.01$ & $<0.01$ & $<0.01$ \\
\hline
\end{tabular}

Treatment or block means followed by the same letter, in the same column, are not significantly different $(\mathrm{P} \leq 0.10)$. *Average \pm one standard deviation. 
The soil particle size distribution will not change and was measured once during the experiment, in August 2011 (Date 1). Soil sand, silt and clay contents $(0-5 \mathrm{~cm})$ were not significantly affected by the grazing treatments. The analysis of variance for sand, silt and clay contents $(0-5 \mathrm{~cm})$ indicated significant block/field effects on the measured values (Table 2, Tables A1-A3 in Appendix A).

\section{Soil Chemical Analysis:}

Soil chemical properties ( $\mathrm{pH}$, bioavailable soil nutrients and soil organic matter (SOM)) were measured once during the experiment. The bioavailable soil nutrients measured in this study were $\mathrm{P}, \mathrm{K}, \mathrm{Ca}, \mathrm{Mg}$, and $\mathrm{Zn}$. These bioavailable elements were selected and measured due to their importance for plant nutrition, and their potential to indicate changes related to the grazing treatments. Soil organic matter and total $\mathrm{N}$ were also determined. The samples were taken in August 2011 (Date1).

The overall surface $(0-5 \mathrm{~cm})$ soil $\mathrm{pH}$ for the study area was $5.5 \pm 0.2$ (Table 3 ). The $\mathrm{pH}$ exhibited little variability across the study area. The average $\mathrm{pH}$ was typical of West Virginia soils, and similar to values reported by the NRCS Custom Soil Report for the research area (4.5 to 5.5). The experimental area exhibited an average surface $(0-5 \mathrm{~cm})$ SOM level of $90.0 \pm 20.2 \mathrm{~g} / \mathrm{kg}$ (Table 3). The reported SOM content for this study was comparable to percentages reported by Teague et al. (2011) in light continuous, multipaddock and enclosure grazing in 3 counties in Texas in which the grazing management treatments were similar to those in this study. Abaye et al., (1994) reported SOM values similar to the values reported in this study. For the study area, the overall average surface $(0-5 \mathrm{~cm})$ soil test phosphorus $(\mathrm{STP})$ and total nitrogen concentrations were $105 \pm 52$ $\mathrm{mg} / \mathrm{kg}$ and $5.0 \pm 1.0 \mathrm{~g} / \mathrm{kg}$, respectively (Table 3 ). 
Table 3. Mean, standard deviation, and analysis of variance for $\mathrm{pH}, \mathrm{SOM}, \mathrm{STP}$ and total $\mathrm{N}$ measured at Date 1.

\begin{tabular}{|c|c|c|c|c|}
\hline & $\mathrm{pH}$ & $\begin{array}{c}\mathrm{SOM} \\
\mathrm{g} / \mathrm{kg}\end{array}$ & $\begin{array}{c}\mathrm{P} \\
\mathrm{mg} / \mathrm{kg}\end{array}$ & $\begin{array}{c}\text { Total N } \\
\mathrm{g} / \mathrm{kg}\end{array}$ \\
\hline \multicolumn{5}{|l|}{ Treatments } \\
\hline Single & $5.6 \pm 0.3^{\mathrm{a}^{*}}$ & $91.7 \pm 17.7^{\mathrm{a}}$ & $110 \pm 60^{\mathrm{a}}$ & $5.0 \pm 1.0^{\mathrm{a}}$ \\
\hline Mixed & $5.6 \pm 0.2^{\mathrm{a}}$ & $88.2 \pm 22.7^{\mathrm{a}}$ & $100 \pm 42^{\mathrm{a}}$ & $5.0 \pm 1.0^{\mathrm{a}}$ \\
\hline \multicolumn{5}{|l|}{ Block/Field } \\
\hline Field 1 & $5.5 \pm 0.3^{\mathrm{a}}$ & $80.7 \pm 17.5^{\mathrm{b}}$ & $105 \pm 57^{\mathrm{a}}$ & $5.0 \pm 1.0^{b}$ \\
\hline Field 2 & $5.5 \pm 0.2^{\mathrm{a}}$ & $85.1 \pm 15.0^{\mathrm{b}}$ & $113 \pm 59^{\mathrm{a}}$ & $5.0 \pm 0.7^{\mathrm{b}}$ \\
\hline Field 3 & $5.6 \pm 0.2^{\mathrm{a}}$ & $106.2 \pm 19.8^{\mathrm{a}}$ & $94 \pm 34^{\mathrm{a}}$ & $6.0 \pm 1.0^{\mathrm{a}}$ \\
\hline Grand Mean & $5.5 \pm 0.2$ & $90.0 \pm 20.2$ & $105 \pm 52$ & $5.0 \pm 1.0$ \\
\hline Treatment & 0.4 & 0.5 & 0.4 & 0.5 \\
\hline Block/Field & 0.2 & $<0.01$ & 0.4 & $<0.01$ \\
\hline
\end{tabular}

Treatment or block means followed by the same letter, in the same column, are not significantly different $(\mathrm{P} \leq 0.10)$. *Average \pm one standard deviation..

The results of the analysis of variances for $\mathrm{pH}, \mathrm{SOM}, \mathrm{STP}$ and total $\mathrm{N}$ are presented in Table 3. The grazing treatments had no significant effect on $\mathrm{pH}$, SOM, STP and total $\mathrm{N}$. The analysis of variance found no difference in soil surface $(0-5 \mathrm{~cm}) \mathrm{pH}$ or STP between blocks/fields. A significant difference between fields was observed in SOM and total N contents (Table 3).

The average $\mathrm{pH}$ for the study site was slightly acidic, but is not considered limiting to grass and legume growth, although the 'optimum' $\mathrm{pH}$ ranges for forage grasses and legumes are 6.0-6.5 and 6.5-7.0, respectively (Penn State, 2012). Abaye et al., (1994) observed that when cattle and sheep graze together, as in mixed grazing, the soil $\mathrm{pH}$ may increase. 
Soil organic matter (SOM) is the "organic fraction of the soil after removing undecomposed plant and animal residues" (SSSA, 2012) and has also been defined as formed by a diverse group of living organisms, and resulting in a wide range in organic materials derived from slightly to well decomposed plant and animal organic residues (Magdoff and Weil, 2004). Management also affects SOM. Franzluebbers (2002) observed that SOM varied among grazing management systems.

Changes in the amount of SOM with depth in the soil profile occur naturally. Figure 8 shows the decline in SOM content with depth in the soil profile. The decrease in SOM with depth is the result of stratification caused by organic material addition and mineralization processes occurring mostly at the soil surface. This stratification of SOM is a common characteristic observed in unmanaged (unaltered), non-tilled, or grassland soils (Prescott et al., 1995). SOM stratification is common when agricultural practices allow organic matter to preferentially accumulate at the soil surface (Hernanz et al., 2009; Franzluebbers, 2002).

In this three-year study, no statistical differences in SOM contents due to the grazing treatments were observed. It is possible that sampling over a longer period of time would allow differences between grazing management treatments to become more evident. Long-term research should be implemented to further understand the effects of mixed and single species grazing on SOM content over time. 


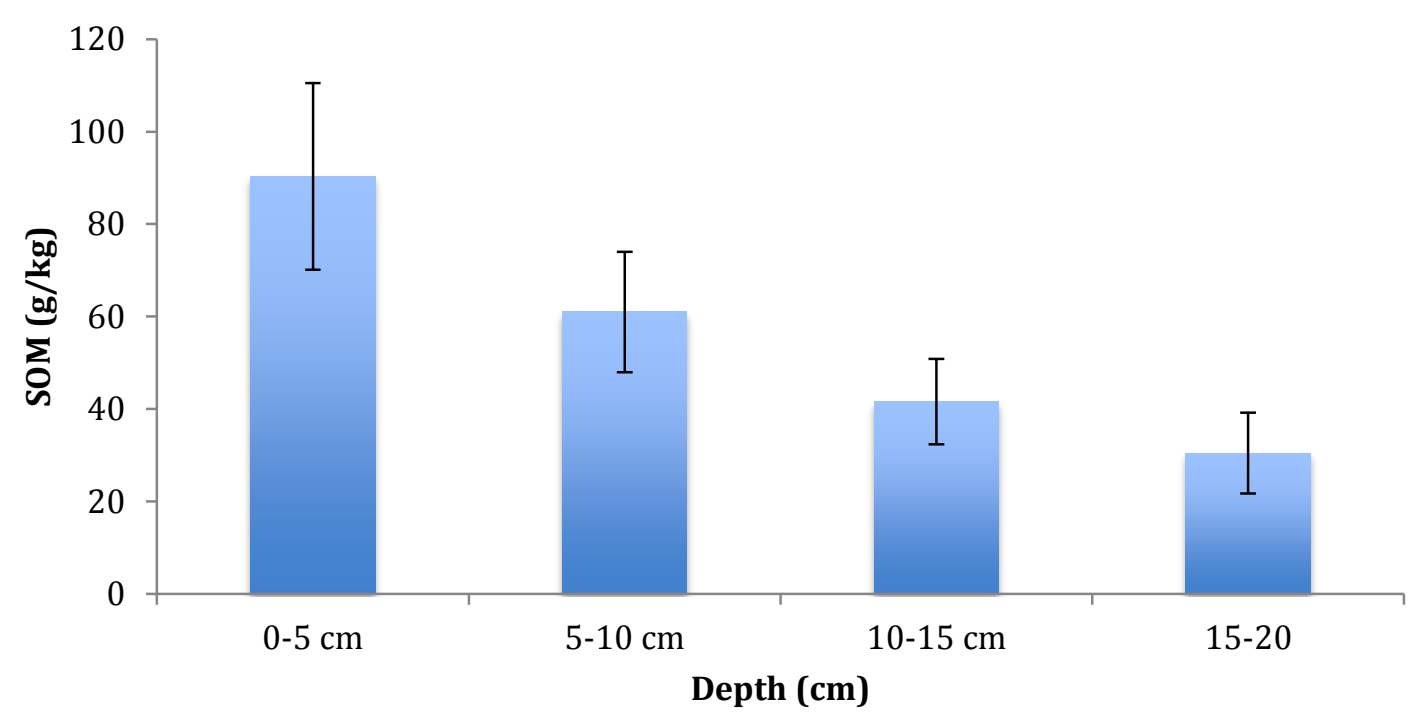

Figure 8. Average soil organic matter (SOM, g/kg) with soil depth.

The average soil test phosphorus (STP) measured in this study $(105 \pm 52 \mathrm{mg} / \mathrm{kg}$ ) was higher than the optimum STP recommendation for mixed grasses (30-50 ppm) reported by Penn State Extension (Penn State, 2012). It is possible to conclude that $\mathrm{P}$ was not limiting plant growth in this study. However, large soil surface STP values indicate an increased risk of $\mathrm{P}$ transport with soil erosion and/or runoff (McDowell and Wilcock, 2007).

A trend in total $\mathrm{N}$ due to the grazing management treatments was observed in this experiment. In two of the three blocks/fields, the mixed grazing system exhibited higher total $\mathrm{N}$ than the single species grazing treatment (Table 3). Because of this inconsistent behavior (Table 3), a statistical relationship between grazing treatment and total $\mathrm{N}$ at the soil surface could not be established. Grazing can affect plant speciation and ecology, and adding excreta to soil surface may have altered total soil N (Dormaar et al., 1990). 
Domaar et al. (1990) found increased ammonium-N, proportional to the stocking rate, but these authors cautioned against extrapolating their results to other grazing systems.

Riaz et al. (2010) observed that $\mathrm{N}$ was mobile in grassland soils, and $\mathrm{N}$ leaching depended greatly on dissolved organic carbon. In this study, total $\mathrm{N}$ was measured only one time, in soil samples taken after spring/summer grazing, in August 2011.

The overall surface $(0-5 \mathrm{~cm})$ soil test potassium $($ STK) in the study area was $321 \pm 159$ $\mathrm{mg} / \mathrm{kg}$ (Table 4). Both STK and STP were highly variable across the study area. The overall surface $(0-5 \mathrm{~cm})$ bioavailable soil $\mathrm{Ca}, \mathrm{Mg}$, and $\mathrm{Zn}$ concentrations in the study area were $2200 \pm 350 \mathrm{mg} / \mathrm{kg}, 75 \pm 34 \mathrm{mg} / \mathrm{kg}$, and $4.5 \pm 2.0 \mathrm{mg} / \mathrm{kg}$, respectively (Table 4).

Table 4. Mean, standard deviation, and analysis of variance statistics for STK, Ca, Mg and $\mathrm{Zn}$ measured at Date 1.

\begin{tabular}{|c|c|c|c|c|}
\hline & STK & $\begin{array}{l}\mathrm{Ca} \\
\quad \mathrm{mg} / \mathrm{k}\end{array}$ & $\mathrm{Mg}$ & $\mathrm{Zn}$ \\
\hline \multicolumn{5}{|l|}{ Treatments } \\
\hline Single & $327 \pm 169^{a}$ & $2220 \pm 310^{\mathrm{a}}$ & $119 \pm 34^{\mathrm{a}}$ & $4.5 \pm 1.5^{\mathrm{a}}$ \\
\hline Mixed & $314 \pm 150^{a}$ & $2180 \pm 400^{\mathrm{a}}$ & $117 \pm 31^{\mathrm{a}}$ & $4.5 \pm 2.5^{\mathrm{a}}$ \\
\hline \multicolumn{5}{|l|}{ Block/Field } \\
\hline Field 1 & $277 \pm 177^{b}$ & $2082 \pm 304^{b}$ & $106 \pm 36^{b}$ & $3.6 \pm 1.1^{\mathrm{b}}$ \\
\hline Field 2 & $302 \pm 123^{b}$ & $2098 \pm 279^{b}$ & $112 \pm 20^{b}$ & $4.8 \pm 2.6^{\mathrm{b}}$ \\
\hline Field 3 & $392 \pm 159^{\mathrm{a}}$ & $2453 \pm 365^{\mathrm{a}}$ & $138 \pm 31^{\mathrm{a}}$ & $5.1 \pm 1.6^{\mathrm{a}}$ \\
\hline Grand Mean & $321 \pm 159$ & $2200 \pm 350$ & $118 \pm 32$ & $4.5 \pm 2.0$ \\
\hline Trentment & & & 0.03 & 070 \\
\hline Treatment & 0.75 & 0.68 & 0.93 & 0.79 \\
\hline Block/Field & $<0.10$ & $<0.01$ & $<0.01$ & $<0.10$ \\
\hline
\end{tabular}

Treatment or block means followed by the same letter, in the same column, are not significantly different $(\mathrm{P} \leq 0.10)$. *Average \pm one standard deviation.

Grazing treatments had no significant effect on STK, Ca, Mg, or Zn (Table 4). The analysis of variance indicated statistically significant differences in soil surface $(0-5 \mathrm{~cm})$ 
STK, $\mathrm{Ca}, \mathrm{Mg}$, and $\mathrm{Zn}$ among blocks/fields (Table 4). The measured soil surface $(0-5 \mathrm{~cm})$ STK, $\mathrm{Ca}, \mathrm{Mg}$, and $\mathrm{Zn}$ did not provide evidence in support of the central hypothesis of the experiment.

The measured STK values in this study were higher than those reported as optimal for mixed grasses (100-200 ppm) by Penn State Extension (Penn State, 2012). It is possible to conclude that in the study area $\mathrm{K}$ was not limiting forage growth. Soil test $\mathrm{K}$ was higher than $200 \mathrm{ppm}$ in much of the area, which could be a health risk to grazing animals (Penn State, 2012). The overall surface $(0-5 \mathrm{~cm})$ bioavailable soil Ca concentration (2200 $\pm 350 \mathrm{mg} / \mathrm{kg}$ ) was not limiting to plant growth. The Mg values measured in this study were similar to those reported as optimal for mixed grasses (120 ppm) by Penn State Extension (Penn State, 2012). In this study, Mg and Zn were not limiting to plant growth.

\section{Soil Structural Properties}

Soil Surface Bulk Density

Soil surface (0-5 cm) bulk density (BD) was measured in August 2011 (Date 1), April 2012 (Date 2) and August 2012 (Date 3). The BD data obtained in August 2011 (Date 1), after spring/summer grazing, exhibited an overall average of $1.03 \pm 0.09 \mathrm{~g} / \mathrm{cm}^{3}$ (Table 5). The BD data obtained in April 2012 (Date 2) showed an overall average value of $0.98 \pm$ $0.10 \mathrm{~g} / \mathrm{cm}^{3}$ (Table 5). This value was slightly lower than the BD measured in August 2011 (Date 1), but the coefficient of variation was similar. At Date 3, the overall average surface $\mathrm{BD}$ increased to $1.06 \pm 0.09 \mathrm{~g} / \mathrm{cm}^{3}$, as compared to the values obtained on Date 2 (Table 5).

Silt textured grasslands soils, similar to the ones found in the study area, tend to exhibit lower BD values, between 1.00 and1.32 g/ $\mathrm{cm}^{3}$ (Blanco-Canqui et al., 2005). Blanco- 
Canqui et al. (2005), working on perennial orchardgrass pastures over a Rayne silt-loam soil in the North Appalachian Experimental Watershed in Ohio, reported BD values similar to those observed in this study.

Table 5. Mean, standard deviation, and analysis of variance statistics for bulk density, by date.

\begin{tabular}{lccc}
\hline \hline & Date 1 & $\begin{array}{c}\text { Date 2 } \\
\mathrm{g} / \mathrm{cm}^{3}\end{array}$ & Date 3 \\
\cline { 2 - 4 } Treatments & $1.03 \pm 0.10^{\mathrm{a}^{*}}$ & $0.99 \pm 0.08^{\mathrm{a}}$ & $1.06 \pm 0.08^{\mathrm{a}}$ \\
Single & $1.03 \pm 0.10^{\mathrm{a}}$ & $0.97 \pm 0.11^{\mathrm{a}}$ & $1.07 \pm 0.09^{\mathrm{a}}$ \\
Mixed & & & \\
Block/Field & $1.08 \pm 0.07^{\mathrm{a}}$ & $1.00 \pm 0.07^{\mathrm{a}}$ & $1.09 \pm 0.07^{\mathrm{a}}$ \\
Field 1 & $1.02 \pm 0.09^{\mathrm{b}}$ & $1.01 \pm 0.09^{\mathrm{a}}$ & $1.10 \pm 0.08^{\mathrm{a}}$ \\
Field 2 & $0.98 \pm 0.09^{\mathrm{b}}$ & $0.92 \pm 0.10^{\mathrm{b}}$ & $1.00 \pm 0.06^{\mathrm{b}}$ \\
Field 3 & & & \\
& $1.03 \pm 0.09^{\mathrm{c}^{*}}$ & $0.98 \pm 0.10^{\mathrm{b}}$ & $1.06 \pm 0.09^{\mathrm{a}}$ \\
Grand Mean & $--------------------P r>\mathrm{F}------------------$ \\
& 0.91 & 0.13 & 0.84 \\
Treatment & $<0.01$ & $<0.01$ & $<0.01$ \\
Block/Field & &
\end{tabular}

Treatment or block means followed by the same letter, in the same column, are not significantly different $(\mathrm{P} \leq 0.10)$. *Average \pm one standard deviation.

Grand means, in the same row and followed by the same letter, are not significantly different $(\mathrm{P} \leq 0.10)$. *Average \pm standard deviation.

No significant effect of treatment on BD measured at Dates 1, 2 or 3 was observed, but significant block/field effects were found (Table 5). Field 3 exhibited significantly lower BD values than Field 1 at every date and lower BD values than those found in Field 2 at Dates 2 and 3.

Effect of sampling date on BD was evaluated at the end of the experiment. A randomized complete block design, with two factors (grazing treatment and sampling date) and three blocks, was used to partition the variance in the BD data among sampling dates. The analysis of variance indicated significant differences in BD between sampling dates 
(Table 5), but no differences due to grazing treatments. The interaction between sampling date and treatment was not also not significant (Table 4C in Appendix C).

Regardless of treatment, after each spring/summer grazing period the surface $(0-5 \mathrm{~cm})$ BD increased (Table 5). The highest surface BD $\left(1.06 \mathrm{~g} / \mathrm{cm}^{3}\right)$ was observed at Date 3, after two periods of spring/summer grazing, and the lowest $\left(0.98 \mathrm{~g} / \mathrm{cm}^{3}\right)$ at Date 2, after stockpiling and winter grazing (Table 5). Removing animal influence on the soil and allowing a stockpiling period can decrease bulk density by favoring root growth, and reducing the stress applied to soil by hoof action. Both cause soil porosity to increase, resulting in the lower BD values observed at Date 2. Drewry's (2006) observation supports our time trend in BD values. In his research, it was observed that bulk density decreased after one winter season, and associated the decrease with soil "rejuvenation" from leaving the grassland free of animals for 140 days. He concluded that summer and autumn were the best periods for the recovery. Chanasyk and Naeth (1995) also measured a decrease in $\mathrm{BD}$ and penetration resistance values in the spring after snowmelt, and an increase in $\mathrm{BD}$ values late in the grazing and growing season.

In our study, bulk density was related to other soil properties. Soil texture was measured in samples taken in August 2011 (Date 1) (Table 2). Soil texture measured at Date 1 was correlated to the $\mathrm{BD}$ measured at the same date. The results of this analysis showed a weak negative relationship between BD and clay content at the soil surface $(0-5 \mathrm{~cm})$, showing that as clay content increased, bulk density decreased (Fig 9). A negative relationship was also observed between surface BD and SOM (Fig. 10), both measured at Date 1. The relationship observed was supported by other reported results (Bauer and Black, 1981; Adams, 2006; Billings, 2006). 


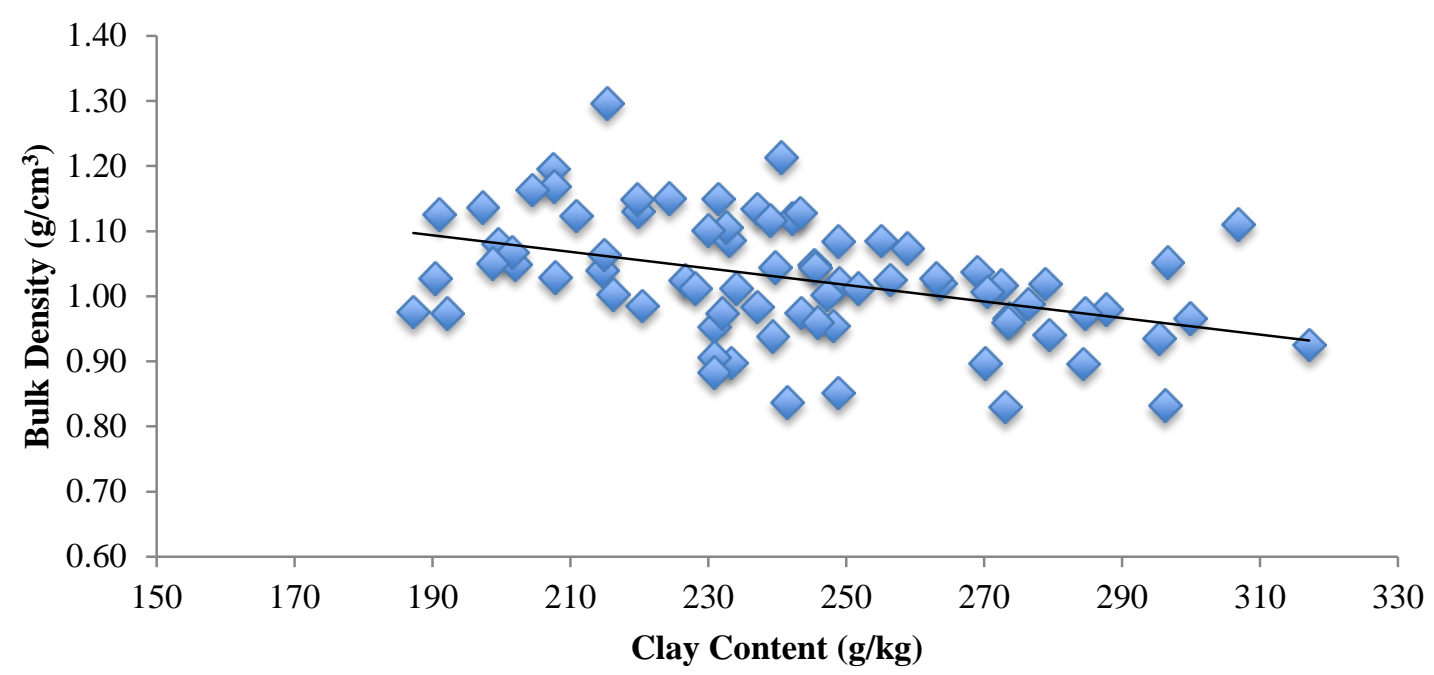

Figure 9 . Relationship between surface $(0-5 \mathrm{~cm})$ bulk density (BD) and clay content across the study area at Date 1 .

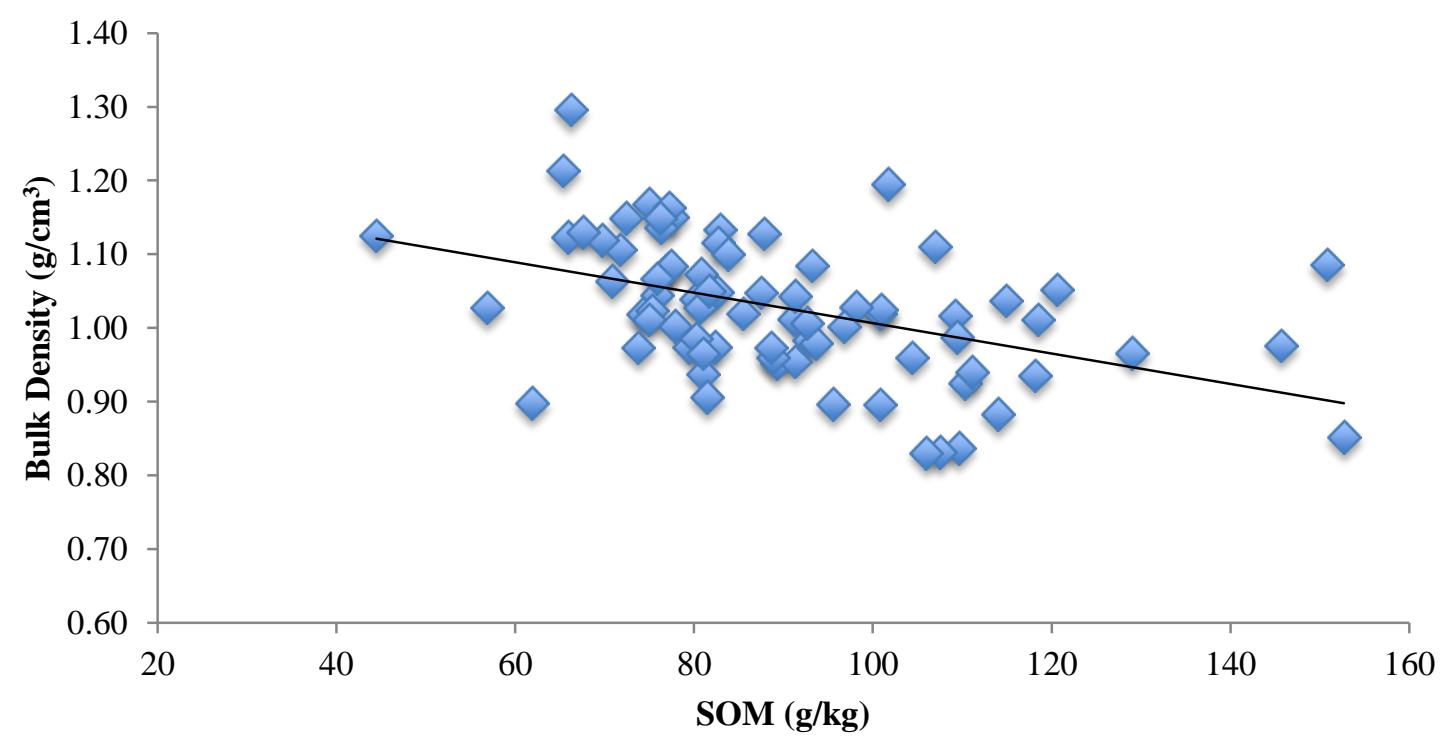

Figure 10. Relationship between surface $(0-5 \mathrm{~cm})$ bulk density $(\mathrm{BD})$ and soil organic matter (SOM) across the study area at Date 1. 
Soil Surface Porosity

Total porosity $(0-5 \mathrm{~cm})$ was calculated using the field BD (sampled at Dates 1, 2, and 3) with the following formula:

$$
f=1-\left(\rho_{b} / \rho_{s}\right)
$$

where $\mathrm{f}$ is total porosity, $\rho_{\mathrm{b}}$ is the field measured bulk density, and $\rho_{\mathrm{s}}$ is particle density $\left(\rho_{\mathrm{s}}=2.65 \mathrm{~g} / \mathrm{cm}^{3}\right)$.

Table 6. Mean, standard deviation, and analysis of variance for porosity by date.

\begin{tabular}{|c|c|c|c|}
\hline & Date 1 & $\begin{array}{c}\text { Date } 2 \\
\mathrm{~cm}^{3} / \mathrm{cm}^{3}\end{array}$ & Date 3 \\
\hline \multicolumn{4}{|l|}{ Treatment } \\
\hline Single & $0.61 \pm 0.03^{\mathrm{a}}$ & $0.63 \pm 0.03^{\mathrm{a}}$ & $0.60 \pm 0.03^{\mathrm{a}}$ \\
\hline Mixed & $0.61 \pm 0.04^{\mathrm{a}}$ & $0.64 \pm 0.04^{\mathrm{a}}$ & $0.60 \pm 0.04^{\mathrm{a}}$ \\
\hline \multicolumn{4}{|l|}{ Block/Field } \\
\hline Field 1 & $0.59 \pm 0.03^{b}$ & $0.62 \pm 0.02^{b}$ & $0.59 \pm 0.03^{b}$ \\
\hline Field 2 & $0.62 \pm 0.04^{\mathrm{a}}$ & $0.62 \pm 0.03^{b}$ & $0.59 \pm 0.03^{b}$ \\
\hline Field 3 & $0.63 \pm 0.03^{\mathrm{a}}$ & $0.66 \pm 0.04^{\mathrm{a}}$ & $0.62 \pm 0.02^{a}$ \\
\hline \multirow[t]{2}{*}{ Grand Mean } & $0.61 \pm 0.04^{b}$ & $0.63 \pm 0.04^{\mathrm{a}}$ & $0.60 \pm 0.03^{c}$ \\
\hline & & --Pr > F---- & ---- \\
\hline Treatment & 0.95 & 0.11 & 0.99 \\
\hline Block/Field & $<0.01$ & $<0.01$ & $<0.01$ \\
\hline
\end{tabular}

Treatment or block means followed by the same letter, in the same column, are not significantly different $(\mathrm{P} \leq 0.10)$. *Average \pm one standard deviation.

Grand means, in the same row and followed by the same letter, are not significantly different $(\mathrm{P} \leq 0.10)$. *Average \pm standard deviation.

The average porosity for the study area was $0.61 \pm 0.04,0.63 \pm 0.04$, and $0.60 \pm 0.03$ for

Date 1, Date 2, and Date 3 respectively (Table 6).

The analysis of variance indicated no significant effect of treatment on porosity at Dates 1, 2, or 3, however a significant effect of block/field was observed (Table 6). Similar to 
BD, Field 3 exhibited significantly higher porosity than Field 1 at every date and Field 3 exhibited significantly higher porosity than Field 2 at Dates 2 and 3.

The effect of sampling date on porosity was evaluated at the end of the experiment. A randomized complete block with three replications and two factors, grazing treatment and sampling date, was used to analyze the variation in porosity (Table 6). The analysis of variance indicated significant differences in porosity due to sampling date, but no difference due to grazing treatment. The interaction between sampling date and treatment was not significant (Table 9C in Appendix C).

The soil surface porosity values calculated for the study area were twice as high as the values reported by González-Barrios et al. (2010) for "good state" and "degraded grassland" sites in northern Mexico. The major difference between these sites were higher sand and organic matter contents at the "good state" sites. The decrease in porosity at the Mexican sites was attributed to reduced macroporosity due to animal trampling and decreased root mass.

\section{Soil Penetration Resistance}

Penetration resistance (0-20 cm) was measured in August 2011 (Date 1), April 2012 (Date 2) and August 2012 (Date 3). Average penetration resistance values, by date and depth, are shown in Tables 7, 8 and 9. For Date 1, the overall average PR for the study area was $523 \pm 185 \mathrm{kPa}$ for the 0-4 cm depth increment, $1206 \pm 305 \mathrm{kPa}$ for the $4-10 \mathrm{~cm}$ depth increment, $1396 \pm 320 \mathrm{kPa}$ for the $10-16 \mathrm{~cm}$ depth increment, and $1523 \pm 325 \mathrm{kPa}$ for the 16-20 cm depth increment (Table 7). Analysis of variance was performed on penetration resistance for each individual depth increment, by date. The analysis of variance for PR at Date 1 is presented in Table 7. 
At Date 1, no significant effect of treatment was observed on surface $(0-4 \mathrm{~cm})$

penetration resistance. A significant effect of treatment $(\mathrm{P}<0.10)$ was observed on penetration resistance at the 4-10, 10-16, and 16-20 cm depth increments. At each of these depths the single species grazing treatment exhibited higher penetration resistance than the mixed species grazing treatment (Table 7). The analysis of variance for PR taken at Date 1 indicated a significant block/field effect at every depth (Table 7).

Table 7. Mean, standard deviation, and analysis of variance for penetration resistance measured at Date 1.

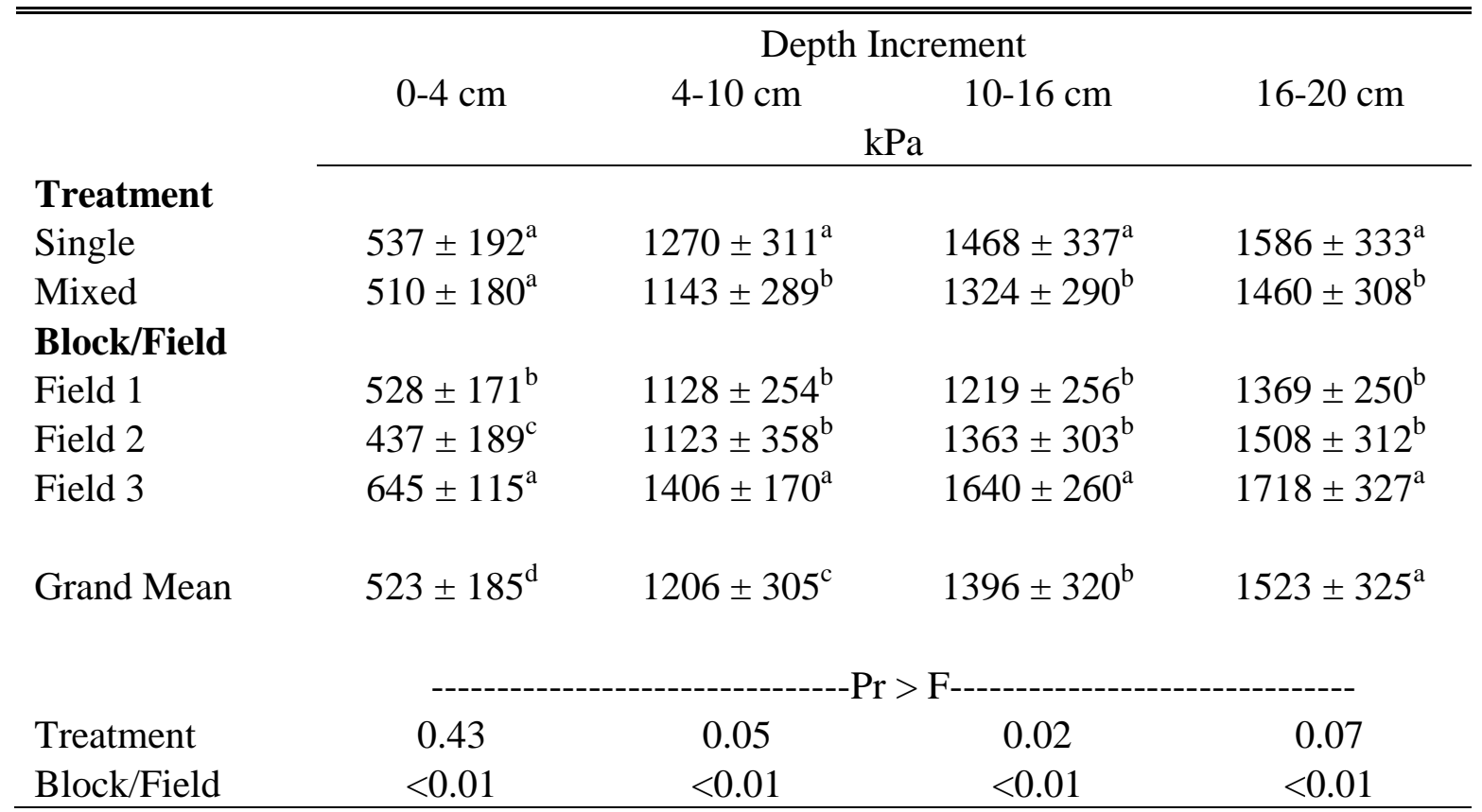

Treatment or block means followed by the same letter, in the same column, are not significantly different $(\mathrm{P} \leq 0.10)$. *Average \pm one standard deviation.

Grand means, in the same row and followed by the same letter, are not significantly different $(\mathrm{P} \leq 0.10)$. *Average \pm standard deviation.

At Date 2, the overall average PR for the for the study area over the 0-4 cm depth increment was $661 \pm 191 \mathrm{kPa}$ (Table 8). The PR increased with depth, and the average measured values were $1302 \pm 285 \mathrm{kPa}, 1529 \pm 341 \mathrm{kPa}$, and $1685 \pm 399 \mathrm{kPa}$ for the 4-10, 
10-16, and 16-20 cm depth increments, respectively (Table 8). The analysis of variance for PR at Date 2 is presented in Table 8.

Table 8. Mean, standard deviation, and analysis of variance for penetration resistance at measured Date 2.

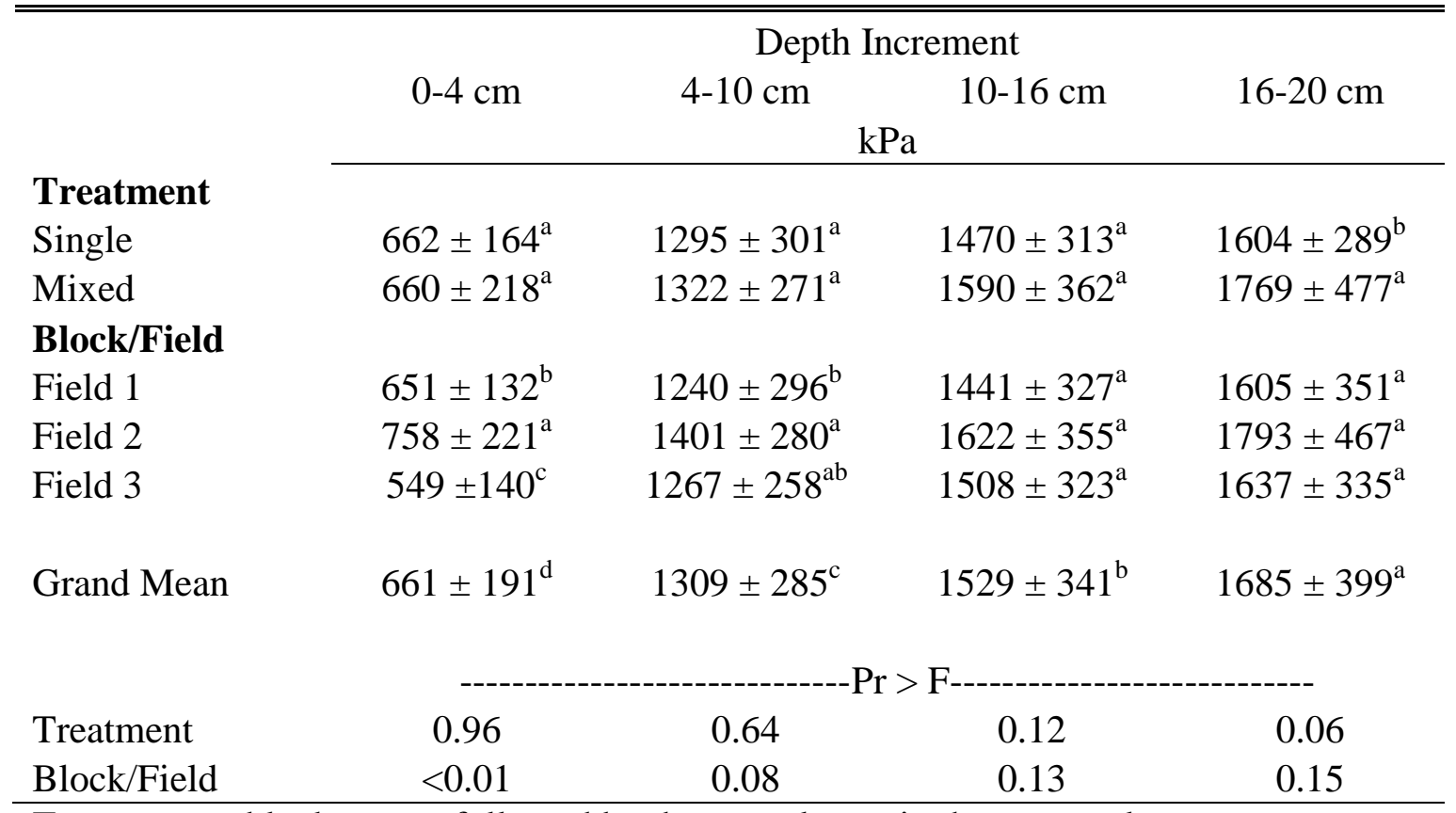

Treatment or block means followed by the same letter, in the same column, are not significantly different $(\mathrm{P} \leq 0.10)$. *Average \pm one standard deviation.

Grand means, in the same row and followed by the same letter, are not significantly different $(\mathrm{P} \leq 0.10)$. *Average \pm standard deviation.

Similarly to Date 1, at Date 2 no significant effect of treatment on PR was observed over the 0-4 cm depth increment. Also at Date 2, no significant effect of treatment on PR was observed over the 4-10 and 10-16 cm depth increments. A significant effect of treatment was observed in penetration resistance at the $16-20 \mathrm{~cm}$ depth increment, where the mixed species grazing treatment exhibited higher PR than the single species grazing treatment (Table 8). Due to the depth, the significant differences in PR cannot be easily explained by the effect of grazing treatment. The analysis of variance for PR taken at Date 2 indicated significant block/field effect at the 0-4 and 4-10 cm depths (Table 8). 
The overall average surface $(0-4 \mathrm{~cm})$ PR for the study area was $851 \mathrm{kPa}$ at Date 3 (Table 9). The overall average PR for the study area, over the 4-10, 10-16, and 16-20 cm depth increments for the study area was 2022, 2545, and $2926 \mathrm{kPa}$, respectively, at Date 3 (Table 9). The analysis of variance for PR at Date 3 is presented in Table 9.

Table 9. Mean, standard deviation, and analysis of variance for penetration resistance measured at Date 3.

\begin{tabular}{lcccc}
\hline \hline & & \multicolumn{3}{c}{ Depth Increment } \\
& $0-4 \mathrm{~cm}$ & $4-10 \mathrm{~cm}$ & $10-16 \mathrm{~cm}$ & $16-20 \mathrm{~cm}$ \\
Treatment & & \multicolumn{3}{c}{$\mathrm{kPa}$} \\
Single & $866 \pm 260^{\mathrm{a}}$ & $2025 \pm 458^{\mathrm{a}}$ & $2537 \pm 518^{\mathrm{a}}$ & $2937 \pm 608^{\mathrm{a}}$ \\
Mixed & $831 \pm 284^{\mathrm{a}}$ & $2018 \pm 364^{\mathrm{a}}$ & $2556 \pm 514^{\mathrm{a}}$ & $2912 \pm 603^{\mathrm{a}}$ \\
Block/Field & & & & \\
Field 1 & $896 \pm 282^{\mathrm{a}}$ & $1693 \pm 267^{\mathrm{c}}$ & $2085 \pm 427^{\mathrm{b}}$ & $2425 \pm 548^{\mathrm{b}}$ \\
Field 2 & $766 \pm 254^{\mathrm{a}}$ & $2088 \pm 293^{\mathrm{b}}$ & $2786 \pm 456^{\mathrm{a}}$ & $3164 \pm 486^{\mathrm{a}}$ \\
Field 3 & $906 \pm 260^{\mathrm{a}}$ & $2285 \pm 455^{\mathrm{a}}$ & $2733 \pm 309^{\mathrm{a}}$ & $3159 \pm 460^{\mathrm{a}}$ \\
& & & & \\
Grand Mean & $851 \pm 270^{\mathrm{d}}$ & $2022 \pm 416^{\mathrm{c}}$ & $2545 \pm 513^{\mathrm{b}}$ & $2926 \pm 602^{\mathrm{a}}$ \\
& & & & \\
Treatment & $------------------------P r>$ F------------------------------- \\
Block/Field & 0.72 & 0.63 & 0.67 & 0.46 \\
\hline
\end{tabular}

Treatment or block means followed by the same letter, in the same column, are not significantly different $(\mathrm{P} \leq 0.10)$. *Average \pm one standard deviation.

Grand means, in the same row and followed by the same letter, are not significantly different $(\mathrm{P} \leq 0.10)$. *Average \pm standard deviation.

The analysis of variance for PR at Date 3 indicated no significant effect due to grazing treatments at the 0-4, 4-10, 10-16 and 16-20 cm depth increments. A significant block/field effect on the measured PR was observed at 4-10, 10-16 and 16-20 cm.

For the study area, PR generally increased with depth (Tables 7, 8 and 9). The increase in PR values with depth was also observed by Chanasyk and Naeth (1995). They observed 
increases in surface PR between May and July of 1988-1991, for grazed foothill fescue grasslands in Alberta, Canada.

A t-test was performed to determine whether there were significant $(\mathrm{P} \leq 0.10)$ differences in PR due to depth. Results indicated significant differences in PR due to depth increment at all sampling dates (Tables 7 to 9). Figure 11 shows the average PR, by depth, across all dates, fields and treatments.

Several studies have found an increase in BD and PR due to grazing. Chanasyk and Naeth (1995) reported that BD and PR were affected by short-duration grazing, increasing by as much as $10 \%$ between moderate and heavily grazed grasslands. The PR values were rarely greater than $2000 \mathrm{kPa}$ between $0-20 \mathrm{~cm}$, and this indicates that PR measured in this study was limiting to root growth (Graecen, 1986).

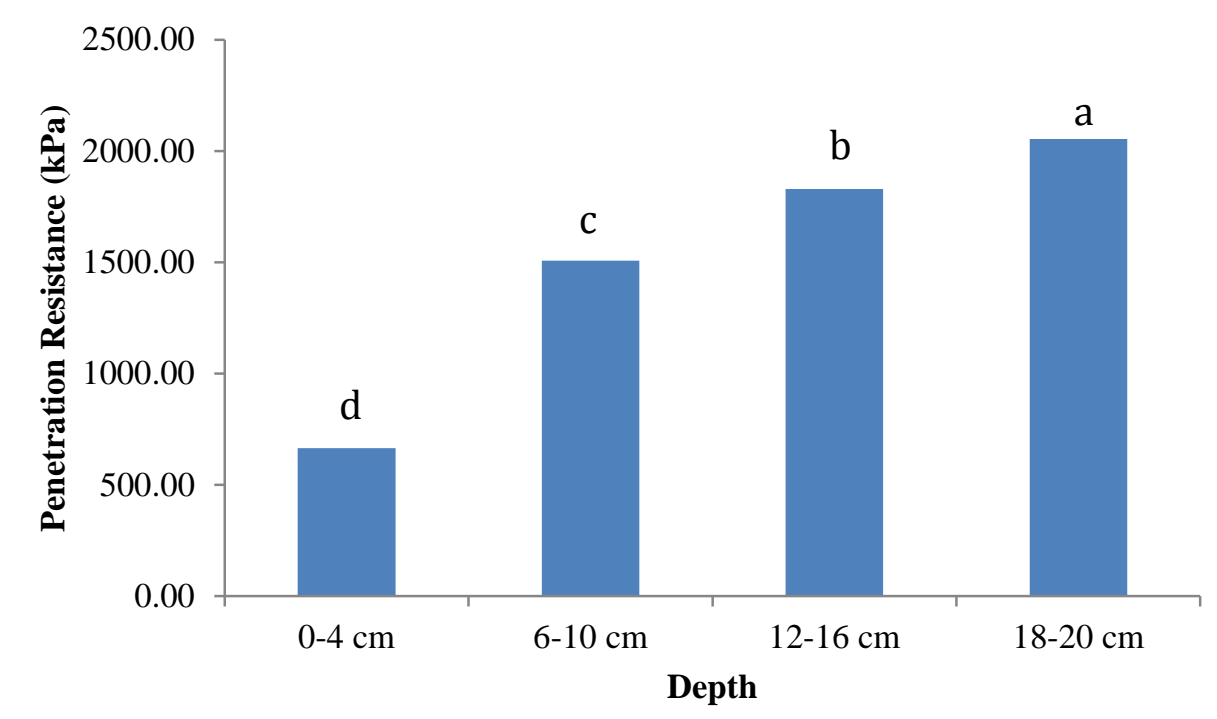

Figure 11. Average penetration resistance by depth increment, across all dates, fields and treatments. Columns topped by the same letter are not significantly different $(\mathrm{P} \leq 0.10)$. 
The effect of sampling date on porosity was evaluated at the end of the experiment. A randomized complete block with three replications and two factors, grazing treatment and sampling date, was used to analyze the variation in porosity (Table 6). The analysis of variance indicated significant differences in porosity due to sampling date, but no difference due to grazing treatment. The interaction between sampling date and treatment was not significant (Table 9C in Appendix C).

The effect of sampling date on PR was determined at the end of the experiment, using a randomized complete block with three replications and two factors, grazing treatment and sampling date was used to analyze variation in PR. At 0-4 $\mathrm{cm}$ and $4-10 \mathrm{~cm}$, the analysis of variance indicated significant differences in PR between sampling dates, but no differences due to grazing treatments (Table 20C-23C in Appendix C). The interaction of sampling date with grazing treatment was not significant.

For PR at the 10-16 and 18-20 cm depth increments, the analysis of variance indicated significant differences between sampling dates, but no differences due to grazing treatments (Tables 24C-27C in Appendix C). However, the interaction of sampling date by treatment was significant $(\mathrm{P} \leq 0.10)$ at both these depths, indicating $\mathrm{PR}$ differences due to grazing treatment were affected by the sampling date.

Soil moisture affects PR measurements (Vaz et al., 2011; Lapen et al., 2004; Gifford et al., 1977). To suppress the effect of changing soil moisture within and between sampling dates, the measured PR data were normalized by field, depth and sampling date. The normalization procedure consisted in first separating the PR data by field and date. For each date and field, the measured PR value, at a specific depth, was divided by the highest PR value observed at that depth, in that field, and for that date. This procedure 
was repeated for all geo-referenced sampling points. The normalized data were analyzed following the same statistical procedure (ANOVA) previously described for the nonnormalized PR values. Results obtained with this method (not presented) were similar to the results obtained for the non-normalized data and supports the conclusion that the measured PR values were not confounded with differences in soil moisture.

Soil Surface Dry Aggregate Stability

Soil surface $(0-5 \mathrm{~cm})$ dry aggregate size distribution was measured at all three dates. Table 10 gives the mean-weight diameter (MWD) data for the dry aggregate size distributions, and the ANOVA, for those same data. The ANOVA for the geometric mean diameter (GMD) data are found in Appendix D. The ANOVA for MWD and GMD gave the same experimental conclusion.

Table 10. Mean, standard deviation, and analysis of variance for dry aggregate stability (MWD) by date.

$\begin{array}{lll}\text { Date } 1 & \text { Date } 2 & \text { Date } 3 \\ \mathrm{~mm}\end{array}$

\section{Treatment}

Single

$22.9 \pm 6.9^{\mathrm{a}}$

$31.1 \pm 7.0^{\mathrm{a}}$

$19.8 \pm 6.4^{\mathrm{a}}$

Mixed

$20.6 \pm 7.7^{\mathrm{a}}$

$31.6 \pm 9.9^{\mathrm{a}}$

$20.0 \pm 7.4^{\mathrm{a}}$

\section{Block/Field}

Field 1

Field 2

Field 3

$21.6 \pm 7.9^{\mathrm{a}}$

$32.6 \pm 9.5^{\mathrm{a}}$

$18.98 \pm 6.0^{\mathrm{b}}$

$23.4 \pm 6.9^{\mathrm{a}}$

$31.3 \pm 8.5^{\mathrm{a}}$

$21.84 \pm 8.5^{\mathrm{a}}$

$19.9 \pm 7.1^{\mathrm{a}}$

$29.9 \pm 7.3^{\mathrm{a}}$

$18.68 \pm 7.3^{b}$

Grand Mean

$21.8 \pm 7.4^{b}$

$31.3 \pm 8.5^{\mathrm{a}}$

$19.9 \pm 6.8^{b}$

Treatment

$-\mathrm{Pr}>\mathrm{F}$

Block/Field

0.22

0.79

0.93

Treatment or block means followed by the same letter, in the same column, are not significantly different $(\mathrm{P} \leq 0.10)$. *Average \pm one standard deviation.

Grand means, in the same row and followed by the same letter, are not significantly different $(\mathrm{P} \leq 0.10)$. *Average \pm standard deviation. 
The dry aggregate stability data obtained in August 2011 (Date 1), after spring/summer grazing, exhibited an overall average dry aggregate MWD, for the study area, of $21.8 \pm$ $7.4 \mathrm{~mm}$ (Table 10). At Date 2, the overall average dry aggregate MWD for the study area was $31.3 \pm 8.5 \mathrm{~mm}$. After spring/summer grazing in 2012, Date 3, the overall average dry aggregate MWD for the study area was $19.9 \pm 6.8 \mathrm{~mm}$.

The analysis of variance analyses for MWD at Dates 1,2 and 3 are presented in Table 10. At each sampling date (Dates 1, 2, and 3), no significant effect of treatment on MWD was observed. The block effect for dry aggregate MWD was not significant at Dates 1 and 2. At Date 3, a significant effect of block was observed and Field 2 exhibited significantly larger dry aggregate diameter than Fields 1 and 3 (Table 10).

The effect of sampling date on MWD was evaluated at the end of the experiment, using the statistical analysis described previously. The two-way analysis of variance indicated significant differences in dry aggregate size between sampling dates (Table 10), but no differences due to grazing treatment. The interaction of sampling date by treatment was not significant (Tables 29C and 31C in Appendix C).

The grazing management systems were established only three years ago, and the possibility arises that not enough time has passed for a significant and detectable change in soil properties. The effect of management practices on dynamic soil properties may not be strong and, as a consequence, the differences between grazing systems were not statistically significant. 


\section{Soil Surface Wet Aggregate Stability}

Soil surface $(0-5 \mathrm{~cm})$ wet aggregate stability was measured at all three sampling dates.

Table 11 gives wet MWD for the wet aggregate size distributions, and the appropriate ANOVA, for all three dates. The ANOVA for the geometric mean diameter (GMD) data are found in Appendix E. The ANOVA for MWD and GMD gave the same experimental conclusion.

Table 11. Mean, standard deviation, and analysis of variance for wet aggregate stability (MWD).

$\begin{array}{ccc}\text { Date } 1 & \text { Date } 2 & \text { Date } 3\end{array}$

\section{Treatment}

Single

$5.94 \pm 0.60^{\mathrm{a}}$

$5.97 \pm 0.50^{\mathrm{a}}$

$6.08 \pm 0.25^{\mathrm{a}}$

Mixed

$6.09 \pm 0.23^{\mathrm{a}}$

$6.04 \pm 0.46^{\mathrm{a}}$

$6.04 \pm 0.41^{\mathrm{a}}$

\section{Block/Field}

Field 1

$6.15 \pm 0.20^{\mathrm{a}}$

$5.90 \pm 0.49^{\mathrm{a}}$

$6.06 \pm 0.31^{\mathrm{a}}$

Field 2

$5.94 \pm 0.17^{\mathrm{a}}$

$6.00 \pm 0.63^{\mathrm{a}}$

$6.02 \pm 0.45^{\mathrm{a}}$

Field 3

$5.91 \pm 0.70^{\mathrm{a}}$

$6.11 \pm 0.16^{\mathrm{a}}$

$6.12 \pm 0.10^{\mathrm{a}}$

Grand Mean

$6.02 \pm 0.44^{\mathrm{a}}$

$6.00 \pm 0.48^{\mathrm{a}}$

$6.07 \pm 0.33^{\mathrm{a}}$

Treatment

0.16

$-\mathrm{Pr}>\mathrm{F}$

Block/Field

0.13

0.35

0.56

Treatment or block means followed by the same letter, in the same column, are not significantly different $(\mathrm{P} \leq 0.10)$. *Average \pm one standard deviation.

Grand means, in the same row and followed by the same letter, are not significantly different $(\mathrm{P} \leq 0.10)$. *Average \pm standard deviation.

The wet aggregate stability data obtained at Date 1, after spring/summer grazing, exhibited an average wet aggregate MWD of $6.02 \pm 0.44 \mathrm{~mm}, 6.00 \pm 0.48 \mathrm{~mm}$ after winter grazing (Date 2), and $6.07 \pm 0.33 \mathrm{~mm}$ at Date 3, after spring/summer grazing (Table 11). Analysis of variance for wet MWD at Dates 1, 2 and 3 found no significant 
effect of treatment (mixed or single species grazing). No significant effect of field/block was found, either (Table 11).

The effect of sampling date on wet aggregate MWD and GMD was evaluated at the end of the experiment. A randomized complete block with two replications and two factors, grazing treatment and sampling date, was used to partition the variation in MWD and GMD. The analysis of variance found no significant difference in MWD due to sampling date or grazing treatment (Table 11). The interaction between sampling date and treatment was not significant. Table $31 \mathrm{C}$ in Appendix C contains details of the ANOVA.

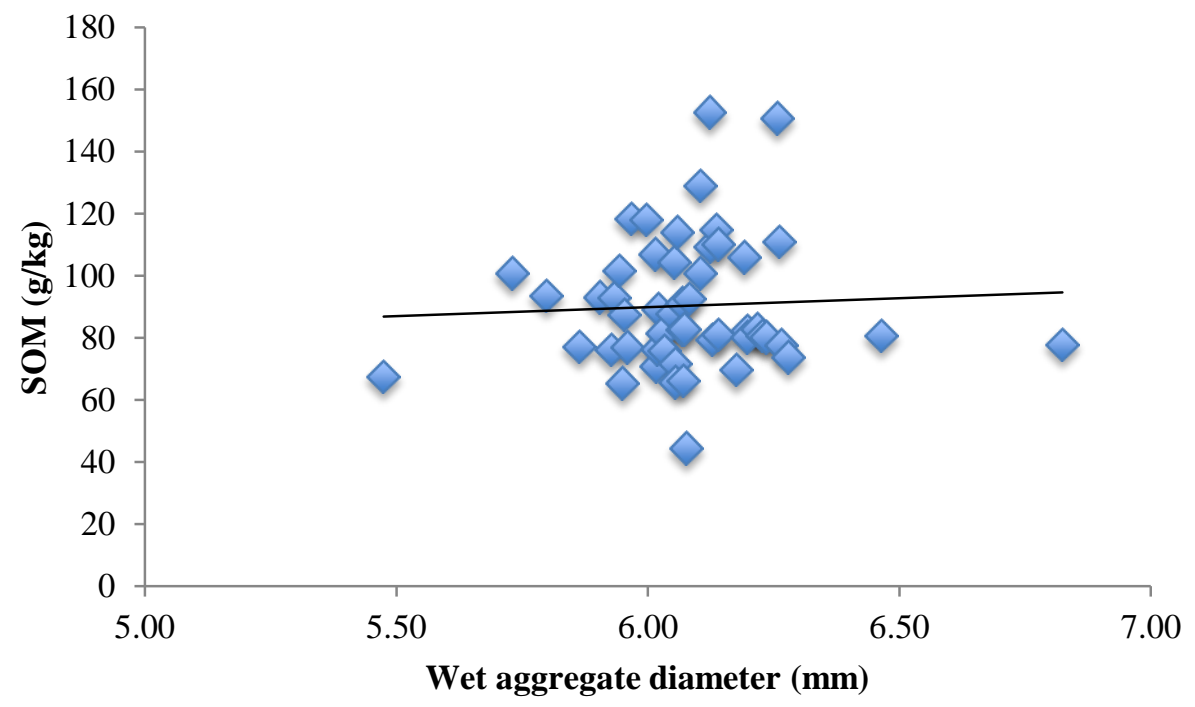

Figure 12. Relationship between wet aggregate size and soil organic matter (SOM) for the study site at Date 1.

Wet aggregate diameter was expected to be correlated with soil organic matter (SOM) (Six, 2002b). Soil organic matter and clay act as soil aggregate cementing agents (Tisdall and Oades, 1982; Elliot, 1986). In this study, the relationship was not found (Fig. 12). 


\section{Soil Hydraulic Properties}

Saturated Hydraulic Conductivity $\left(\mathrm{K}_{\mathrm{sat}}\right)$

Saturated hydraulic conductivity $\left(\mathrm{K}_{\mathrm{sat}}\right)$ was measured at three sampling dates as described in the materials and methods section. The Wooding infiltrometer (Wooding, 1968) was used to measure $\mathrm{K}_{\mathrm{sat}}$ at Date 1 (August 2011); and the single ring infiltrometer (Smith and Doran, 1996; USDA, 2001) was used at Dates 2 and 3 (April 2012 and August 2012, respectively). In April 2012 (Date 2), a standard saturated hydraulic conductivity method described in the Soil Quality Test Kit Guide (2001) was performed. In August 2012 (Date 3) a standard method (USDA, 2001) and a "Modified Method" described in the materials and methods section were performed.

At Date 1 the Wooding infiltrometer data were used to estimate an average $\mathrm{K}_{\text {sat }}$ of $0.22 \pm$ $0.13 \mathrm{~cm} / \mathrm{min}$ for the study area (Table 12 ). According to the USDA-NRCS $\mathrm{K}_{\mathrm{sat}}$ classification, the overall $\mathrm{K}_{\mathrm{sat}}$ measured with the Wooding infiltrometer was ranked in the moderately rapid $(0.085-0.25 \mathrm{~cm} / \mathrm{min}) \mathrm{K}_{\text {sat }}$ class (Table $1 \mathrm{~F}$ in Appendix F). At Date 2, the single-ring infiltrometer (standard method) found an average $\mathrm{K}_{\text {sat }}$ of $0.81 \pm 1.06 \mathrm{~cm} / \mathrm{min}$ for the entire study area (Table 12). The high coefficient of variation (131\%) for Date 2 saturated hydraulic conductivity values was indicative of the high variability in hydraulic properties that exists at a smaller spatial scale in grassland soils. According to the USDANRCS $K_{\text {sat }}$ classification, the overall $\mathrm{K}_{\text {sat }}$ measured with the single ring infiltrometer (standard method) was ranked in the rapid $\mathrm{K}_{\mathrm{sat}}$ class $(0.25-0.85 \mathrm{~cm} / \mathrm{min})($ Table $1 \mathrm{~F}$ in Appendix F). At Date 3 the $\mathrm{K}_{\text {sat }}$ measured with the single-ring infiltrometer (standard method) averaged $1.84 \pm 1.28 \mathrm{~cm} / \mathrm{min}$ over the entire study area, resulting in a very rapid $\mathrm{K}_{\mathrm{sat}}\left(>0.85 \mathrm{~cm} / \mathrm{min}\right.$ ) classification (Table $1 \mathrm{~F}$ in Appendix F). At Date 3 the average $\mathrm{K}_{\text {sat }}$ for the entire study area was $1.86 \pm 1.50 \mathrm{~cm} / \mathrm{min}$ for the single-ring infiltrometer 
(Modified Method). This also resulted in a very rapid $\mathrm{K}_{\text {sat }}(>0.85 \mathrm{~cm} / \mathrm{min})$ classification (Table 1F in Appendix F).

Table 12. Overall statistics for soil saturated hydraulic conductivity.

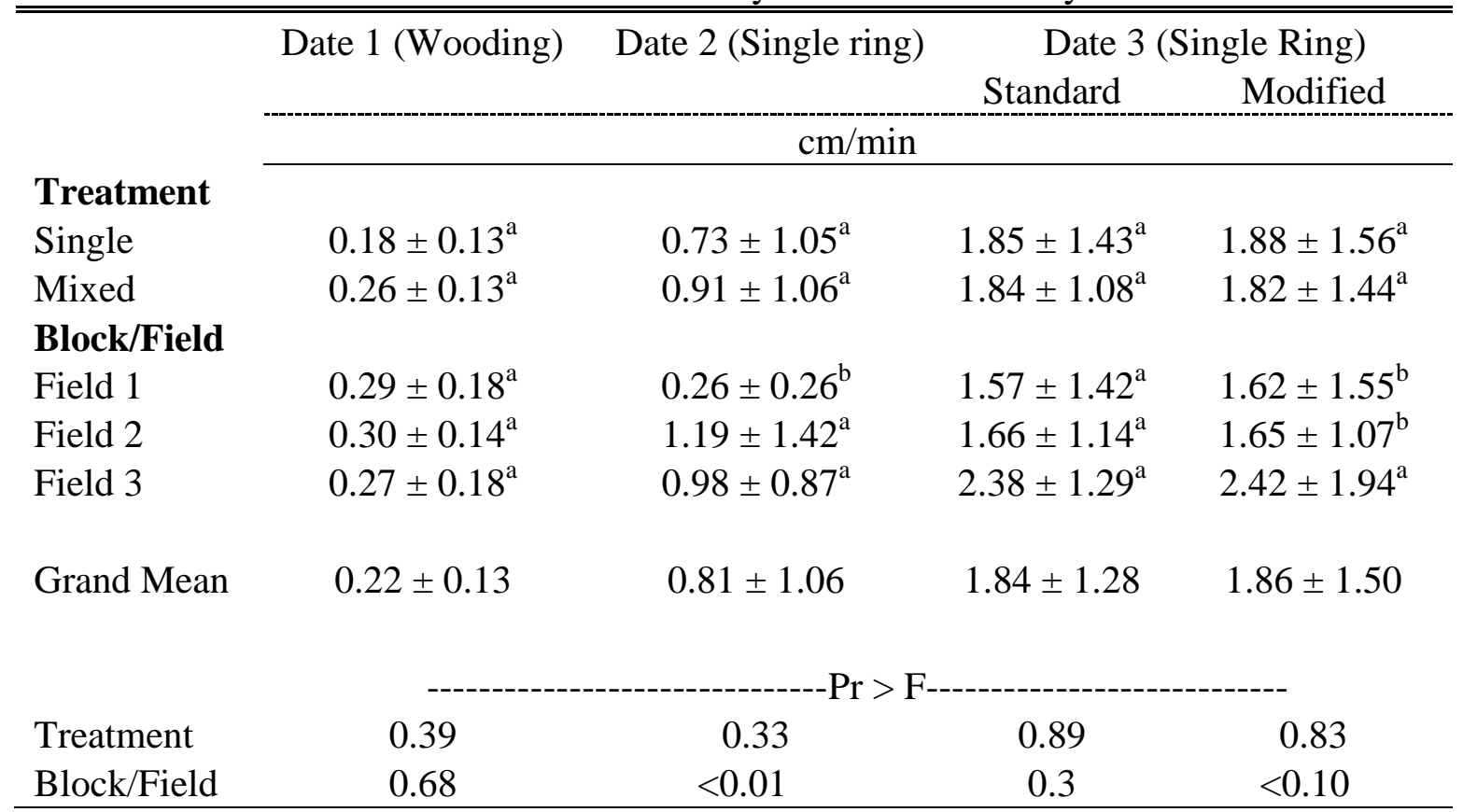

Treatment or block means followed by the same letter, in the same column, are not significantly different $(\mathrm{P} \leq 0.10)$. *Average \pm one standard deviation.

No significant effect due to grazing treatment was observed in $\mathrm{K}_{\text {sat }}$ at any sampling date.

The analysis of variance found a significant block/field effect on single ring infiltrometer (standard method) $\mathrm{K}_{\text {sat }}$ at Date 2 and on the single ring infiltrometer (Modified Method) $\mathrm{K}_{\text {sat }}$ at Date 3 (Table 12).

To determine the effect of sampling date on saturated hydraulic conductivity, the $\mathrm{K}_{\text {sat }}$ data obtained using the standard method single ring infiltrometer were analyzed at the end of the experiment. Only standard method single ring infiltrometer saturated hydraulic conductivity was measured over Dates 2 and 3. A randomized complete block with three replications and two factors, grazing treatment and sampling date, was used (Table 4F in 
Appendix F). The analysis of variance indicated significant differences in $\mathrm{K}_{\text {sat }}$ due to sampling date, but no differences due to grazing treatments. The interaction of sampling date by treatment was not significant (Table 4F in Appendix F).

Slower infiltration rates decrease the ability of the soil to take in water, increasing overland flow and water erosion. No other studies comparing mixed to single species grazing systems were found, for comparison with the results obtained in this study. However, the saturated hydraulic conductivity values measured in this study are slightly higher than those measured by Naeth et al. (1990) in an ungrazed grassland. The authors reported values as low as $0.17 \mathrm{~cm} / \mathrm{h}$ on "heavy grazed" grassland fields (4.4 animal unit month (AUM) ha ${ }^{-1}$ ).

Soil hydraulic properties were expected to be related to soil structural properties. Figure 13 shows the weak negative relationship between field measured bulk density and saturated hydraulic conductivity (single ring standard method) at Date 2. This would be the expected outcome in the presence of animals. When aggregates are packed closely together, generating a high bulk density, total porosity decreased, affecting the ability of the soil to infiltrate and conduct water.

Previous studies have reported that grasslands exhibit highly variable saturated hydraulic conductivities. Kodesova et al. (2011) reported $\mathrm{K}_{\text {sat }}$ values as low as $0.0175 \mathrm{~cm} / \mathrm{min}$ and as high as $0.049 \mathrm{~cm} / \mathrm{min}$, while other studies, such as that of Lou et al. (2010) reported $\mathrm{K}_{\text {sat }}$ values as high as $1.69 \mathrm{~cm} / \mathrm{min}$ and as low as $0.25 \mathrm{~cm} / \mathrm{min}$. The minimum saturated hydraulic conductivity measured for this study was $0.01 \mathrm{~cm} / \mathrm{min}$ and the maximum measured $\mathrm{K}_{\text {sat }}$ was $9.55 \mathrm{~cm} / \mathrm{min}$. 


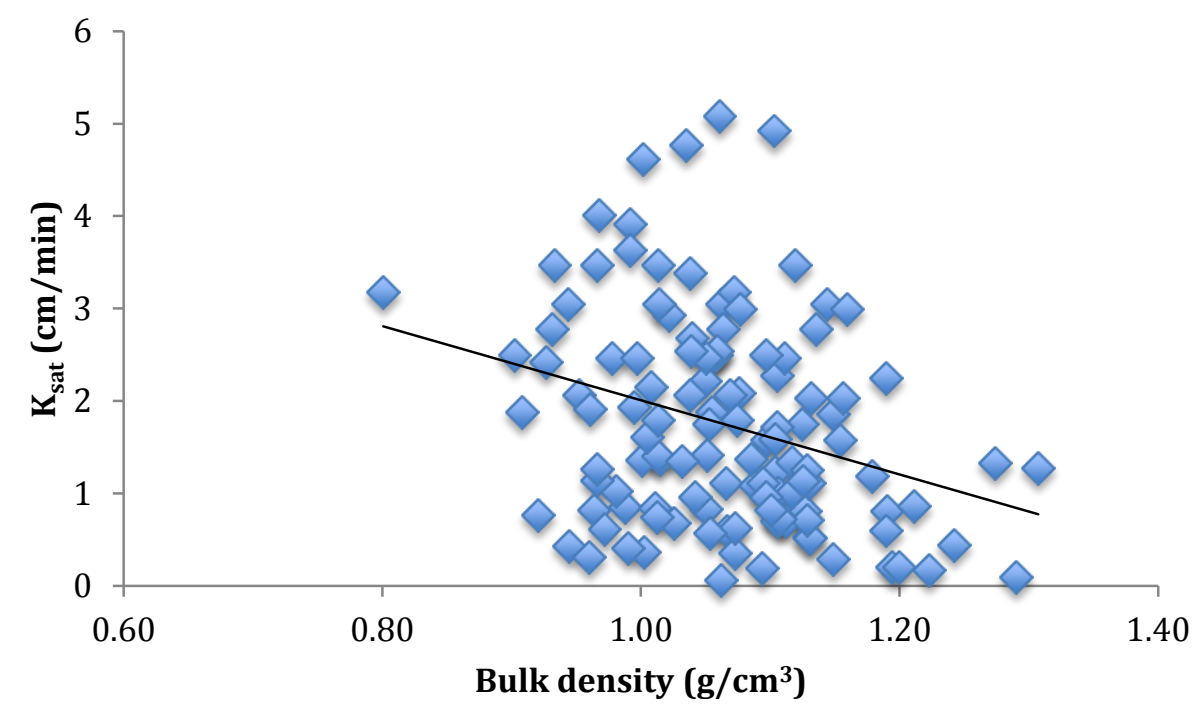

Figure 13. Relationship between bulk density and saturated hydraulic conductivity (single ring standard method) at Date 2 .

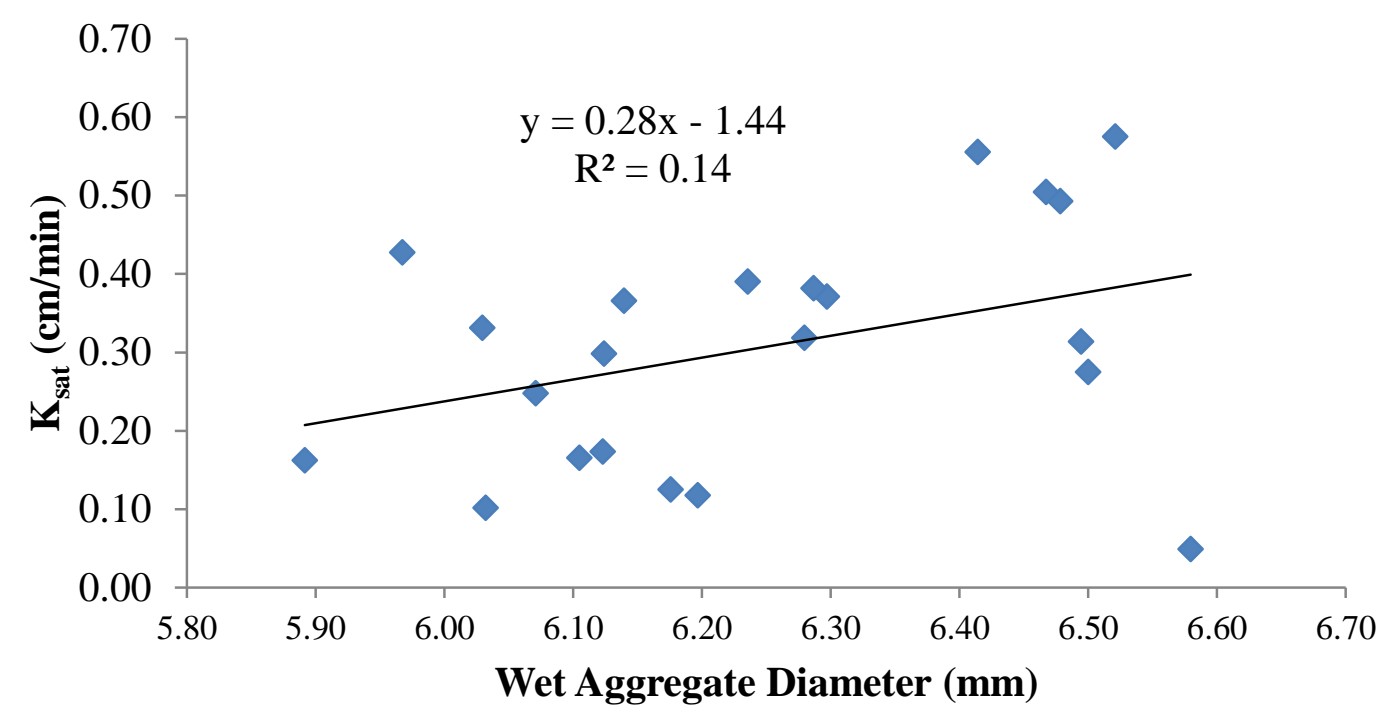

Figure 14. Relationship between wet aggregate diameter and saturated hydraulic conductivity (Wooding infiltrometer) at sampling Date 1.

In this study, Pearson correlation coefficients showed saturated hydraulic conductivity was positively correlated ( $\mathrm{r}=0.37)$ to wet aggregate stability (Fig. 14). Several authors have reported strong correlations among wet aggregate stability and saturated hydraulic conductivity (Brady and Weil, 2002; D'Haene et al., 2008). Although a weak 
relationship, the data obtained in this study showed that as wet aggregate diameter increases, saturated hydraulic conductivity increases. As a consequence, water is more easily and consistently conducted throughout the soil profile, especially with these aggregates, more resistant to breakage under wet conditions. 


\section{Experiment 2: Runoff Study}

Erosion measures (runoff, sediment) were collected continuously over time. However, based on the schedule of the grazing management practices, and seasonal weather, this experiment was divided into three periods: Period 1, from May 2011 to October 2011; Period 2, from November 2011 to February 2012; and Period 3, from March 2012 to October 2012. Continuously collected parameters (runoff, sediment) were processed and analyzed by period. Recorded runoff volumes and sediment weights were averaged by plot, for each period. Soil variables (bulk density, porosity, aggregate stability) associated with the erosion plots were measured at Date 1 (August 2011) and Date 3 (August 2012) (Fig. 5b).

\section{Soil structural properties}

Soil surface bulk density

Soil surface bulk density $(0-5 \mathrm{~cm})$ was sampled at Date 1 (August 2011) and Date 3 (August 2012). The BD measured at Date 1, after 2011 spring/summer grazing, exhibited an overall average BD of $1.03 \pm 0.08 \mathrm{~g} / \mathrm{cm}^{3}$ (Table 13). The BD data measured at Date 3, after $2012 \mathrm{spring} /$ summer grazing, exhibited an overall average BD of $1.00 \pm 0.05 \mathrm{~g} / \mathrm{cm}^{3}$. Bulk density exhibited little variation in the study area. The analyses of variance for BD at Dates 1 and 3 are presented in Table 13.

The results of the analysis of variance for BD at Date 1 is presented in Table 13, No significant effect of treatment on BD was observed, though the single species grazing $\left(1.06 \pm 0.08 \mathrm{~g} / \mathrm{cm}^{3}\right)$ exhibited higher BD than mixed species grazing $\left(0.99 \pm 0.08 \mathrm{~g} / \mathrm{cm}^{3}\right)$ (Table 13). The analysis of variance for BD at Date 1 showed no significant effect of 
field, enclosure, and treatment by enclosure (Table 13). The results indicated that BD at Date 1 was not affected by the presence of animals in the field, or by the grazing system.

Table 13. Mean, standard deviation, and analysis of variance for bulk density in the runoff study.

\section{Block/Field}

Field 1

Field 2

Field 3

Treatment

Single

Mixed

\section{Date 1}

Date 3

Enclosure

Enclosed

Open

\begin{tabular}{cc} 
Date 1 & Date 3 \\
g/cm & \\
\hline & \\
$0.98 \pm 0.08^{\mathrm{a}}$ & $1.03 \pm 0.04^{\mathrm{a}}$ \\
$1.03 \pm 0.07^{\mathrm{a}}$ & $0.97 \pm 0.06^{\mathrm{a}}$ \\
$1.06 \pm 0.10^{\mathrm{a}}$ &. \\
& \\
$1.06 \pm 0.08^{\mathrm{a}}$ & $1.01 \pm 0.05^{\mathrm{a}}$ \\
$0.99 \pm 0.08^{\mathrm{a}}$ & $0.99 \pm 0.06^{\mathrm{a}}$
\end{tabular}

Grand Mean

$1.03 \pm 0.08$

$1.00 \pm 0.05$

Block/Field

$\begin{array}{cc}0.54 & 0.11 \\ 0.29 & 0.49 \\ 0.55 & <0.01 \\ 0.36 & 0.29\end{array}$

Treatment

$1.04 \pm 0.07^{\mathrm{a}}$

$0.97 \pm 0.03^{b}$

Enclosure

0.36

$1.03 \pm 0.06^{\mathrm{a}}$

Treatment*Enclosure

$1.01 \pm 0.10^{\mathrm{a}}$

Block, treatment or enclosure means followed by the same letter, in the same column, are not significantly different $(\mathrm{P} \leq 0.10)$. *Average \pm one standard deviation.

The analysis of variance for Date 3 indicated that grazing treatment did not explain the variability observed in BD (Table 13). Single species grazing $\left(1.01 \pm 0.05 \mathrm{~g} / \mathrm{cm}^{3}\right)$ exhibited slightly higher BD than mixed species grazing $\left(0.99 \pm 0.06 \mathrm{~g} / \mathrm{cm}^{3}\right)$ (Table 13$)$. For Date 3, no significant effect of field or treatment by enclosure on BD variability was detected. A significant effect of enclosure on BD was observed. The BD of the open erosion plots was significantly higher BD than that of the closed erosion plots (Table 13). The interaction of enclosure by treatment was not significant (Table 13). The results 
indicated that BD at Date 3 was affected by the presence of animals grazing in the field. Regardless of grazing system, animals grazing in the vicinity of the erosion plots significantly compacted the surface $0-5 \mathrm{~cm}$ of soil.

Soil surface porosity

Porosity was calculated from the bulk density data taken within $30 \mathrm{~cm}$ of the erosion plots on Date 1 (August 2011) and Date 3 (August 2012). Total porosity $(0-5 \mathrm{~cm})$ was calculated using the following formula:

$$
\mathrm{f}=1-\left(\rho_{\mathrm{b}} / \rho_{\mathrm{s}}\right)
$$

where $\mathrm{f}$ is total porosity, $\rho_{\mathrm{b}}$ is the field measured bulk density, and $\rho_{\mathrm{s}}$ is particle density and $\rho_{\mathrm{s}}=2.65 \mathrm{~g} / \mathrm{cm}^{3}$.

The porosity data obtained at Date 1, after spring/summer grazing in 2011, exhibited an overall value of $0.61 \pm 0.03 \mathrm{~cm}^{3} / \mathrm{cm}^{3}$ and $0.62 \pm 0.02 \mathrm{~cm}^{3} / \mathrm{cm}^{3}$ at Date 3 , after spring/summer grazing in 2012 (Table 14).

The analyses of variance for porosity at Dates 1 and 3 are also presented in Table 14. No significant effect of treatment, field, enclosure, or treatment by enclosure was observed on porosity Date 1 , indicating that porosity at Date 1 was not affected by the presence of animals in the field, or by the grazing system. The analysis of variance for porosity at Date 3 showed no significant effect of treatment and treatment by enclosure on porosity. However, there was a significant effect of field and enclosure on porosity (Table 14). The enclosed erosion plots exhibited significantly higher porosity than the open erosion plots. The results indicated that regardless of grazing system, animals grazing in the vicinity of the erosion plots significantly decreased surface porosity at the $0-5 \mathrm{~cm}$ depth (Table 14 ). 
Table 14. Mean, standard deviation and analysis of variance for erosion plot porosity.

\section{Block/Field}

Field 1

Field 2

Field 3

Treatment

Single

Mixed

Enclosure

Enclosed

Open

Grand Mean
Date 1

$0.63 \pm 0.03^{\mathrm{a}}$

$0.61 \pm 0.03^{\mathrm{a}}$

$0.60 \pm 0.04^{\mathrm{a}}$

$0.60 \pm 0.03^{\mathrm{a}}$

$0.62 \pm 0.03^{\mathrm{a}}$

$0.61 \pm 0.03^{\mathrm{a}}$

$0.62 \pm 0.04^{\mathrm{a}}$

$0.61 \pm 0.03$

$\begin{array}{cc}0.50 & <0.10 \\ 0.24 & 0.31 \\ 0.53 & <0.10 \\ 0.36 & 0.31\end{array}$

Date 3 $\mathrm{cm}^{3} / \mathrm{cm}^{3}$

$0.61 \pm 0.01^{\mathrm{b}}$

$0.63 \pm 0.02^{\mathrm{a}}$

$0.62 \pm 0.02^{\mathrm{a}}$

$0.63 \pm 0.02^{\mathrm{a}}$

$0.63 \pm 0.01^{\mathrm{a}}$

$0.61 \pm 0.02^{b}$

$0.62 \pm 0.02$

Block/Field

Block, treatment or enclosure means followed by the same letter, in the same column, are not significantly different $(\mathrm{P} \leq 0.10)$. *Average \pm one standard deviation.

Soil surface penetration resistance

Penetration resistance (0-20 cm depth) was measured on August 2012 (Date 3). Average

PR values by depth, treatment and enclosure are shown in Table 15. Analysis of variance was performed for PR, for each depth increment. The average surface $(0-4 \mathrm{~cm}) \mathrm{PR}$ value for the study area was $480 \pm 291 \mathrm{kPa}, 1497 \pm 380 \mathrm{kPa}$ for the 6-10 cm depth, $2090 \pm 507$ $\mathrm{kPa}$ for the 12-16 $\mathrm{cm}$ depth, and $2376 \pm 561 \mathrm{kPa}$ for the $18-20 \mathrm{~cm}$ depth (Table 15).

Analysis of variance for the PR measured at the 0-4, 12-16, and 18-20 cm depths showed no significant effect of treatment, field, enclosure or treatment by enclosure (Table 15). A significant effect of enclosure on PR at 6-10 cm was observed. The open erosion plots exhibited higher PR than the enclosed erosion plots (Table 15). The results indicated that 
regardless of grazing system, animals grazing in the vicinity of the erosion plots increased penetration resistance at the $6-10 \mathrm{~cm}$ depth.

Table 15. Erosion plot penetration resistance at Date 3.

\begin{tabular}{|c|c|c|c|c|}
\hline & \multicolumn{3}{|c|}{$\mathrm{kPa}$} & $18-20 \mathrm{~cm}$ \\
\hline Block/Field & & & & \\
\hline Field 1 & $618 \pm 395^{\mathrm{a}}$ & $1356 \pm 357^{\mathrm{a}}$ & $1875 \pm 600^{\mathrm{a}}$ & $1978 \pm 205^{\mathrm{a}}$ \\
\hline Field 2 & $437 \pm 371^{\mathrm{a}}$ & $1593 \pm 610^{\mathrm{a}}$ & $2175 \pm 703^{\mathrm{a}}$ & $2419 \pm 762^{\mathrm{a}}$ \\
\hline Field 3 & $409 \pm 176^{a}$ & $1531 \pm 266^{\mathrm{a}}$ & $2187 \pm 371^{\mathrm{a}}$ & $2641 \pm 525^{\mathrm{a}}$ \\
\hline \multicolumn{5}{|l|}{ Treatment } \\
\hline Single & $562 \pm 378^{a}$ & $1647 \pm 380^{\mathrm{a}}$ & $2255 \pm 548^{\mathrm{a}}$ & $2481 \pm 567^{\mathrm{a}}$ \\
\hline Mixed & $399 \pm 175^{\mathrm{a}}$ & $1347 \pm 353^{\mathrm{a}}$ & $1924 \pm 485^{\mathrm{a}}$ & $2271 \pm 600^{\mathrm{a}}$ \\
\hline \multicolumn{5}{|l|}{ Enclosure } \\
\hline Enclosed & $313 \pm 151^{\mathrm{a}}$ & $1189 \pm 210^{b}$ & $1759 \pm 400^{\mathrm{a}}$ & $2114 \pm 489^{a}$ \\
\hline Open & $647 \pm 313^{a}$ & $1805 \pm 211^{\mathrm{a}}$ & $2420 \pm 383^{\mathrm{a}}$ & $2638 \pm 546^{\mathrm{a}}$ \\
\hline \multirow[t]{2}{*}{ Grand Mean } & $480 \pm 291$ & $1497 \pm 380$ & $2090 \pm 507$ & $2376 \pm 561$ \\
\hline & \multicolumn{4}{|c|}{$\operatorname{Pr}>F$} \\
\hline Block/Field & 0.48 & 0.68 & 0.84 & 0.45 \\
\hline Treatment & 0.57 & 0.21 & 0.49 & 0.41 \\
\hline Enclosure & 0.13 & $<0.10$ & 0.34 & 0.39 \\
\hline Treatment*Enclosure & 0.33 & 0.41 & 0.63 & 0.22 \\
\hline
\end{tabular}

Block, treatment or enclosure means followed by the same letter, in the same column, are not significantly different $(\mathrm{P} \leq 0.10)$. *Average \pm one standard deviation.

Soil surface dry aggregate stability

Soil surface $(0-5 \mathrm{~cm})$ dry aggregate stability was determined from intact core samples taken in the vicinity of the erosion plots at Dates 1 and 3, after spring/summer grazing of 2011 and 2012, respectively (Fig. 5b). The dry aggregate stability data obtained at Date 1 exhibited an overall mean-weight diameter (MWD) of $16.0 \pm 4.8 \mathrm{~mm}$, and a geometricmean diameter (GMD) of $2.3 \pm 0.3 \mathrm{~mm}$ (Table 16$)$. The dry aggregate stability data obtained at Date 3, after spring/summer grazing, showed an average MWD of $14.9 \pm 6.3$ 
$\mathrm{mm}$ and an average GMD of $2.2 \pm 0.4 \mathrm{~mm}$ (Table 16). The analysis of variance for dry aggregate stability MWD and GMD for Dates 1 and 3 are presented in Table 16.

Table 16. Mean, standard deviation and analysis of variance for the erosion plot dry aggregate stability for Dates 1 and 3 .

\begin{tabular}{ccrr} 
& Date 1 & \multicolumn{2}{c}{ Date 3 } \\
MWD & GMD & MWD & GMD \\
\hline \multicolumn{3}{c}{$\mathrm{mm}$}
\end{tabular}

\section{Block/Field}

Field 1

Field 2

Field 3

Treatment

Single

Mixed

Enclosure

Enclosed

Open

Grand Mean

Block/Field

Treatment

Enclosure

Treatment*Enclosure

$\begin{array}{ll}14.8 \pm 7.7^{\mathrm{a}} & 2.3 \pm 0.4^{\mathrm{a}} \\ 17.6 \pm 1.5^{\mathrm{a}} & 2.4 \pm 0.1^{\mathrm{a}} \\ 15.7 \pm 4.1^{\mathrm{a}} & 2.2 \pm 0.1^{\mathrm{a}}\end{array}$

$16.1 \pm 5.7^{\mathrm{a}}$

$2.3 \pm 0.3^{\mathrm{a}}$

$16.0 \pm 4.4^{\mathrm{a}}$
$19.9 \pm 4.0^{\mathrm{a}}$

$9.9 \pm 3.1^{\mathrm{b}}$

$2.5 \pm 0.3^{\mathrm{a}}$

$1.9 \pm 0.1^{\mathrm{b}}$

$$
13.0 \pm 4.6^{\mathrm{b}} \quad 2.2 \pm 0.2^{\mathrm{b}}
$$

$19.1 \pm 2.7^{\mathrm{a}}$

$2.5 \pm 0.2^{\mathrm{a}}$

$14.7 \pm 5.4^{\mathrm{a}}$

$2.1 \pm 0.3^{\mathrm{a}}$

$15.1 \pm 7.9^{\mathrm{a}}$

$2.2 \pm 0.5^{\mathrm{a}}$

$12.1 \pm 5.5^{\mathrm{b}} \quad 2.0 \pm 0.3^{\mathrm{b}}$

$17.7 \pm 6.4^{\mathrm{a}} \quad 2.3 \pm 0.4^{\mathrm{a}}$

$16.0 \pm 4.8 \quad 2.3 \pm 0.3$

$14.9 \pm 6.3$

$2.2 \pm 0.4$

$\operatorname{Pr}>\mathrm{F}$

0.74

$<0.10$

$<0.10$

0.65

0.76

0.73

0.31

$<0.10$

0.10

$<0.10$

$<0.10$

0.45

0.74

0.73

0.70

Block, treatment or enclosure means followed by the same letter, in the same column, are not significantly different $(\mathrm{P} \leq 0.10)$. *Average \pm one standard deviation.

There was no significant effect of Block/Field on MWD and GMD at the first sampling date (Table 16), but there was a significant effect of field on variation in both MWD and GMD at Date 3, with Block/Field 1 exhibiting greater values, in both parameters, than Block/Field 2. There was no significant effect of treatment or treatment by enclosure on MWD or GMD at either sampling date (Table 16). A significant effect of enclosure on dry aggregate stability was observed on Dates 1 and 3. The open erosion plots exhibited 
significantly larger dry aggregate size, both MWD and GMD, than the closed erosion plots (Table 16). The results indicated that regardless of grazing management system, animal presence did affect dry aggregate size distribution.

In summary, there was no difference in dry aggregate stability due to treatment at sampling Dates 1 and 3. However, the open erosion plots had significantly larger dry aggregate mean-weight and geometric-mean diameters than the enclosed erosion plots at both sampling dates.

Soil surface wet aggregate stability

Soil surface $(0$ to $5 \mathrm{~cm})$ wet aggregate stability was determined from the bulk density samples taken adjacent to the erosion plots at Date 1 (Fig. 5b). These wet aggregate stability data, obtained in August 2011 after spring/summer grazing, exhibited a study area average wet mean-weight diameter (MWD) of $6.36 \pm 0.20 \mathrm{~mm}$ and an average wet geometric-mean diameter (GMD) of $1.68 \pm 0.28 \mathrm{~mm}$ at Date 1 (Table 17).

The analysis of variance for wet aggregate MWD and GMD led to the same experimental conclusions. There was no significant effect of treatment, field, enclosure, or treatment by enclosure on wet aggregate MWD (Table 17). The GMD was more sensitive, exhibiting significant enclosure and treatment by enclosure effects. The open erosion plots exhibited slightly smaller wet aggregate size than the closed erosion plots (Table 17) and that difference was accentuated by the single species grazing treatment, which accounted for the interaction (data not shown). 
Table 17. Mean, standard deviation and analysis of variance for the erosion plot wet aggregate stability determined at Date 1).

\begin{tabular}{lccc}
\hline \hline & & Date 1 & \\
& & & GMD \\
\cline { 2 - 4 } Block/Field & & $\mathrm{mm}$ & \\
Field 1 & $6.4 \pm 0.2^{\mathrm{a}}$ & & $1.6 \pm 0.2^{\mathrm{a}}$ \\
Field 2 & $6.3 \pm 0.3^{\mathrm{a}}$ & $1.7 \pm 0.2^{\mathrm{a}}$ \\
Field 3 & $6.4 \pm 0.2^{\mathrm{a}}$ & $1.6 \pm 0.2^{\mathrm{a}}$ \\
Treatment & & \\
Single & $6.4 \pm 0.2^{\mathrm{a}}$ & $1.8 \pm 0.4^{\mathrm{a}}$ \\
Mixed & $6.4 \pm 0.2^{\mathrm{a}}$ & & $1.6 \pm 0.2^{\mathrm{a}}$ \\
Enclosure & & & \\
Enclosed & $6.3 \pm 0.1^{\mathrm{a}}$ & & $1.8 \pm 0.3^{\mathrm{a}}$ \\
Open & $6.4 \pm 0.3^{\mathrm{a}}$ & & $1.6 \pm 0.2^{\mathrm{b}}$ \\
& & & \\
Grand Mean & $6.4 \pm 0.2$ & & $1.7 \pm 0.3$ \\
& & $\operatorname{Pr}>\mathrm{F}$ & \\
Block/Field & 0.69 & & 0.14 \\
Treatment & 0.89 & & 0.17 \\
Enclosure & 0.52 & & $<0.10$ \\
Treatment*Enclosure & 0.22 & & $<0.10$ \\
\hline Block, & & & \\
\hline
\end{tabular}

Block, treatment or enclosure means followed by the same letter, in the same column, are not significantly different $(\mathrm{P} \leq 0.10)$. *Average \pm one standard deviation.

Soil surface erodibility

The $\mathrm{K}$ factor (soil erodibility coefficient) (RUSLE model) for the surface $0-5 \mathrm{~cm}$ of soil was determined using the following equation:

$$
\mathrm{K}=2.8 \times 10^{-7} M^{1.14}(12-a)+4.3 \times 10^{-3}(b-2)+3.3 \times 10^{-3}(c-3)
$$

where $M$ is the particle size parameter $(\mathrm{M}=[(\%$ silt $+\%$ sand $)] \mathrm{x}(100-\%$ clay $)]), a$ is the organic matter content, $b$ is the soil structure, and $c$ is the permeability class (Fangmeier et al., 2006). Due to the high organic matter contents measured in the study site (> 4\%), the USLE nomogram (Wischmeier et al., 1971) was not recommended for determination of the $\mathrm{K}$ factor. The $\mathrm{K}$ factor for each runoff plot is presented in Table 18 . 
Table 18. Soil surface $(0-5 \mathrm{~cm}) \mathrm{K}$ factor, by erosion plot.

\begin{tabular}{cccccccc}
\hline \hline Plot & Field & Treatment & Enclosure & Silt & $\begin{array}{c}\text { Sand } \\
\mathrm{g} / \mathrm{kg}\end{array}$ & $\mathrm{OM}$ & $\begin{array}{c}\mathrm{K} \text { factor } \\
\mathrm{Mg} \mathrm{ha} \mathrm{MJ}^{-1} \mathrm{~mm}^{-1}\end{array}$ \\
\hline 1 & 1 & Single & Open & 537 & 212 & 49.9 & 0.04 \\
2 & 1 & Single & Enclosed & 497 & 171 & 49.9 & 0.03 \\
3 & 1 & Mixed & Open & 493 & 202 & 49.9 & 0.04 \\
4 & 1 & Mixed & Enclosed & 520 & 192 & 49.9 & 0.04 \\
5 & 2 & Mixed & Enclosed & 484 & 208 & 53.0 & 0.04 \\
6 & 2 & Mixed & Open & 475 & 205 & 53.0 & 0.03 \\
7 & 2 & Single & Open & 500 & 260 & 53.0 & 0.04 \\
8 & 2 & Single & Enclosed & 472 & 237 & 53.0 & 0.04 \\
9 & 3 & Single & Open & 510 & 210 & 65.0 & 0.03 \\
10 & 3 & Single & Enclosed & 447 & 225 & 65.0 & 0.03 \\
11 & 3 & Mixed & Open & 492 & 186 & 65.0 & 0.03 \\
12 & 3 & Mixed & Enclosed & 470 & 212 & 65.0 & 0.03 \\
\hline
\end{tabular}

The average $\mathrm{K}$ factor for the study area was $0.035\left(\mathrm{Mg}_{\mathrm{ga} \mathrm{MJ}}^{-1} \mathrm{~mm}^{-1}\right)$, which falls in the "low erodibility class" (Presant and Acton, 1984). Typical K values range from 0.13 to $0.58 \mathrm{Mg}$ ha $\mathrm{MJ}^{-1} \mathrm{~mm}^{-1}$, but in this study the average $\mathrm{K}$ value was much lower. The low $\mathrm{K}$ values estimated for this site could be a consequence if high organic matter contents, high infiltration/permeability rates, and a strong surface soil structure.

\section{Soil hydrologic and water erosion variables}

\section{Surface Soil Saturated Hydraulic Conductivity}

A total of 24 Wooding infiltrometer measurements (Wooding, 1968) were performed within $30 \mathrm{~cm}$ of the erosion plots ( 2 per plot) at Date 1 . The two measurements were averaged by plot, and statistical analysis was performed on the average values (Table 19).

The overall average $\mathrm{K}_{\mathrm{sat}}$ was $0.36 \pm 0.16 \mathrm{~cm} / \mathrm{min}$. According to the USDA-NRCS classification system, the overall $\mathrm{K}_{\text {sat }}$ measured in this study was rapid (0.25-0.85 $\mathrm{cm} / \mathrm{min}$ ) (Table $1 \mathrm{~F}$ in Appendix F). The results of the analysis of variance indicated no 
statistically significant effect of treatment, field, enclosure, or treatment by enclosure on $\mathrm{K}_{\text {sat }}($ Table 19).

Table 19. Mean, standard deviation, and analysis of variance for saturated hydraulic conductivity near the erosion plots at Dates 1 and 3.

\begin{tabular}{clc} 
Date 1 & \multicolumn{2}{c}{ Date 3} \\
\hline Wooding & $\begin{array}{l}\text { Standard } \\
\mathrm{cm} / \mathrm{min}\end{array}$ & Modified
\end{tabular}

\section{Block/Field}

Field 1

Field 2

Field 3

Treatment

Single

Mixed

Enclosure

Enclosed

Open

Grand Mean

Block/Field

Treatment

Enclosure

Treatment*Enclosure

$$
\begin{aligned}
& 0.41 \pm 0.14^{\mathrm{a}} \\
& 0.32 \pm 0.14^{\mathrm{a}} \\
& 0.34 \pm 0.22^{\mathrm{a}}
\end{aligned}
$$

$$
2.3 \pm 2.9^{\mathrm{a}}
$$$$
2.2 \pm 2.3^{\mathrm{a}}
$$$$
2.6 \pm 2.4^{\mathrm{a}}
$$$$
2.6 \pm 1.5^{\mathrm{a}}
$$$$
3.3 \pm 2.6^{\mathrm{a}}
$$$$
3.3 \pm 3.1^{\mathrm{a}}
$$

$$
0.37 \pm 0.16^{\mathrm{a}}
$$

$2.7 \pm 3.0^{\mathrm{a}}$

$0.34 \pm 0.16^{\mathrm{a}}$

$2.8 \pm 2.6^{\mathrm{a}}$

$3.0 \pm 3.0^{\mathrm{a}}$

$1.4 \pm 0.9^{\mathrm{b}}$

$0.37 \pm 0.10^{\mathrm{a}}$

$4.6 \pm 1.9^{\mathrm{a}}$

$3.7 \pm 2.3^{\mathrm{a}}$

$0.34 \pm 0.21^{\mathrm{a}}$

$0.86 \pm 0.91^{b}$

$0.68 \pm 0.29^{b}$

$0.36 \pm 0.16$

$2.7 \pm 2.4$

$2.2 \pm 2.2$

Block, treatment or enclosure means followed by the same letter, in the same column, are not significantly different $(\mathrm{P} \leq 0.10)$. *Average \pm one standard deviation.

\section{Single Ring Infiltrometer}

The standard (2.5 cm initial wetting) and "Modified" ( $5 \mathrm{~cm}$ initial wetting) methods were used to measure saturated hydraulic conductivity near the erosion plots at Date 3 (Table 19). The single ring standard method gave an average $K_{\text {sat }}$ of $2.72 \pm 2.42 \mathrm{~cm} / \mathrm{min}$ at Date

3, which falls in the 'very rapid' USDA-NRCS classification (Table 1F in Appendix F). 
The analysis of variance for $\mathrm{K}_{\mathrm{sat}}$ measured at Date 3 is presented in Table 19. No significant effect of treatment, field, and treatment by enclosure on single ring standard method $\mathrm{K}_{\text {sat }}$ was observed at Date 3. A significant effect of enclosure was observed, and the enclosed erosion plots exhibited a significantly faster $\mathrm{K}_{\mathrm{sat}}$ than the open erosion plots (Table 19). This outcome indicated that regardless of the grazing treatment, the presence of grazing animals negatively impacted water infiltration.

The single ring Modified Method at Date 3 exhibited an average $K_{\text {sat }}$ of $2.2 \pm 2.2 \mathrm{~cm} / \mathrm{min}$, which was slightly slower than the average found with the standard method, though the value still falls in the 'very rapid' USDA-NRCS classification (Table 1F in Appendix F). The analysis of variance for $\mathrm{K}_{\mathrm{sat}}$ measured by the single ring Modified Method at Date 3 is presented in Table 19. No effect due to field was observed, but significant effects due to treatment, enclosure and treatment by enclosure were found. The average $\mathrm{K}_{\mathrm{sat}}$ under single species grazing was faster than that under mixed species grazing (Table 19). The enclosed erosion plots exhibited a significantly faster $\mathrm{K}_{\mathrm{sat}}$ than the open erosion plots (Table 19). A slower saturated hydraulic conductivity in the presence of animals would be the expected and was also found with the single ring standard method. The significant treatment by enclosure interaction indicated that the effect of treatment $\mathrm{K}_{\mathrm{sat}}$ was especially reduced in the erosion plot by enclosure (not shown).

In summary, for the characterization of the erosion plots in Experiment 2, no differences in $\mathrm{K}_{\mathrm{sat}}$ due to the grazing treatments were measured with the Wooding and single ring standard method infiltrometers. However, at Date 3, significant effects of treatment, enclosure, and their interaction were on $\mathrm{K}_{\mathrm{sat}}$ were found with the single ring Modified Method. 
Enclosed erosion plots were considered "control" plots in the comparison of grazed and ungrazed plots. Significant differences in dry aggregate stability and saturated hydraulic conductivity due to erosion plot enclosure were observed, regardless of grazing treatment, at the latest sampling date, Date 3.

\section{Weather analysis}

Runoff, sediment, and weather data were first divided into three time periods. The periods corresponded to the spring and summer (March to October) and the fall and winter (November to February) seasons (Fig. 5b). Period 1 starts in May of 2011 (when erosion plot construction ceased) and ends in October 2011. Period 2 starts in November 2011 and ends in February 2012. Period 3 began in March 2012 and concluded in October 2012. Figure 15 shows the total monthly precipitation for the three periods (May 2011 to October 2012). The figure clearly shows that the 2012 summer was drier than the 2011 summer.

Table 20 shows the cumulative precipitation for each Period, as well as the number of rainy days, and rainy days with "above-average precipitation" within each period, and for the duration of the study. During Period $1,8.6 \%$ of rainy days were "above-average cumulative precipitation" events. Period 2 exhibited the lowest percentage of rainy days that were "above-average" (3.6\%). During Period 3 the largest percentage of "above average" rainy days $(9.4 \%)$ were observed.

There was a relationship between grazing management and the seasonally defined periods. The seasonally defined periods corresponded to the winter and spring/summer 
grazing periods. The highest total monthly rainfall was observed during the stockpiling period, when animals were absent from the paddocks (August through November 2011).

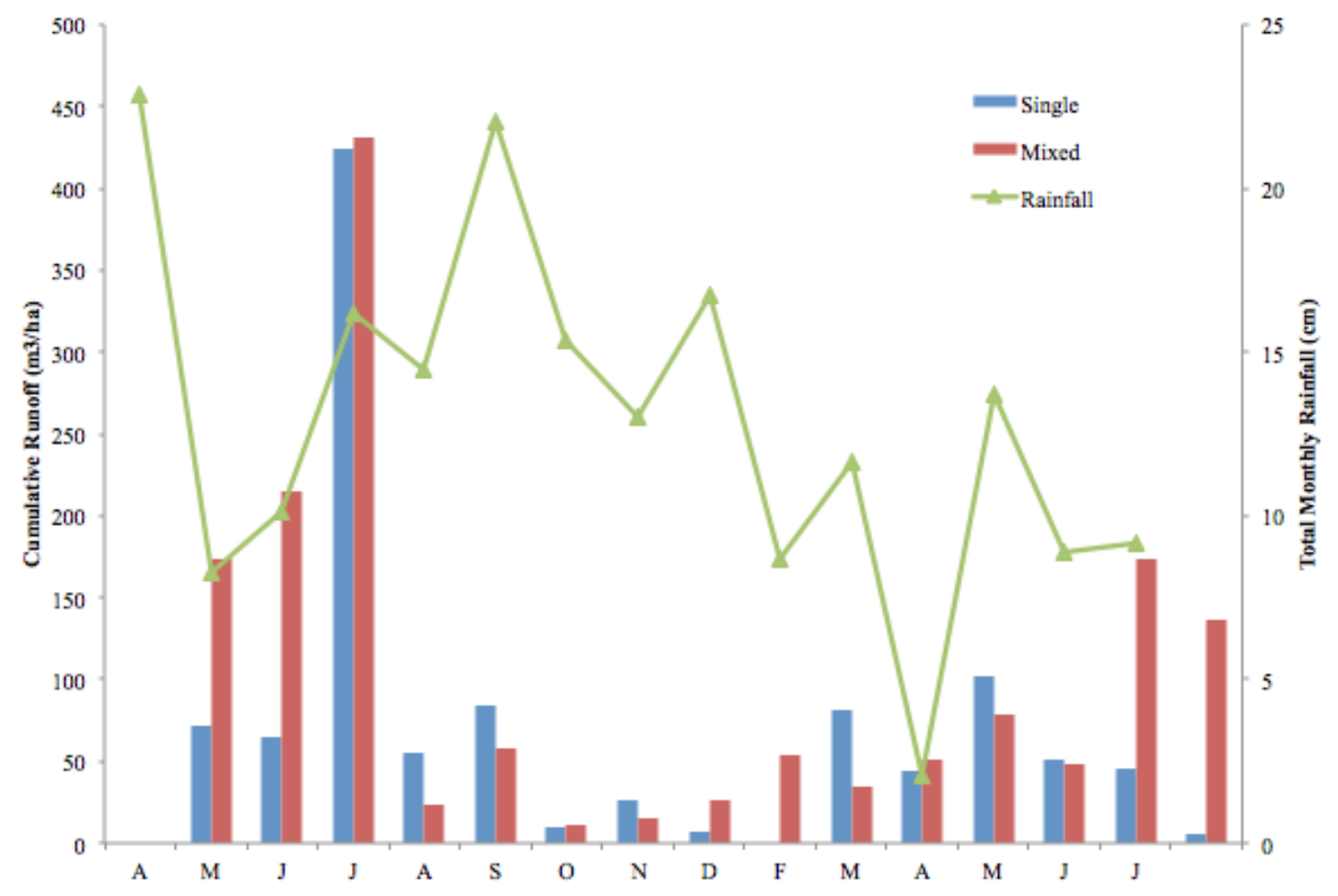

Figure 15. Monthly rainfall and runoff, by treatment, during the study period. 
Table 20. Cumulative precipitation data for the three Periods. Data obtained from the weather station at the WVU Reedsville Farm.

\begin{tabular}{|c|c|c|c|c|c|c|}
\hline & Total days & $\begin{array}{c}\text { Number } \\
\text { of } \\
\text { Rainy } \\
\text { Days }\end{array}$ & $\begin{array}{c}\text { Total } \\
\text { Precipitation } \\
\text { by Period } \\
\text { (cm) }\end{array}$ & $\begin{array}{c}\text { Average } \\
\text { Precipitation } \\
\text { per } \\
\text { Rainy Day } \\
\text { (cm) }\end{array}$ & $\begin{array}{c}\text { Number of rainy } \\
\text { days with } \\
\text { "cumulative } \\
\text { precipitation } \\
\text { above average" }\end{array}$ & $\begin{array}{l}\% \text { rainy days with } \\
\text { "cumulative } \\
\text { precipitation above } \\
\text { the average" }\end{array}$ \\
\hline Period 1 & 171 & 81 & 78.1 & 0.96 & 7 & 8.6 \\
\hline Period 2 & 183 & 55 & 60.6 & 1.10 & 2 & 3.6 \\
\hline Period 3 & 155 & 32 & 31.8 & 0.99 & 3 & 9.4 \\
\hline Total & 509 & 168 & 170.5 & 3.05 & 12 & 21.6 \\
\hline
\end{tabular}


Runoff and sediment measurements

A total of 37 runoff water and sediment collection events were completed between May 2011 and August 2012. Runoff water and sediment were collected after every significant $(>1.3 \mathrm{~cm})$ rain event. Table 21 shows average runoff and sediment production by period, treatment, and enclosure.

\section{Runoff}

The runoff data collected during Period 1 (May to August 2011) exhibited an overall average, across all plots (open and closed; single and mixed), of $14.7 \mathrm{~m}^{3} /$ ha, with a coefficient of variation (CV) of $142 \%$, indicating that runoff was highly variable in the study area (Table 21). The analysis of variance for Period 1 (March to August 2011) runoff is presented in Table 21. No significant effect of treatment, field, enclosure, or treatment by enclosure on average Period 1 runoff was observed. In Period 1, the open erosion plots exhibited a slightly higher runoff volume than the enclosed erosion plots (Table 21).

Runoff collected during Period 2 (November 2011 to February 2012) exhibited an overall average value of $14.4 \mathrm{~m}^{3} /$ ha, with a $\mathrm{CV}$ of $83 \%$, again indicating that runoff was highly variable among the erosion plots (Table 21). The analysis of variance for Period 2 (September 2011 to March 2012) is found in Table 21. No significant effect of treatment, field, enclosure, or treatment by enclosure on average runoff was observed during this period. The mixed species grazing exhibited slightly higher runoff values $\left(15.1 \mathrm{~m}^{3} / \mathrm{ha}\right)$ than did single species grazing $\left(13.6 \mathrm{~m}^{3} / \mathrm{ha}\right)$ (Table 21$)$. Open erosion plots exhibited slightly higher runoff volumes $\left(16.7 \mathrm{~m}^{3} / \mathrm{ha}\right)$ than did the enclosed erosion plots $(10.9$ $\mathrm{m}^{3} / \mathrm{ha}$ ). Although not statistically significant, these results may indicate, regardless of 
grazing management, animal activity in the erosion plots negatively affected soil water infiltration.

Table 21. Mean, standard deviation, and analysis of variance for runoff by period, treatment, field, and enclosure.

\section{Block/Field}

\begin{tabular}{lll} 
Period 1 & Period 2 & Period 3 \\
\hline & $\mathrm{m}^{3} / \mathrm{ha}$ &
\end{tabular}

Field 1

Field 2

Field 3

Treatment

Single

Mixed

Enclosure

Enclosed

Open

Grand Mean

Block/Field

Treatment

Enclosure

Treatment*Enclosure

Block, treatment or enclosure means followed by the same letter, in the same column, are not significantly different $(\mathrm{P} \leq 0.10)$. *Average \pm one standard deviation.

Runoff volume data collected during Period 3 (March to October 2012) exhibited an overall average value of $17.4 \mathrm{~m}^{3} / \mathrm{ha}$, with a $\mathrm{CV}$ of $133 \%$ (Table 21 ). The runoff volume was highly variable. The analysis of variance for Period 3 (Table 21) again found no significant effect of treatment, field, enclosure, or treatment by enclosure on runoff during this period. In Period 3, single species grazing exhibited lower runoff values than did the mixed species grazing, but the difference was not significant (Table 21). The enclosed erosion plots gave slightly higher runoff volumes than the open erosion plots, 
but again the difference was not significant (Table 21). It was observed that runoff volumes collected at the beginning of the experiment were highly variable when compared to volumes collected during the last three months (June to August 2012) of the experiment, during Period 3. Based on visual assessment (runoff volume, color/turbidity of runoff), the highly variable volumes could be attributed to the time of erosion plot establishment. An additional visual assessment of the runoff waters produced during the last three months of the experiment indicated that open plots produced darker colored water than the enclosed plots (Fig. 16).

Figure 17 compares total runoff to total precipitation for each of the three collection periods. Between August and November 2011, the highest total precipitation and nearly the lowest runoff were recorded. During this time interval, the forage in the fields was being stockpiled for the winter, and the hydraulic conductivity and infiltration rates increased due to the production and accumulation of larger amount of root mass and vegetative cover. These factors resulted in low runoff. Results obtained by Naeth et al. (1990) support this study's observations. Those authors observed that the higher forage biomass found in the "ungrazed" treatment increased steady state infiltration in relation to that observed in grazed areas.

\section{Sediment Production}

The sediment collected during Period 1 (May to August 2011) exhibited an overall mean of $2.0 \times 10^{-3} \mathrm{Mg} / \mathrm{ha}$, with a CV of $100 \%$, indicating that sediment production was highly variable across the study area (Table 22). The analysis of variance for Period 1 (May to August 2011) is given in Table 22. There was no significant effect of treatment, field, enclosure, or the treatment by enclosure interaction on sediment production. 


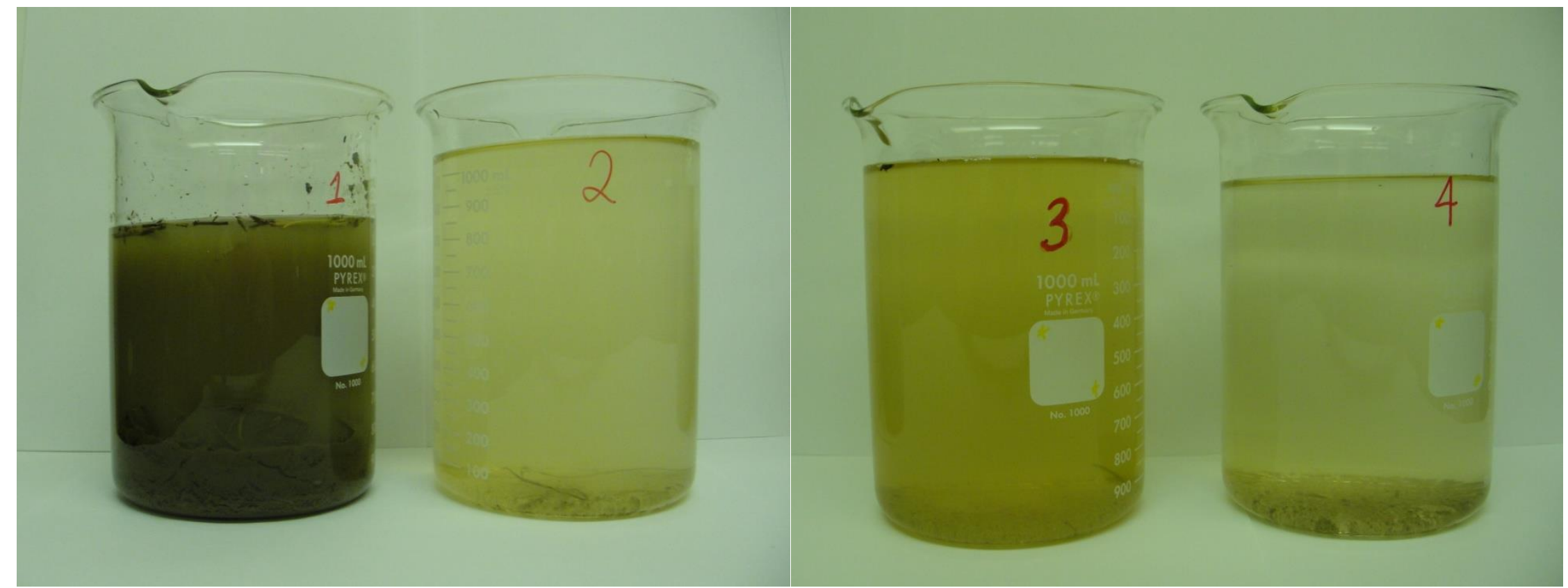

Figure 16. Runoff water visual characteristics: Breaker 1 is from an open erosion plot under single species grazing, Beaker 2 represents is from an enclosed erosion plot under single species grazing; Beaker 3 is from an open erosion plot under mixed species grazing; and Beaker 4 is from an enclosed plot under mixed species grazing. All samples came from Block/Field 1. 


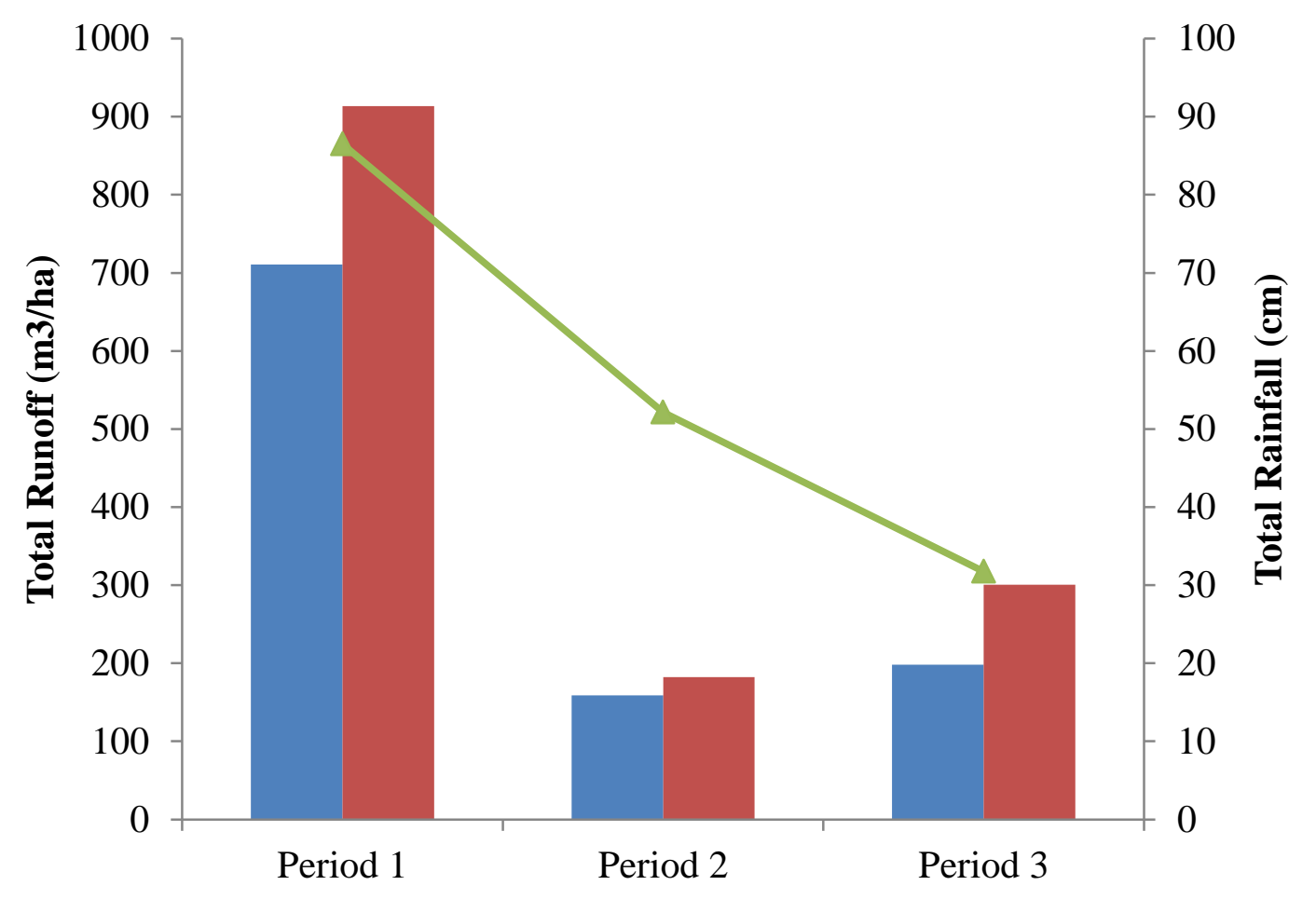

Figure 17. Total rainfall and total runoff by period and treatment recorded during the study.

The single species grazing produced slightly more sediment than the mixed species grazing, and the enclosed erosion plots produced slightly more sediment than the open erosion plots, but these differences were not significant (Table 22).

The sediment collected during Period 2 (November 2011 to February 2012) exhibited an overall average of $1.2 \times 10^{-2} \mathrm{Mg} / \mathrm{ha}$, with a coefficient of variation of $217 \%$, and indicating that sediment production remained extremely variable during the second period (Table 22). The analysis of variance for Period 2 is presented in Table 22. No significant effect of treatment, field, enclosure, or the treatment by enclosure interaction on sediment production during this period was observed. Although not significantly different, single species grazing produced about twice as much sediment as mixed species grazing (Table 22). The open erosion plots again produced 
more sediment than the closed erosion plots, but again the difference was not significantly different (Table 22).

During Period 3 (March to August 2012) sediment production averaged of $3.1 \times 10^{-3} \mathrm{Mg} / \mathrm{ha}$, with a CV of $126 \%$, indicating that sediment production was slightly less variable than observed in Period 2, but still high (Table 22). The analysis of variance for Period 3 found no significant effect of treatment, field, or treatment by enclosure on average sediment production, but a significant effect of erosion plot enclosure was observed (Table 22).

The single species grazing produced slightly less sediment than the mixed species grazing during this period, though the difference was not statistically significant. The enclosed erosion plots produced significantly more sediment than the open erosion plots (Table 22). These results were unexpected, but during the experiment there was increased mice activity in the enclosed plots with time. It is possible that increasing mice activity loosened more soil and increased sediment production. Mice activity was not measured. The sediment production measured in this study was lower than that reported by Cerdan et al. (2010), who reported that non-grazed grasslands eroded at rates as high as $0.4 \mathrm{t} \mathrm{ha}^{-1} \mathrm{yr}^{-1}$ (or $\left.3.6 \times 10^{5} \mathrm{~g} \mathrm{ha}^{-1} \mathrm{yr}^{-1}\right)$.

Sediment production was related to other soil physical properties. At Date 3, dry aggregate stability (MWD) measured at Date 3 was negatively correlated with sediment production during Period 3 (Fig. 18). As dry aggregate stability increased, sediment production decreased. 
Table 22. Mean, standard deviation, and analysis of variance for sediment production, by period, according to treatment, field, and erosion plot enclosure.

\begin{tabular}{|c|c|c|c|}
\hline & Period 1 & Period 2 & Period 3 \\
\hline & \multicolumn{3}{|c|}{$\mathrm{m}^{3} / \mathrm{ha}$} \\
\hline \multicolumn{4}{|l|}{ Block/Field } \\
\hline Field 1 & $2.8 \times 10^{-3} \pm 2.4 \times 10^{-3 \mathrm{a}}$ & $1.2 \times 10^{-2} \pm 2.2 \times 10^{-2 \mathrm{a}}$ & $3.0 \times 10^{-3} \pm 4.6 \times 10^{-3 \mathrm{a}}$ \\
\hline Field 2 & $6.9 \times 10^{-4} \pm 4.0 \times 10^{-4 \mathrm{a}}$ & $2.3 \times 10^{-2} \pm 4.3 \times 10^{-2 \mathrm{a}}$ & $4.0 \times 10^{-3} \pm 4.2 \times 10^{-3 \mathrm{a}}$ \\
\hline Field 3 & $1.6 \times 10^{-3} \pm 1.7 \times 10^{-3 \mathrm{a}}$ & $4.7 \times 10^{-3} \pm 5.3 \times 10^{-3 \mathrm{a}}$ & $2.3 \times 10^{-3} \pm 1.9 \times 10^{-3} \mathrm{a}$ \\
\hline \multicolumn{4}{|l|}{ Treatment } \\
\hline Single & $2.5 \times 10^{-3} \pm 2.5 \times 10^{-3 \mathrm{a}}$ & $1.7 \times 10^{-2} \pm 3.5 \times 10^{-2 \mathrm{a}}$ & $2.8 \times 10^{-3} \pm 3.1 \times 10^{-3 a}$ \\
\hline Mixed & $1.5 \times 10^{-3} \pm 1.4 \times 10^{-3 \mathrm{a}}$ & $6.9 \times 10^{-3} \pm 7.6 \times 10^{-3} \mathrm{a}$ & $3.4 \times 10^{-3} \pm 4.6 \times 10^{-3} \mathrm{a}$ \\
\hline \multicolumn{4}{|l|}{ Enclosure } \\
\hline Enclosed & $2.1 \times 10^{-3} \pm 2.3 \times 10^{-3 \mathrm{a}}$ & $5.1 \times 10^{-3} \pm 4.0 \times 10^{-3 \mathrm{a}}$ & $4.3 \times 10^{-3} \pm 4.7 \times 10^{-3 a}$ \\
\hline Open & $1.8 \times 10-^{3} \pm 1.8 \times 10^{-3 \mathrm{a}}$ & $2.0 \times 10^{-2} \pm 3.7 \times 10^{-2 \mathrm{a}}$ & $2.4 \times 10^{-3} \pm 3.1 \times 10^{-3 b}$ \\
\hline \multirow[t]{2}{*}{ Grand Mean } & $2.0 \times 10^{-3} \pm 2.0 \times 10^{-3}$ & $1.2 \times 10^{-2} \pm 2.6 \times 10^{-2}$ & $3.1 \times 10^{-3} \pm 3.9 \times 10^{-3}$ \\
\hline & \multicolumn{3}{|c|}{$\operatorname{Pr}>F$} \\
\hline Block/Field & 0.25 & 0.27 & 0.20 \\
\hline Treatment & 0.28 & 0.27 & 0.19 \\
\hline Enclosure & 0.66 & 0.15 & $<0.10$ \\
\hline Treatment*Enc & 0.29 & 0.30 & 0.67 \\
\hline
\end{tabular}

Block, treatment or enclosure means followed by the same letter, in the same column, are not significantly different $(\mathrm{P} \leq 0.10)$. *Average \pm one standard deviation. 


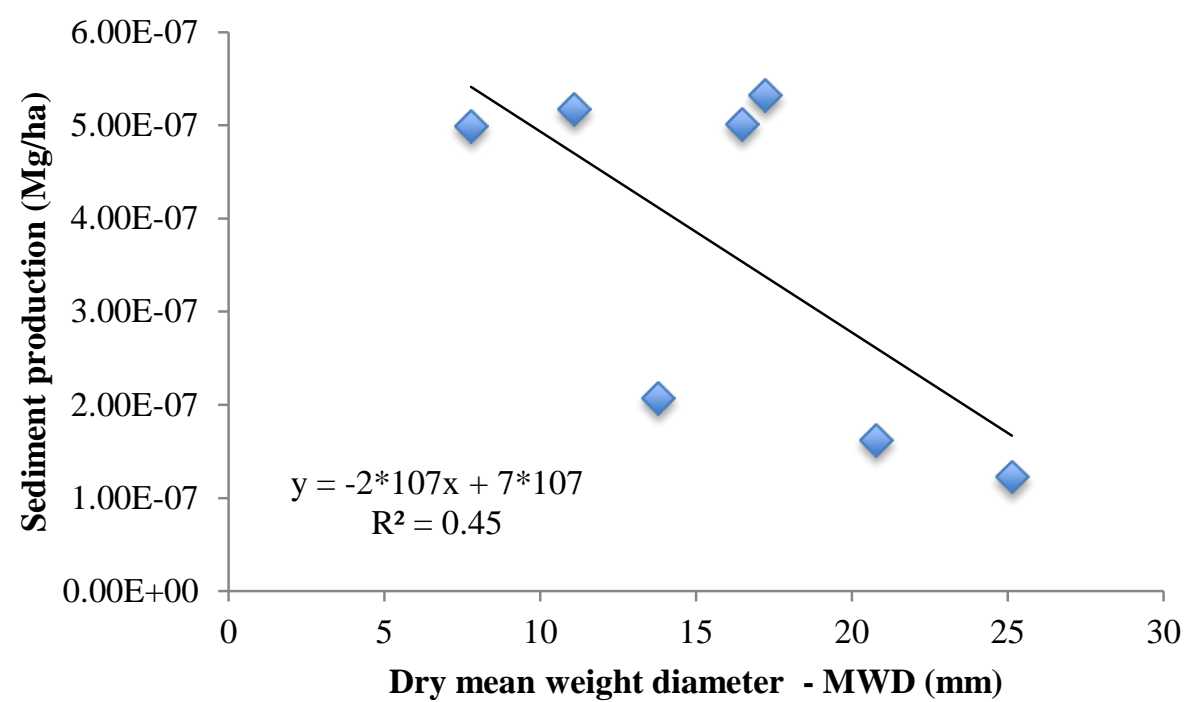

Figure 18. Relationship between surface $(0-5 \mathrm{~cm})$ dry aggregate stability (MWD) at Date 3 and sediment production $(\mathrm{Mg} / \mathrm{ha}$ ) during Period 3. 


\section{CHAPTER 5. CONCLUSIONS}

This study was designed to determine the effect of animal activity on soils and to characterize soil properties affecting water erosion. The experimental design established for the two experiments (grazing and erosion) presented in this document, produced information on the effects of mixed and single species grazing management on grassland soils. The differences between soil characteristics measured for each grazing system were not always statistically significant. However, the results reported in this study produced limited evidence that agreed with the study's main hypothesis: The single species grazing system would generate greater environmental impact - land degradation- than the mixed species grazing system. Overall, soil nutrient contents were well above optimums published by the Penn State Extension Service. This observation may be attributed to historical fertilizer inputs. In general, the single species grazing treatment exhibited higher SOM than the mixed species grazing surface soil $(0-5 \mathrm{~cm})$. Soil organic matter is an important variable when considering soil structure and related variables. For SOM, no statistically significant differences due to the grazing treatments were observed. However, with more sampling, over a longer period of time, it is possible that differences between grazing management treatments would become more evident.

Soil physical properties such as bulk density, penetration resistance, dry and wet aggregate stability were more degraded in the single species treatment than with mixed species grazing. Most of the differences between the grazing treatments for the previously listed properties were not statistically significant, but the results consistently support the study's hypothesis.

Saturated hydraulic conductivity values did not support the study's hypothesis regarding the grazing treatments until Date 3. At that time, the single ring infiltrometer found faster saturated hydraulic conductivity values for the mixed species grazing system.

An effect of date was observed in soil properties such as bulk density, dry aggregate stability, penetration resistance, and saturated hydraulic conductivity (single ring standard method). Observing an effect of date on the above soil properties implies that seasonal weather, forage and animal management activities are very important when interpreting the data. At different dates, animal presence influenced soil properties in differing ways. This study showed improvement in soil physical properties after winter grazing. 
It was hypothesized that the single species grazing system would generate higher environmental impact - land degradation- than the mixed species grazing system. However, though not statistically significant, runoff was larger for mixed species grazing management during Periods 2 and 3, while sediment production was greater for the single species grazing system during Periods 1 and 2. In the erosion experiment, there was a period of time in which plots should be allowed to equilibrate to field conditions after being installed. Early runoff and sediment measurements will show greater variation if this time is not allowed. Towards the end of this study, it was observed that the erosion plots were starting to produce results that supported the study's hypothesis. During Periods 1 and 2 the single species system produced more sediment than the mixed species system, but this difference was not statistically significant. Overall, there is evidence that the mixed species grazing treatment is more sustainable in terms of soil structural properties and soil erosion.

Additional research, over a longer period of time, would be recommended to better assess the impact of grazing animals on grassland ecosystems. There are many studies that address the estimation or measurement of erosion rates for differing land management systems. However, the literature lacks research on the impacts of mixed species grazing on soil erosion rates and associated soil physical, structural and hydrologic properties. The generally great variability in soil properties observed in this study further indicates the importance of site-specific land management research. Based on these observations, the effects of the animals used in mixed and single species grazing systems will be affected by preexisting soil and landscape characteristics. Depending on slope, climate, and individual soil properties, the effect/impact of the grazing on the grassland ecosystem could be accelerated or decelerated. This study increased our knowledge on the initial effects of mixed and single species grazing on soil properties, runoff and soil erosion and sediment production, and can be used to aid landowners desiring more sustainable livestock grazing management alternatives. 
References

Abaye, A.O., V.G. Allen, and J.P. Fontenot. 1994. Influence of grazing cattle and sheep together and separately on animal performance and forage quality. Journal of Animal Science 72: 1013-1022.

Adams, W.A. 2006. The effect of organic matter on the bulk and true densities of some uncultivated podzolic soils. European Journal of Soil Sci. 24: 10-17.

Atkin, T. 2006. Sustainable Grasslands. USDA-National Resources Conservation Service Massachusetts State Office, Amherst, MA.

Bauer, A., and A.L. Black. 1981. Soil carbon, nitrogen, and bulk density comparisons in two cropland tillage systems after 25 years and in virgin grassland. Soil Sci. Soc. Am. J. 45:1166-1170.

Bennie, J., M. Hill, R. Baxter, and B. Huntley. 2006. Influence of slope and aspect on long-term vegetation change in British chalk grasslands. Journal of Ecology 94:355-368.

Betteridge, K., A.D. Mackay, T.G. Shepherd, D.J. Barker, P.J. Budding, B.P. Devantier, and D.A. Costall. 1999. Effect of cattle and sheep treading on surface configuration of a sedimentary hill soil. Australian Journal of Soil Research 37:743-760.

Billings, S.A. 2006. Soil organic matter dynamics and land use change at a grassland/forest ecotone. Soil Biology \& Biochemistry. 38: 2934-2943.

Bilotta, G.S., R.E. Brazier, and P.M. Haygarth. 2007. The Impacts of Grazing Animals on the Quality of Soils, Vegetation, and Surface Waters in Intensively Managed Grasslands. Advances in Agronomy 94:237-280.

Blanco-Canqui, H., R. Lal, L.B. Owens, W.M. Post, and R.C. Izaurralde. 2005. Strength Properties and Organic Carbon of Soils in the North Appalachian Region. Soil Sci. Soc. Of Am. J. 69: 663-673.

Brady, N. and R. Weil. 2002. The Nature and Properties of Soils. Thirteenth Edition. Prentice Hall, Upper Saddle River, NJ.

Carroll, C., L. Merton, and P. Bruger. 2000. Impact of vegetative cover and slope on runoff, erosion, and water quality for field plots on a range of soil and spoil materials on central Queensland coal mines. Australian Journal of Soil Research 38:313-327.

Casanova, M., I. Messing, and A. Joel. 2000. Influence of aspect on slope gradient in hydraulic conductivity measured by tension infiltrometer. Hydrol. Process. 14:155-164.

Cerdan, O., G. Grovers, Y. Le Bissonnais, K. Van Oost, J. Poesen, N. Saby, A. Gobin, A. Vacca, J. Quinton, K. Auerswald, A. Klik, F.J.P.M. Kwaad, D. Raclot, I. Ionita, J. Rejman, S. 
Rousseva, T. Muxart, M.J. Roxo, and T. Dostal. 2010. Rates and spatial variations of soil erosion in Europe: A study based on erosion plot data. Geomorphology 122: 167-177.

Chanasyk, D.S., and M.A. Naeth. 1995. Grazing impacts on bulk density and soil strength in the foothills fescue grasslands of Alberta, Canada. Canadian J. of Soil Sci. 75:551-557.

Cherwin, K. and A. Knapp. 2012. Unexpected patterns of sensitivity to drought in three semiarid grasslands. Oecologia. 169: 845-852.

D’Haene, K., J. Vermang, M. Cornelis, B. Leroy, W. Schiettecatte, S. De Neve, D. Gabriels, G. Hofman. 2008. Reduced tillage effects on physical properties of silt loam soils growing root crops. Soil and Tillage Research. 99:279-290.

Diaz-Zorita, M., J.H. Grove and E. Perfect. 2007. Sieving duration and sieve loading impacts on dry soil fragment size distributions. Soil and Tillage Research 94:15-20.

Dormaar, J.F., S. Smoliak, and W.D. Willms. 1990. Distribution of nitrogen fractions in grazed and ungrazed fescue grassland Ah horizons. Journal of Range Management 43: 6-9.

Drewry, J.J. 2006. Natural recovery of soil physical properties from treading damage on pastoral soils in New Zealand and Australia: A review. Agriculture, Ecosystems, and Environment 114: 159-169.

Elliot, E.Y. 1986. Aggregate structure and carbon, nitrogen, and phosphorus in native and cultivated soils. Soil Sci. Soc. Am. J. 50: 627-633

Elrashidi, M.A. 2010. Testing Methods for Phosphorus and Organic Matter. Available at http://soils.usda.gov/technical/methods/ (accessed 24 Sept. 2010; validated 26 Jan. 2011) NRCS Soils.

Environmental Protection Agency (EPA). 2012. Pasture, Rangeland, and Grazing Operations Best Management Practices (BMPs). Available at http://www.epa.gov/oecaagct/anprgbmp.html\#Using\%20the\%20Clean\%20Water\%20Stat e\%20Revolving\%20Fund (accessed 2 Nov. 2012; validated 29 Nov. 2012)

Epstein, E., W.J. Grand, and R.A. Struchtemeyer. 1966. Effects of stones on runoff, erosion, and soil moisture. Soil Sci. Soc. Amer. Proc. 30.

Evans, R. 1997. Soil erosion in the UK initiated by grazing animals. Applied Geography 17: 127-141.

Fangmeier, D.D., W.J. Elliot, S.R. Workman, R.L. Huffman, and G.O. Schwab. 2006. Soil and water conservation engineering. Fifth Edition. Thomson Delmar Learning. Clifton Park, NY. 
Food and Agriculture Organization of the United Nations (FAO). 2012. How to manage grasslands and rangelands? Available at http://www.fao.org/agriculture/crops/corethemes/theme/spi/scpi-home/managing-ecosystems/management-of-grasslands-andrangelands/grasslands_how/en/ (Accessed 2 Nov. 2012; verified 28 Nov. 2012.)

Franzluebbers, A.J. 2002. Soil organic matter stratification ratio as an indicator of soil quality. Soil \& Tillage Research 66: 95-106.

Franzluebbers, A.J. 2006. Integrated Crop-Livestock Systems in the Southeastern USA. Agron. J. 99:361-372.

Gee, G.W. and D. Or. 2002. Particle-size analysis. Methods of Soil Analysis. Part 4. Physical Methods. Soil Science Society of America, Inc. Madison, WI. Soil Science Society of America pp. 255-293.

Gifford, G.F., Faust, R.H., and G.B. Coltharp. 1977. Measuring soil compaction on rangeland. J. Range Manage. 30: 457-460.

González-Barrios, J.L., E. Chávez Ramírez, L.Descroix, I. Sánchez Cohen, G. González Cervantes, and A. López Santos. 2010. Soil porosity affected by cattle trampling in highland agriculture of Northern Mexico. Proceedings: 19th World Congress of Soil Science, Soil Solutions for a Changing World. 150-153.

Gonzalez-Pelayo, O., Andreu, V., Campo, J., Gimeno-Garcia, E., J.L. Rubio. 2006. Hydrological properties of a Mediterranean soil burned with different fire intensities. Catena 68:186193.

Graecen, E.L. 1986. Root response to soil mechanical properties. Trans. 13th Congress. Inter. Soc. Soil Sci. Hamburg 5: 20-47.

Greenwood, K.L. and B.M. McKenzie. 2001. Grazing effects on soil physical properties and the consequences for pastures: a review. Australian Journal of Experimental Agriculture. 41: 1231-1250.

The Heinz Center. 2002. The State of the Nation's Ecosystems: The Indicators. Cambridge University Press. New York, NY 10011. pp. 157-173.

Hallett, P.D., T. Baumgartl, I.M. Young, 2001. Subcritical water repellency of aggregates from a range of soil management practices. Soil Science Society of America Journal 65: 184190.

Haygarth, P.M., and S.C. Jarvis. 1996. Soil derived phosphorus in surface runoff from grazed grassland lysimeters. Water Research 31: 140-148. 
Hernanz, J.L., V. Sanchex-Giron, L. Navarrete. 2009. Soil carbon sequestration and stratification in a cereal/leguminous crop rotation with three tillage systems in semiarid conditions. Agriculture, Ecosystems and Environment 133: 114-122.

Hofmann, L. and R.E. Ries. 1991. Relationship of soil and plant characteristics to erosion and runoff on pasture and range. Journal of Soil and Water Conservation 46: 143-147

Hribar, C. 2010. Understanding Concentrated Animal Feeding Operations and Their Impact on Communities. National Association of Local Boards of Health. Bowling Green, Ohio.

Ingram, L.J., P.D. Stahl, G.E. Schuman, J.S. Buyer, G.F. Vance, G.K. Ganjegunte, J.M. Welker, and J.D. Derner. 2008. Grazing impacts on soil carbon and microbial communities in a mixed-grass ecosystem. Soil Science Society of America Journal 72: 939-948.

Kemper, W.D. and R.C. Rosenau. 1986. Chapter 17: Aggregate Stability and Size Distribution. Methods of Soil Analysis, Part 1. Physical and Mineralogical Methods. American Society of Agronomy, Inc. Madison, Wisconsin USA. pp. 425-442.

Kodesova, R., V. Jirku, V. Kodes, M. Mulhanselova, A. Nikodem, A. Zigova. 2011. Soil structure and soil hydraulic properties of Haplic Luvisol used as arable land and grassland. Soil and Tillage Research. 111(2):154-161.

Lado, M., M. Ben-Hur, and S. Assouline. 2005. Effects of effluent irrigation on seal formation, infiltration, and soil loss during rainfall. Soil Science Society of America Journal 69:1432-1439.

Lapen, D.R., E.G. Gregoric, W.E. Curnoe, G.C. Topp, M.E. Edwards. 2004. Combination cone penetration resistance/water content instrumentation to evaluate cone penetration - water content relationship in tillage research. Soil \& Tillage Research 79: 51-62.

Lou, L., H. Lin, J. Schmidt. 2010. Quantitative relationships between soil macropore characteristics and preferential flow and transport. Soil Science Society of America Journal 74: 1929-1937.

Magdoff, F., and R.R. Weil. 2004. Soil Organic Matter in Sustainable Agriculture. CRC Press. 398 pp.

McCauley, A. 2005. Soil and Water Management Module 3: Managing for Soil Erosion. Montana State University.

McCool, D.K., C.D. Pannkuk, A.C. Kennedy, and P.S. Fletcher. 2008. Effects of burn/low-till on erosion and soil quality. Soil and Tillage Research 101:2-9.

McDowell, R.W., and R. J. Wilcock. 2007. Sources of sediment and phosphorus in stream flow of a highly productive dairy farmed catchment. J. Environ. Qual. 36:540-548. 
Melich, A. 1984. Melich No. 3 Soil test extractant: A modification of Melich No. 2 extractant. Commun. Soil Sci. Plant Anal. 15: 1409-1416.

Mississippi State University Extension Service. 2010. Phosphorus Fertility. Available at http://msucares.com/crops/soils/phosphorus.html (accessed 12 Nov. 2010; verified 26 Jan. 2011) Mississippi State University Extension Service and Experiment Station.

Naeth, M.A., R.L. Rothwell, D.S. Chanasyk, and A.W. Bailey. 1990. Grazing impacts on infiltration in mixed prairie and fescue grassland ecosystems of Alberta. Can. J. Soil Sci. 70: 593-605

Nearing, M.A., M.H. Nichols, and A. Kimoto. 2005. Spatial patterns of soil erosion and deposition in two small, semiarid watersheds. Journal of Geophysical Research 110: 11

Nolan, T., J. Connolly, and M. Wachendorf. 2001. Mixed grazing and climatic determinants of white clover (Trifolium repens L.) contents in a permanent pasture. Annals of Botany. 88:713-724.

Olff H., and M. Ritchie. 1998. Effects of herbivores on grassland plant diversity. TREE 13: 261265.

Peiper, R.D. and R.K. Heitschmidt. 1988. Is short-duration grazing the answer? Journal of Soil and Water Conservation 43: 133-137.

Penn State Extension Service. 2012. Soil Test Recommendations for Agronomic Crops: Established Mixed Grasses. Available at: http://www.aasl.psu.edu/Agro\%20HdBk.html (Accessed 27 Nov. 2012; verified 28 Nov 2012). Penn State Agricultural Analytical Services Lab.

Pietola, L., R. Horn, and M. Yli-Halla. 2004. Effects of trampling by cattle on hydraulic and mechanical properties of soil. Soil and Tillage Research 82: 99-108.

Pearson, C.J. and R.L. Ison. 2004. Agronomy of Grassland Systems. Cambridge University Press. New York, NY 10011.

Presant, E. W., and C. J. Acton. 1984. The Soils of the Regional Municipality of HaldimandNorfolk. Report No. 57, Ontario Institute of Pedology. Cited by: Classifying Prime and Marginal Agricultural Soils and Landscapes: Guidelines for Application of the Canada Land Inventory in Ontario. Ministry of Agriculture, Food and Rural Affairs. Ontario, Canada. Available at http://www.omafra.gov.on.ca/english/landuse/classify.htm\#references (Accessed 29 Nov. 2012; verified 30 Nov. 2012.

Prescott, C.E., G.F. Weetman, L.E. DeMontigny, C.M. Preston, R.J. Keenan. 1995. Carbon chemistry and nutrient supply in cedar-hemlock and hemlock-amabilis fir forest floors. 
In: McFee,W.W., Kelley, J.M. (Eds.), Carbon Forms and Functions in Forest Soils. Soil Sci. Soc. Am., Madison, WI. pp. 377-396.

Reszkowska, A., J. Krummelbien, L. Gan, S. Peth, and R. Horn. 2010. Influence of grazing on soil water and gas fluxes of two Inner Mongolian steppe ecosystems. Soil and Tillage Research 111:190-189

Riaz, M., I. Mian, M. Cresser. 2010. Litter effects on N dynamics and potential leaching in acid grassland soils. $19^{\text {th }}$ World Congress of Soil Science, Soil Solutions for a changing world. 1-6 August 2010, Brisbane Australia.

Rodda, J.C. 1967. The Rainfall Measurement Problem. International Association of Hydrological Sciences pp. 215-231.

SAS Institute Inc. 2009. SAS 9.2 Procedures Guide. Cary, NC.

Sharpley, A.N. 1995. Depth of surface soil-runoff interaction as affected by rainfall, soil slope, and management. Soil Science Society of America Journal. 49:1010-1015.

Six, J., R.T. Conant, E. A. Paul, and K. Paustian. 2002a. Stabilization mechanisms of soil organic matter: Implications for C-saturation of soils. Plant and Soil 241: 155-176.

Six, J., C. Feller, K. Denef, S. M. Ogle, J. Moraes, A. Albrecht. 2002b. Soil organic matter, biota and aggregation in temperate and tropical soils - Effects of no-tillage. Agronomie $22: 755-775$.

Smith, J.L. and J.W. Doran. 1996. Measurement and use of $\mathrm{pH}$ and electrical conductivity for soil quality analysis. In J.W. Doran and A. J. Jones (eds.) Methods for Assessing Soil Quality. SSSA Spec. Publ. \# 49. Soil Science Society of America, Madison, WI. p.169185.

Soil Science Society of America. 2012. Glossary of soil science terms. Available at https://www.soils.org/publications/soils-glossary/\#. Accessed 26 Nov. 2012; verified 30 Nov. 2012.

Teague, W.R., S.L. Dowhower, S.A. Baker, N. Haile, P.B. DeLaune, and D.M. Conover. 2011. Grazing management impacts on vegetation, soil biota, and soil chemical, physical and hydrological properties in tall grass prairie. Agriculture, Ecosystems, and Environment 141: 310-322.

Tiessen, K.H.D., S. Li, D.A. Lobb, G.R. Mehuys, H.W. Rees, and T.L. Chow. 2009. Using repeated measurements of ${ }^{137} \mathrm{Cs}$ and modelling to identify spatial patterns of tillage and water erosion within potato production in Atlantic Canada. Geoderma 153:104-118.

Tisdall, J.M., and J.M. Oades. 1982. Organic matter and water-stable aggregates in soils. European Journal of Soil Sci. 33:141-163. 
Thurow, T., W. Blackburn, and C. Taylor Jr. 1988. Infiltration and interrill erosion responses to selected livestock grazing strategies, Edwards Plateau, Texas. Society for Range Management 41:296-302.

Troeh, F., J.A. Hobbs, and R.L. Donahue. 2004. Soil and Water Conservation for Productivity and Environmental Protection. Prentice Hall, Upper Saddle River, New Jersey.

USDA-National Resources Conservation Service. 2013. Saturated Hydraulic Conductivity in Relation to Soil Texture. Available at http://www.mo10.nrcs.usda.gov/references/guides/properties/sathydcond.html (accessed 29 March 2013; verified 30 March 2013).

USDA-National Resources Conservation Service. 2011. Custom Soil Resource Report for Preston County, West Virginia. Available at http://websoilsurvey.nrcs.usda.gov/app/homepage.htm (accessed 15 Oct. 2010; verified 26 Jan. 2011)

USDA-NRCS-ARS. 2001. Soil Quality Test Kit and Interpretive Guide. Accessible on the Internet at http://soils.usda.gov/sqi/assessment/test_kit.html (verified 11/29/2012)

Vaz, C.M.P., J.M. Manieri, I.C. Maria, M. Tuller. 2011. Modeling and correction of soil penetration resistance for varying soil water content. Geoderma 166: 92-101.

Wedin, W.F. and S.L. Fales. 2009. Grassland: Quietness and strength for a New American Agriculture. American Society of Agronomy, Crop Science Society of America, Soil Science Society of America, Madison, Wisconsin. Chapter 4 pp. 57-74

Willard, A. 2010. Hydrologic Soil Grouping Determination for Appalachian Minesoils. Master of Science Thesis. West Virginia University, Morgantown, WV.

Wilson, M.J. 1999. The orgin and formation of clay minerals in soils: past, present and future perspectives. Clay Minerals 34:7-25.

Wischmeier, W.H., C.B. Johnson, B.V. Cross. 1971. A soil erodibility nomograph for farm-land and construction sites, J. Soil Water Cons. 26: 189-193.

Wooding, R.A. 1968. Steady infiltration from a shallow circular pond. Water Resour. Res. 4:1259-1273.

Yoder, R.E. 1936. A direct method of aggregate analysis and a study of the physical nature of erosion losses. J. Am. Soc. Agron. 28: 337-351.

Zhou, Z.C., Z.T. Gan, Z.P. Shangguan, and Z.B. Dong. 2010. Effects of grazing on soil physical properties and soil erodibility in semiarid grassland of the Northern Loess Plateau (China). Catena 82:87-91. 


\section{APPENDIX A \\ Experiment 1: Soil Particle Analysis}

Table A1. Clay content $(0-5 \mathrm{~cm})$ LSD mean comparison for block/field.

Block/Field

\begin{tabular}{ll} 
& $\mathrm{g} / \mathrm{kg}$ \\
\cline { 2 - 3 } 1 & $2.23^{\mathrm{c}}$ \\
2 & $2.36^{\mathrm{b}}$ \\
3 & $2.71^{\mathrm{a}}$
\end{tabular}

Same letters in the same columns indicate no statistically significant differences at $\mathrm{P}<0.10$.

Table A2. Sand content $(0-5 \mathrm{~cm})$ LSD mean comparison for block/field.

\begin{tabular}{cc} 
Block/Field & Overall sand content $(0-5 \mathrm{~cm})$ mean. \\
& $\mathrm{g} / \mathrm{kg}$ \\
\cline { 2 - 2 } 1 & $2.46^{\mathrm{a}}$ \\
2 & $2.66^{\mathrm{a}}$ \\
3 & $2.05^{\mathrm{b}}$
\end{tabular}

Same letters in the same columns indicate no statistically significant differences at $\mathrm{P}<0.10$.

Table A3. Silt content $(0-5 \mathrm{~cm})$ LSD mean comparison for block/field.

Block/Field

2

3
Overall silt content $(0-5 \mathrm{~cm})$ mean.

$\mathrm{g} / \mathrm{kg}$

$5.32^{\mathrm{a}}$

$4.98^{\mathrm{b}}$

$5.24^{\mathrm{a}}$

Same letters in the same columns indicate no statistically significant differences at $\mathrm{P}<0.10$. 


\section{APPENDIX B}

\section{Experiment 1: Soil Chemical Analysis}

Table 1B. Soil Test K (0-5 cm) LSD mean comparison for block/field.

Block/Field

1

2

3
Overall STK mean

$\mathrm{mg} / \mathrm{kg}$
$276.8^{\mathrm{b}}$
$302.4^{\mathrm{b}}$
$392.4^{\mathrm{a}}$

Same letters in the same columns indicate no statistically significant differences at $\mathrm{P}<0.10$.

Table 2B. Soil Test Ca $(0-5 \mathrm{~cm})$ LSD mean comparison for block/field.

Block/Field

1

2

3
Overall STCa mean $\mathrm{mg} / \mathrm{kg}$ $2082^{\mathrm{b}}$ $2098^{\mathrm{b}}$

$2453^{\mathrm{a}}$

Same letters in the same columns indicate no statistically significant differences at $\mathrm{P}<0.10$.

Table 3B. Soil Test Mg $(0-5 \mathrm{~cm})$ LSD mean comparison for block/field.

Block/Field

1

2

3
Overall STMg mean

$\mathrm{mg} / \mathrm{kg}$
$106.2^{\mathrm{b}}$
$112.1^{\mathrm{b}}$
$138.1^{\mathrm{a}}$

Same letters in the same columns indicate no statistically significant differences at $\mathrm{P}<0.10$.

Table 4B. Soil Test Zn $(0-5 \mathrm{~cm})$ LSD mean comparison for block/field.

$\begin{array}{cr}\text { Block/Field } & \begin{array}{r}\text { Overall STZ } \\ \mathrm{mg} / \mathrm{kg}\end{array} \\ 1 & 3.62^{\mathrm{b}} \\ 2 & 4.81^{\mathrm{a}} \\ 3 & 5.09^{\mathrm{a}}\end{array}$

Same letters in the same columns indicate no statistically significant differences at $\mathrm{P}<0.10$.

Table 5B. Total N (0-5 cm) LSD mean comparison for block/field. 
Block/Field

Overall total $\mathrm{N}$ mean

\begin{tabular}{lc} 
& $\mathrm{mg} / \mathrm{kg}$ \\
\cline { 2 - 3 } 3 & $0.46^{\mathrm{b}}$ \\
3 & $0.47^{\mathrm{b}}$ \\
& $0.58^{\mathrm{a}}$
\end{tabular}

Same letters in the same columns indicate no statistically significant differences at $\mathrm{P}<0.10$.

Table 6B. Soil organic matter $(\mathrm{OM})(0-5 \mathrm{~cm})$ LSD mean comparison for block/field.

Block/Field

Overall SOM mean

\begin{tabular}{cc} 
& $\mathrm{g} / \mathrm{kg}$ \\
\cline { 2 - 3 } 1 & $80.67^{\mathrm{b}}$ \\
3 & $85.10^{\mathrm{b}}$ \\
$106.18^{\mathrm{a}}$
\end{tabular}

Same letters in the same columns indicate no statistically significant differences at $\mathrm{P}<0.10$. 


\section{APPENDIX C \\ Experiment 1: Soil Structural Properties}

Table 1C. Bulk Density (BD) LSD mean comparison for block/field (Date 1).

Block/Field

Difference between BD means

$\mathrm{g} / \mathrm{cm} 3$

$\begin{array}{ll}1 & 1.08^{\mathrm{a}} \\ 2 & 1.02^{\mathrm{b}} \\ 3 & 0.98^{\mathrm{b}}\end{array}$

Same letters in the same columns indicate no statistically significant differences at $\mathrm{P}<0.10$.

Table 2C. Bulk Density (BD) LSD mean comparison for block/field (Date 2).

Block/Field

Difference between BD means

\begin{tabular}{lc} 
& $\mathrm{g} / \mathrm{cm} 3$ \\
\cline { 2 - 3 } 1 & $1.00^{\mathrm{a}}$ \\
2 & $1.01^{\mathrm{a}}$ \\
3 & $0.92^{\mathrm{b}}$
\end{tabular}

Same letters in the same columns indicate no statistically significant differences at $\mathrm{P}<0.10$.

Table 3C. Bulk Density (BD) LSD mean comparison for block/field (Date 3).

Block/Field

2

3
Difference between BD means

$\mathrm{g} / \mathrm{cm} 3$
$1.09^{\mathrm{a}}$
$1.10^{\mathrm{a}}$
$1.00^{\mathrm{b}}$

Same letters in the same columns indicate no statistically significant differences at $\mathrm{P}<0.10$.

Table 4C. Analysis of variance table for bulk density.

\begin{tabular}{lccccc}
\hline \hline Source & df & Sum of Squares & Mean Square & F Value & $\operatorname{Pr}>\mathrm{F}$ \\
\hline Treatment & 1 & $2.23 \times 10^{-3}$ & $2.23 \times 10^{-3}$ & 0.33 & 0.57 \\
Field & 2 & 0.52 & 0.26 & 38.74 & $<.0001^{* *}$ \\
Date & 2 & 0.46 & 0.23 & 33.8 & $<.0001 * *$ \\
Treatment*Date & 2 & $1.35 \times 10^{-2}$ & $6.73 \times 10^{-3}$ & 1 & 0.37 \\
$* * \mathrm{P}<0.01$. & & & & &
\end{tabular}


Table 5C. Bulk density LSD means comparison for date.

Date

1 (August 2011)

2 (April 2012)

3 (August 2012)
Bulk density means

$1.03^{\mathrm{b}}$

$0.98^{\mathrm{c}}$

$1.06^{\mathrm{a}}$

Same letters in the same columns indicate no statistically significant differences at $\mathrm{P}<0.10$.

Table 6C. Porosity LSD means comparison for block/field (Date 1).

Block/Field

2

3
Porosity means

$$
\begin{aligned}
& 0.59^{\mathrm{b}} \\
& 0.62^{\mathrm{a}} \\
& 0.63^{\mathrm{a}}
\end{aligned}
$$

Same letters in the same columns indicate no statistically significant differences at $\mathrm{P}<0.10$.

Table 7C. Porosity LSD means comparison for block/field (Date 2).

Block/Field

1

2

3

Porosity means
$0.62^{\mathrm{b}}$
$0.62^{\mathrm{b}}$
$0.66^{\mathrm{a}}$

Same letters in the same columns indicate no statistically significant differences at $\mathrm{P}<0.10$.

Table8C. Porosity LSD means comparison for block/field (Date 3).

Block/Field

1

2

3
Porosity means

$0.59^{b}$
$0.59^{b}$
$0.62^{a}$

$0.59^{\mathrm{b}}$

$0.62^{\mathrm{a}}$

Same letters in the same columns indicate no statistically significant differences at $\mathrm{P}<0.10$.

Table 9C. Analysis of variance table for porosity.

\begin{tabular}{lccccc}
\hline \hline Source & df & Sum of Squares & Mean Square & F Value & Pr $>$ F \\
\hline Treatment & 1 & $5.69 \times 10^{-4}$ & $5.69 \times 10^{-4}$ & 0.58 & 0.45 \\
Field & 2 & $7.71 \times 10^{-2}$ & $3.85 \times 10^{-2}$ & 39.23 & $<.0001^{* *}$ \\
Date & 2 & $6.66 \times 10^{-2}$ & $3.33 \times 10^{-2}$ & 33.92 & $<.0001^{* *}$ \\
Treatment*Date & 2 & $1.89 \times 10^{-3}$ & $9.45 \times 10^{-4}$ & 0.96 & 0.38 \\
$* * \mathrm{P}<0.01$. & & & & &
\end{tabular}

Table 10C. Porosity LSD means comparison for date.

Date

1 (August 2011)

2 (April 2012)
Porosity means

$0.61^{\mathrm{b}}$

$0.63^{\mathrm{a}}$ 
3 (August 2012)

$0.60^{\mathrm{c}}$

Same letters in the same columns indicate no statistically significant differences at $\mathrm{P}<0.10$.

Table 11C. Penetration resistance (0-4 cm) LSD mean comparison for block/field (Date 1).

Block/Field

Penetration resistance $(0-4 \mathrm{~cm})$ means

1

2

3

$\mathrm{kPa}$
$528^{\mathrm{b}}$
$437^{\mathrm{c}}$
$645^{\mathrm{a}}$

Same letters in the same columns indicate no statistically significant differences at $\mathrm{P}<0.10$.

Table 12C. Penetration resistance (4-10 cm) LSD mean comparison for block/field (Date 1).

Block/Field

\begin{tabular}{lc} 
& $\mathrm{kPa}$ \\
\cline { 2 - 3 } 3 & $1128^{\mathrm{b}}$ \\
3 & $1123^{\mathrm{b}}$ \\
1 & $1406^{\mathrm{a}}$
\end{tabular}

Same letters in the same columns indicate no statistically significant differences at $\mathrm{P}<0.10$.

Table 13C. Penetration resistance (10-16 cm) LSD mean comparison for block/field (Date 1).

Block/Field

\begin{tabular}{lr} 
& $\mathrm{kPa}$ \\
\cline { 2 - 3 } 3 & $1219^{\mathrm{b}}$ \\
3 & $1363^{\mathrm{b}}$ \\
$1640^{\mathrm{a}}$
\end{tabular}

Same letters in the same columns indicate no statistically significant differences at $\mathrm{P}<0.10$.

Table 14C. Penetration resistance $(16-20 \mathrm{~cm})$ LSD mean comparison for block/field (Date 1).

Block/Field

\begin{tabular}{lr} 
& $\mathrm{kPa}$ \\
\cline { 2 - 3 } 3 & $1369^{\mathrm{b}}$ \\
3 & $1508^{\mathrm{b}}$ \\
1 & $1718^{\mathrm{a}}$
\end{tabular}

Same letters in the same columns indicate no statistically significant differences at $\mathrm{P}<0.10$.

Table 15C. Penetration resistance (0-4 cm) LSD mean comparison for block/field (Date 2).

Block/Field Penetration resistance $(0-4 \mathrm{~cm})$ means 


\begin{tabular}{ll} 
& $\mathrm{kPa}$ \\
\cline { 2 - 3 } 1 & $651^{\mathrm{b}}$ \\
2 & $758^{\mathrm{a}}$ \\
3 & $549^{\mathrm{c}}$
\end{tabular}

Same letters in the same columns indicate no statistically significant differences at $\mathrm{P}<0.10$.

Table 16C. Penetration resistance (4-10 cm) LSD mean comparison for block/field (Date 2).

Block/Field

$\begin{array}{lc} & \mathrm{kPa} \\ 1 & 1240^{\mathrm{b}} \\ 2 & 1401^{\mathrm{a}} \\ 3 & 1267^{\mathrm{ab}}\end{array}$

Same letters in the same columns indicate no statistically significant differences at $\mathrm{P}<0.10$.

Table 17C. Penetration resistance (4-10 cm) LSD mean comparison for block/field (Date 3).

Block/Field

$\begin{array}{ll} & \mathrm{kPa} \\ 1 & 1693^{\mathrm{c}} \\ 2 & 2088^{\mathrm{b}} \\ 3 & 2285^{\mathrm{a}}\end{array}$

Same letters in the same columns indicate no statistically significant differences at $\mathrm{P}<0.10$.

Table 18C. Penetration resistance (10-16 cm) LSD mean comparison for block/field (Date 3).

Block/Field

1

2

3
Penetration resistance $(10-16 \mathrm{~cm})$ means

$\mathrm{kPa}$
$2085^{\mathrm{b}}$
$2786^{\mathrm{a}}$
$2733^{\mathrm{a}}$

Same letters in the same columns indicate no statistically significant differences at $\mathrm{P}<0.10$.

Table 19C. Penetration resistance (16-20 cm) LSD mean comparison for block/field (Date 3).

Block/Field

Penetration resistance $(16-20 \mathrm{~cm})$ means

\begin{tabular}{ll} 
& $\mathrm{kPa}$ \\
2 & $2425^{\mathrm{b}}$ \\
3 & $3164^{\mathrm{a}}$ \\
\cline { 2 - 3 } & $3159^{\mathrm{a}}$
\end{tabular}

Same letters in the same columns indicate no statistically significant differences at $\mathrm{P}<0.10$.

Table 20C. Analysis of variance table for penetration resistance $(0-4 \mathrm{~cm})$. 


\begin{tabular}{lccccc} 
Source & df & Sum of Squares & Mean Square & F Value & Pr > F \\
\hline Treatment & 1 & 23575.51 & 23575.51 & 0.49 & 0.48 \\
Field & 2 & 102037.57 & 51018.78 & 1.06 & 0.35 \\
Date & 2 & 3988617.58 & 1994308.79 & 41.42 & $<.0001 * *$ \\
Treatment*Date & 2 & 9291.44 & 4645.72 & 0.1 & 0.91 \\
$* *$ P $<0.10$. & & & & &
\end{tabular}

Table 21C. Penetration resistance $(0-4 \mathrm{~cm})$ LSD means comparison for date.

\begin{tabular}{cc}
\hline \hline Date & Penetration resistance means \\
\cline { 2 - 3 } 1 (August 2011) & $\mathrm{kPa}$ \\
2 (April 2012) & $523^{\mathrm{c}}$ \\
3 (August 2012) & $661^{\mathrm{b}}$ \\
$851^{\mathrm{a}}$ \\
Same letters in the same columns indicate no statistically significant differences at $\mathrm{P}<0.10$.
\end{tabular}

Table 22C. Analysis of variance table for penetration resistance $(4-10 \mathrm{~cm})$.

\begin{tabular}{lccccc}
\hline \hline Source & df & Sum of Squares & Mean Square & F Value & Pr $>$ F \\
\hline Treatment & 1 & 73362.02 & 73362.02 & 0.72 & 0.40 \\
Field & 2 & 3176113.86 & 1588056.93 & 15.54 & $<.0001 * *$ \\
Date & 2 & 29176234.86 & 14588117.43 & 142.79 & $<.0001 * *$ \\
Treatment*Date & 2 & 244264.07 & 122132.04 & 1.2 & 0.30 \\
$* *$ P $<0.10$. & & & & &
\end{tabular}

Table 23C. Penetration resistance $(4-10 \mathrm{~cm})$ LSD means comparison for date.

\begin{tabular}{cc}
\hline \hline Date & Difference between penetration resistance means \\
\cline { 2 - 2 } 1 (August 2011) & $\mathrm{kPa}$ \\
2 (April 2012) & $1206^{\mathrm{c}}$ \\
3 (August 2012) & $1309^{\mathrm{b}}$ \\
$2022^{\mathrm{a}}$
\end{tabular}

Same letters in the same columns indicate no statistically significant differences at $\mathrm{P}<0.10$.

Table 24C. Analysis of variance table for penetration resistance $(10-16 \mathrm{~cm})$.

\begin{tabular}{lccccc}
\hline \hline Source & df & Sum of Squares & Mean Square & F Value & Pr $>$ F \\
\hline Treatment & 1 & 853.09 & 853.09 & 0.01 & 0.94 \\
Field & 2 & 6319096.14 & 3159548.07 & 23.97 & $<.0001 * *$ \\
Date & 2 & 58636025.25 & 29318012.63 & 222.42 & $<.0001 * *$ \\
Treatment*Date & 2 & 680770.22 & 340385.11 & 2.58 & $0.07 * *$ \\
$* *$ P $<0.10$. & & & & &
\end{tabular}


Table 25C. Penetration resistance $(10-16 \mathrm{~cm})$ LSD means comparison for date.

Date

Penetration resistance $(10-16 \mathrm{~cm})$ means

1 (August 2011)

Penetration resistance $(10-16 \mathrm{~cm})$ means
$\mathrm{kPa}$
$1396^{\mathrm{c}}$
$1529^{\mathrm{b}}$
$2545^{\mathrm{a}}$

2 (April 2012)

$2545^{\mathrm{a}}$

3 (August 2012)

Same letters in the same columns indicate no statistically significant differences at $\mathrm{P}<0.10$.

Table 26C. Analysis of variance table for penetration resistance $(16-20 \mathrm{~cm})$.

\begin{tabular}{lccccc}
\hline \hline Source & df & Sum of Squares & Mean Square & F Value & Pr $>\mathrm{F}$ \\
\hline Treatment & 1 & 184.83 & 184.83 & 0 & 0.97 \\
Field & 2 & 6487423.79 & 3243711.90 & 18.07 & $<.0001^{* *}$ \\
Date & 2 & 87147041.21 & 43573520.61 & 242.79 & $<.0001^{* *}$ \\
Treatment*Date & 2 & 920043.34 & 460021.67 & 2.56 & $0.079 * *$ \\
$* * \mathrm{P}<0.10$. & & & & &
\end{tabular}

Table 27C. Penetration resistance $(16-20 \mathrm{~cm})$ LSD means comparison for date.

\begin{tabular}{cc}
\hline \hline Date & Penetration resistance $(16-20 \mathrm{~cm})$ means \\
\cline { 2 - 2 } 1 (August 2011) & $\mathrm{kPa}$ \\
2 (April 2012) & $1523^{\mathrm{c}}$ \\
3 (August 2012) & $1685^{\mathrm{b}}$ \\
$2926^{\mathrm{a}}$
\end{tabular}

Same letters in the same columns indicate no statistically significant differences at $\mathrm{P}<0.10$

Table 28C. Dry aggregate stability (MWD) LSD mean comparison for block/field at Date 3.

Block/Field

\begin{tabular}{lc} 
& $\mathrm{mm}$ \\
\cline { 2 - 3 } 3 & $18.98^{\mathrm{ab}}$ \\
3 & $21.84^{\mathrm{a}}$ \\
\cline { 2 - 3 } & $18.68^{\mathrm{b}}$
\end{tabular}

Same letters in the same columns indicate no statistically significant differences at $\mathrm{P}<0.10$

Table 29C. Analysis of variance table for dry aggregate size (MWD).

\begin{tabular}{lccccc}
\hline \hline Source & df & Sum of Squares & Mean Square & F Value & $\operatorname{Pr}>\mathrm{F}$ \\
\hline Treatment & 1 & 32.66 & 32.66 & 0.57 & 0.45 \\
Field & 2 & 349.55 & 174.78 & 3.03 & $0.05^{* *}$ \\
Date & 2 & 8765.66 & 4382.83 & 76.07 & $<.0001^{* *}$ \\
Treatment*Date & 2 & 102.35 & 51.17 & 0.89 & 0.41 \\
$* * \mathrm{P}<0.10$. & & & & &
\end{tabular}


Table 30C. Dry aggregate stability (MWD) LSD means comparison for date.

Date

Difference between dry aggregate (MWD) means

1 (August 2011)

$\mathrm{mm}$

2 (April 2012)

$21.8^{\mathrm{b}}$

3 (August 2012)

$31.3^{\mathrm{a}}$

$19.9^{\mathrm{b}}$

Same letters in the same columns indicate no statistically significant differences at $\mathrm{P}<0.10$.

Table 31C. Analysis of variance table for wet aggregate stability (MWD).

\begin{tabular}{lccccc}
\hline \hline Source & df & Sum of Squares & Mean Square & F Value & Pr > F \\
\hline Treatment & 1 & 0.26 & 0.26 & 1.53 & 0.22 \\
Field & 2 & 0.27 & 0.14 & 0.8 & 0.45 \\
Date & 2 & 0.23 & 0.11 & 0.66 & 0.52 \\
Treatment*Date & 2 & 0.38 & 0.19 & 1.12 & 0.33
\end{tabular}




\section{APPENDIX D \\ Experiment 1: Dry aggregate stability (GMD) analysis (not included in the main text)}

Table 1D. Analysis of variance table for dry aggregate diameter (GMD) at Date 1.

\begin{tabular}{lccccc}
\hline \hline Source & df & Sum of Squares & Mean Square & F & Pr $>$ F \\
\hline Treatments (Single/Mixed) & 1 & 0.25 & 0.25 & 1.25 & 0.27 \\
Blocks/Fields & 2 & 0.88 & 0.44 & 2.22 & 0.12 \\
Residual & 2 & 14.15 & 0.20 & & \\
\hline Total & 5 & 15.23 & & &
\end{tabular}

$* * \mathrm{P}<0.1$.

The analysis of variance for dry aggregate stability (GMD) for Date 1 was presented in table 1D.

At Date 1, no significant effect on dry aggregate GMD size was observed due to grazing treatments. The analysis of variance for GMD taken at Date 1 did not indicate significant block/field effect on the measured values. At Date 1, the overall average GMD was higher for the single species grazing $(2.7 \mathrm{~mm})$ than the mixed species grazing $(2.6 \mathrm{~mm})$ (Table 50 in main text). Although not statistically significant, this observation did not agree with the study's hypothesis: the single species grazing system will have a higher environmental impact than the mixed species grazing system.

Table 2D. Analysis of variance table for dry aggregate diameter (GMD) at Date 2.

\begin{tabular}{lccccc}
\hline \hline Source & df & Sum of Squares & Mean Square & F & Pr $>$ F \\
\hline Treatments (Single/Mixed) & 1 & 0.03 & 0.03 & 0.08 & 0.78 \\
Blocks/Fields & 2 & 2.11 & 1.06 & 2.75 & $0.07 * *$ \\
Residual & 2 & 45.32 & 0.38 & & \\
\hline Total & 5 & 47.48 & & & \\
$* * \mathrm{P}<0.10$. & & & & &
\end{tabular}

The analysis of variance for dry aggregate stability (GMD) for Date 2 was presented in table 2D.

At Date 2, no significant effect on dry aggregate GMD size was observed due to grazing treatments. The analysis of variance for GMD taken at Date 2 indicated a significant block/field 
effect on the measured values (Table 2D, Table 3D). In samples taken during Date 2, no difference was observed in average dry aggregate stability (GMD) between the mixed species $(3.2 \mathrm{~mm})$ and single species grazing treatments $(3.2 \mathrm{~mm})$ (Table 50 in main text). This observation did not support the study's hypothesis: the single species grazing system will have a higher environmental impact than the mixed species grazing system.

Table 3D. Dry aggregate (GMD) LSD mean comparison for block/field at Date 1 .

\section{Block/Field Dry aggregate (GMD) Means}

\begin{tabular}{cc} 
& $\mathrm{mm}$ \\
\cline { 2 - 3 } & $2.69^{\mathrm{ab}}$ \\
2 & $2.76^{\mathrm{a}}$ \\
3 & $2.50^{\mathrm{b}}$
\end{tabular}

Same letters in the same columns indicate no statistically significant differences at $\mathrm{P}<0.10$.

Table 4D. Analysis of variance table for dry aggregate diameter (GMD) at Date 3.

\begin{tabular}{lccccc}
\hline \hline Source & df & Sum of Squares & Mean Square & $\mathrm{F}$ & $\mathrm{Pr}>\mathrm{F}$ \\
\hline Treatments (Single/Mixed) & 1 & $9.1 \times 10-4$ & $9.1 \times 10-4$ & 0.01 & 0.94 \\
Blocks/Fields & 2 & 1.37 & 0.68 & 4.34 & $0.02^{* *}$ \\
Residual & 2 & 18.60 & 0.16 & & \\
\hline Total & 5 & 19.98 & & &
\end{tabular}

$* * \mathrm{P}<0.10$.

The analysis of variance for dry aggregate stability (GMD) for Date 3 was presented in table 4D.

At Date 3, no significant effect on dry aggregate GMD size was observed due to grazing treatments. The analysis of variance for GMD taken at Date 3 indicated a significant block/field effect on the measured values (Table 4D, Table 5D). In samples taken during Date 3, no difference was observed in average dry aggregate stability (GMD) between the mixed species $(2.5 \mathrm{~mm})$ and single species grazing treatments $(2.5 \mathrm{~mm})$ (Table 50 in main text). This observation did not agree with the study's hypothesis: the single species grazing system will have a higher environmental impact than the mixed species grazing system. 
Table 5D. Dry aggregate (GMD) LSD mean comparison for Block/Field at Date 3.

\begin{tabular}{cc} 
Block/Field & Dry aggregate $(\mathrm{GM}$ \\
& $\mathrm{mm}$ \\
\cline { 2 - 2 } & $2.50^{\mathrm{ab}}$ \\
2 & $2.64^{\mathrm{a}}$ \\
3 & $2.38^{\mathrm{b}}$
\end{tabular}

Effect of sampling date on dry aggregate size (GMD) was evaluated. A randomized complete block with two factors, grazing treatment and sampling date, and three replications was used to analyze the dry aggregate stability data between sampling dates (Table 6D). The analysis of variance indicated significant differences in dry aggregate size between sampling dates, but no differences due to grazing treatments; the interactions sampling date by treatment was not significant indicating that grazing treatment did not explain the variability of dry aggregate size (Table 6D).

Table 6D. Analysis of variance table for dry aggregate size (GMD).

\begin{tabular}{lccccc}
\hline \hline Source & df & Sum of Squares & Mean Square & F Value & $\operatorname{Pr}>\mathrm{F}$ \\
\hline Treatment & 1 & 0.04 & 0.04 & 0.15 & 0.69 \\
Field & 2 & 3.66 & 1.83 & 7.23 & $0.0009^{* *}$ \\
Date & 2 & 32.84 & 16.42 & 64.84 & $<.0001^{* *}$ \\
Treatment*Date & 2 & 0.28 & 0.14 & 0.56 & 0.57 \\
$* * \mathrm{P}<0.10$. & & & & &
\end{tabular}




\section{APPENDIX E}

\section{Experiment 1:Wet aggregate stability (GMD) analysis (not included in the main text)}

Table 1E. ANOVA table for wet aggregate diameter (GMD) at Date 1.

\begin{tabular}{lccccc}
\hline \hline Source & df & Sum of Squares & Mean Square & $\mathrm{F}$ & $\operatorname{Pr}>\mathrm{F}$ \\
\hline Among Treatments (Single/Mixed) & 1 & 0.05 & 0.05 & 2.51 & 0.12 \\
Among Blocks (Fields 1,2,3) & 2 & 0.12 & 0.06 & 2.84 & $0.07 * *$ \\
Residual & 2 & 1.00 & 0.02 & & \\
\hline Total & 5 & 1.16 & & & \\
$* * \mathrm{P}<0.1$. & & & & &
\end{tabular}

The analysis of variance for wet aggregate stability (GMD) for Date 1 was presented in table 1E.

At Date 1, no significant effect on wet aggregate GMD size was observed due to grazing treatments. The analysis of variance for GMD taken at Date 1 indicated a significant block/field effect on the measured values (Table 1E, Table 2E). At Date 1, the overall average wet GMD was slightly higher for the mixed species grazing $(2.11 \mathrm{~mm})$ than the single species grazing $(2.09$ $\mathrm{mm}$ ) (Table 50 in main text). Although not statistically significant, this observation agreed with the study's hypothesis: the single species grazing system will have a higher environmental impact than the mixed species grazing system.

Table 2E. Wet aggregate (GMD) LSD mean comparison for Block/Field at Date 1.

\begin{tabular}{cc} 
Block/Field & Wet aggregate $(\mathrm{GMD}$ \\
& $\mathrm{mm}$ \\
\cline { 2 - 3 } 2 & $2.16^{\mathrm{a}}$ \\
2 & $2.06^{\mathrm{b}}$ \\
3 & $2.07^{\mathrm{b}}$
\end{tabular}

Table 3E. Analysis of variance table for wet aggregate diameter (GMD) at Date 2.

\begin{tabular}{lllllll}
\hline \hline Source & df & Sum of Squares & Mean Square & F & Pr $>$ F \\
\hline
\end{tabular}




\begin{tabular}{llllll} 
Among Treatments (Single/Mixed) & 1 & 0.01 & 0.01 & 0.58 & 0.45 \\
Among Blocks (Fields 1,2,3) & 2 & 0.07 & 0.04 & 1.56 & 0.22 \\
Residual & 2 & 2.59 & 0.02 & & \\
\hline Total & 5 & 2.67 & & &
\end{tabular}
$* * \mathrm{P}<0.1$.

The analysis of variance for wet aggregate stability (GMD) for Date 2 was presented in table 3E.

At Date 2, no significant effect on wet aggregate GMD size was observed due to grazing treatments. The analysis of variance for GMD taken at Date 2 did not indicate significant block/field effect on the measured values. In samples taken during Date 2, no difference was observed in average wet aggregate stability (GMD) between the mixed species $(2.11 \mathrm{~mm})$ and single species grazing treatments $(2.09 \mathrm{~mm})$ (Table 50 in main text). This observation did not agree with the study's hypothesis: the single species grazing system will have a higher environmental impact than the mixed species grazing system.

Table 4E. Analysis of variance table for wet aggregate diameter (GMD) at Date 3.

\begin{tabular}{lccccc}
\hline \hline Source & df & Sum of Squares & Mean Square & F & Pr > F \\
\hline Treatments (Single/Mixed) & 1 & $3.3 \times 10^{-3}$ & $3.3 \times 10^{-3}$ & 0.26 & 0.61 \\
Blocks/Fields & 2 & 0.01 & 0.01 & 0.47 & 0.62 \\
Residual & 2 & 1.44 & 0.01 & & \\
\hline Total & 5 & 1.45 & & &
\end{tabular}

The analysis of variance for wet aggregate stability (GMD) for Date 3 was presented in table 4E.

At Date 3, no significant effect on wet aggregate GMD size was observed due to grazing treatments. The analysis of variance for GMD taken at Date 3 did not indicate significant block/field effect on the measured values. In samples taken during Date 3, no difference was observed in average wet aggregate stability (GMD) between the mixed species $(2.11 \mathrm{~mm})$ and single species grazing treatments $(2.12 \mathrm{~mm})$ (Table 50 in main text). This observation did not agree with the study's hypothesis: the single species grazing system will have a higher environmental impact than the mixed species grazing system. 
Table 5E. Analysis of variance Table for wet aggregate stability (GMD).

\begin{tabular}{lccccc}
\hline \hline Source & df & Sum of Squares & Mean Square & F Value & Pr $>$ F \\
\hline Treatment & 1 & 0.03 & 0.03 & 1.68 & 0.20 \\
Field & 2 & 0.02 & 0.01 & 0.41 & 0.66 \\
Date & 2 & 0.02 & 0.01 & 0.58 & 0.56 \\
Treatment*Date & 2 & 0.04 & 0.02 & 1.16 & 0.32
\end{tabular}

Effect of sampling date on wet aggregate size (GMD) was evaluated. A randomized complete block with two factors, grazing treatment and sampling date, and three replications was used to analyze the wet aggregate stability data between sampling dates (Table 5E). The analysis of variance indicated no significant differences in wet aggregate size between sampling dates, or grazing treatments; the interactions sampling date by treatment was not significant indicating that grazing treatment did not explain the variability of wet aggregate size (Table 5E). 


\section{APPENDIX F}

\section{Experiment 1: Soil Hydraulic Properties}

Table 1F. Soil Textural Classes \& Related Saturated Hydraulic Conductivity Classes (Modified from USDA, 2013)

\begin{tabular}{|c|c|c|c|c|}
\hline Texture & Textural Class & General & $\mathrm{K}_{\mathrm{sat}}$ Class & $\begin{array}{l}\mathrm{K}_{\text {sat }} \text { Rate } \\
\text { (cm/min) }\end{array}$ \\
\hline $\begin{array}{l}\text { Coarse sand } \\
\text { Sands }\end{array}$ & Coarse & Sandy & V. rapid & $>0.85$ \\
\hline $\begin{array}{l}\text { Loamy sands } \\
\text { Sandy loam }\end{array}$ & Coarse & Sandy & Rapid & $0.25-0.85$ \\
\hline $\begin{array}{l}\text { Fine sandy loam } \\
\text { Very fine sandy } \\
\text { loam } \\
\text { Loam } \\
\text { Silt loam } \\
\end{array}$ & Mod. coarse & Loamy & Mod. Rapid & $0.085-0.25$ \\
\hline $\begin{array}{l}\text { Silt } \\
\text { Clay loam } \\
\text { Sandy clay loam }\end{array}$ & Medium & Loamy & Moderate & $0.025-0.085$ \\
\hline $\begin{array}{l}\text { Silty clay loam } \\
\text { Sandy clay } \\
\text { Silty clay }\end{array}$ & Mod. fine & Loamy & Mod. slow & $0.0085-0.025$ \\
\hline Clay & $\begin{array}{c}\text { Fine and very } \\
\text { fine }\end{array}$ & Clayey & Slow & $0.0025-0.0085$ \\
\hline $\begin{array}{l}\text { Cd horizon Natric } \\
\text { ortstein }\end{array}$ & zon, fragipan, & & $\begin{array}{l}\text { Very Slow or } \\
\text { impermeable }\end{array}$ & $0.00-0.0025$ \\
\hline
\end{tabular}

Table 2F. Saturated hydraulic conductivity (single ring (standard method)) LSD mean comparison for block/field at Date 2.

\begin{tabular}{cc} 
Block/Field & Overall $\mathrm{K}_{\text {sat }}$ mean \\
\cline { 2 - 3 } 1 & $\mathrm{~cm} / \mathrm{min}$ \\
2 & $0.26^{\mathrm{b}}$ \\
3 & $1.19^{\mathrm{a}}$ \\
& $0.98^{\mathrm{a}}$
\end{tabular}

Same letters in the same columns indicate no statistically significant differences at $\mathrm{P}<0.10$.

Table 3F. Saturated hydraulic conductivity (single ring (modified method) LSD mean comparison for block/field at Date 3.

Block/Field $\quad$ Overall $\mathrm{K}_{\text {sat }}$ mean 


$\begin{array}{cc} & \mathrm{cm} / \mathrm{min} \\ 1 & 1.57^{\mathrm{b}} \\ 2 & 1.66^{\mathrm{b}} \\ 3 & 2.38^{\mathrm{a}}\end{array}$

Same letters in the same columns indicate no statistically significant differences at $\mathrm{P}<0.10$.

Table 4F. Analysis of variance table for $\mathrm{K}_{\text {sat }}$ (single ring (standard method) infiltrometer).

\begin{tabular}{lrrrrr}
\hline \hline Source & df & \multicolumn{1}{c}{ Sum of Squares } & Mean Square & F Value & \multicolumn{1}{c}{$\operatorname{Pr}>$ F } \\
\hline Treatment & 1 & $9.7 \times 10^{-5}$ & $9.7 \times 10^{-5}$ & 0.25 & 0.61 \\
Field & 2 & $1.7 \times 10^{-3}$ & $8.7 \times 10^{-4}$ & 2.26 & 0.11 \\
Date & 1 & $1.8 \times 10^{-2}$ & $1.8 \times 10^{-2}$ & 46.04 & $<.0001^{* *}$ \\
Treatment*Date & 1 & $2.0 \times 10^{-4}$ & $2.0 \times 10^{-4}$ & 0.52 & 0.47 \\
$* * \mathrm{P}<0.10$. & & & & &
\end{tabular}

Table 5F. Saturated hydraulic conductivity (single ring (standard method)) LSD mean comparison for date.

\section{Date}

Date 2 (April 2012)

Date 3 (August 2012)
Overall $\mathrm{K}_{\text {sat }}$ mean

$\mathrm{cm} / \mathrm{min}$

$0.810^{\mathrm{b}}$

$1.840^{\mathrm{a}}$ 


\section{APPENDIX G}

\section{Experiment 2: Soil Structural Properties}

Table 1G. Bulk Density LSD means comparison for enclosure (Date 3).

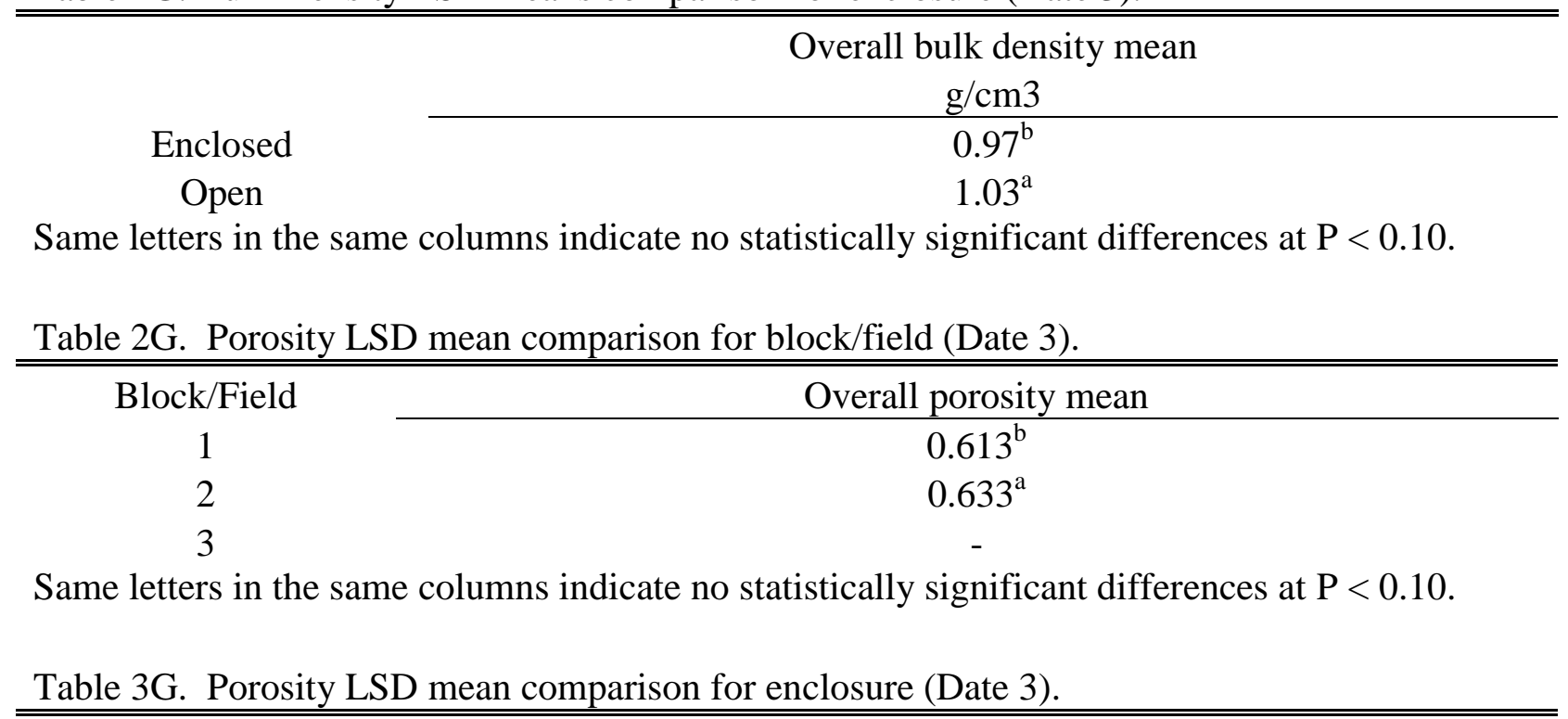

Enclosed

Open

Same letters in the same columns indicate no statistically significant differences at $\mathrm{P}<0.10$.

Table 4G. Dry aggregate stability (MWD) LSD means comparison for enclosure (Date 1).

Overall dry aggregate stability (MWD) means

Open

Closed

$\mathrm{mm}$
$19.06^{\mathrm{a}}$
$12.99^{\mathrm{b}}$




\section{APPENDIX H \\ Experiment 2: Dry aggregate stability (GMD) analysis (not included in the main text)}

Table 1H. ANOVA table for dry aggregate diameter (GMD) at Date 1.

\begin{tabular}{lccccc}
\hline \hline Source & df & Sum of Squares & Mean Square & $\mathrm{F}$ & $\operatorname{Pr}>\mathrm{F}$ \\
\hline Treatment & 1 & $7.0 \times 10^{-3}$ & $7.0 \times 10^{-3}$ & 0.11 & 0.76 \\
Field & 2 & $4.1 \times 10^{-2}$ & $2.0 \times 10^{-2}$ & 0.32 & 0.74 \\
Treatment*Field & 2 & $7.7 \times 10^{-2}$ & $3.8 \times 10^{-2}$ & 0.6 & 0.59 \\
Enclosure & 1 & $3.0 \times 10^{-1}$ & $3.0 \times 10^{-1}$ & 4.68 & $0.10^{* *}$ \\
Treatment*Enclosure & 1 & $8.0 \times 10^{-3}$ & $8.0 \times 10^{-3}$ & 0.13 & 0.74
\end{tabular}

$* * \mathrm{P}<0.10$.

The analysis of variance for dry aggregate stability (GMD) for Date 1 was presented in table $1 \mathrm{H}$.

In the split-plot analysis, no significant effect of treatment on GMD was observed on Date 1.

However the single species grazing $(2.33 \pm 0.29 \mathrm{~mm})$ exhibited slightly larger dry aggregate size

than the mixed species grazing $(2.28 \pm 0.23 \mathrm{~mm})$ (Table 60 in main text). Although not

statistically significant, the dry aggregate stability data taken at Date 1 for the erosion plots did

not support the study's hypothesis: the single species grazing system will have a higher

environmental impact than the mixed species grazing.

The split-plot ANOVA of dry aggregate (GMD) size for Date 1 indicated no significant effect of field on the measured values. A significant effect of enclosure on dry aggregate stability was observed on Date 1. The open erosion plots $(2.46 \pm 0.22 \mathrm{~mm})$ exhibited significantly larger dry aggregate sizes than the closed erosion plots $(2.15 \pm 0.17 \mathrm{~mm})$ at Date 1 (Table 60 in main text). This observation did not support the study's hypothesis: the open erosion plots will exhibit signs of a higher environmental impact than closed erosion plots. However, this could be a sign of soil compaction due to animal presence. 
At Date 1, the interaction of field by treatment was not significant indicating that grazing treatment did not explain the variability of dry aggregate (GMD) size found between fields. The interaction of enclosure by treatment was not significant indicating that grazing treatment did not explain the variability of dry aggregate (GMD) size found between enclosures.

Table 2H. ANOVA table for dry aggregate diameter (GMD) at Date 3.

\begin{tabular}{lccccc}
\hline \hline Source & df & Sum of Squares & Mean Square & F & $\operatorname{Pr}>\mathrm{F}$ \\
\hline Treatment & 1 & 0.02 & 0.02 & 1.84 & 0.31 \\
Field & 1 & 0.76 & 0.76 & 85.72 & $0.01 * *$ \\
Treatment*Field & 1 & 0.05 & 0.05 & 5.8 & 0.14 \\
Enclosure & 1 & 0.21 & 0.21 & 23.94 & $0.04 * *$ \\
Treatment*Enclosure & 1 & 0.002 & 0.002 & 0.2 & 0.70 \\
$* * \mathrm{P}<0.10$ & & & & &
\end{tabular}

The analysis of variance for dry aggregate stability (GMD) for Date 1 was presented in table\#\#. In the split-plot analysis, no significant effect of treatment on GMD was observed on Date 3. However the single species grazing $(2.13 \pm 0.33 \mathrm{~mm})$ exhibited slightly smaller dry aggregate size than the mixed species grazing $(2.22 \pm 0.48 \mathrm{~mm})$. Although not statistically significant, the dry aggregate stability data taken at Date 3 for the erosion plots did not support the study's hypothesis: the single species grazing system will have a higher environmental impact than the mixed species grazing.

The split-plot ANOVA of dry aggregate (GMD) size for Date 3 indicated a significant effect of field on the measured values (Table $2 \mathrm{H}$, Table $3 \mathrm{H}$ ). Due to equipment malfunctions, samples were only obtained for the Fields 1 and 2. A significant effect of enclosure on dry aggregate stability was observed on Date 3. The open erosion plots $(2.34 \pm 0.42 \mathrm{~mm})$ exhibited significantly larger dry aggregate size than the closed erosion plots $(2.01 \pm 0.32 \mathrm{~mm})$ at Date 3 . This observation did not agree with the study's hypothesis: the open erosion plots will exhibit signs of a higher environmental impact than closed erosion plots. However, this could be a sign of soil compaction due to animal presence. 
Table 3H. Dry aggregate stability (GMD) LSD means comparison for enclosure (Date 3).

Overall dry aggregate (GMD) mean

Block/Field

1

$\mathrm{mm}$

$2.49^{\mathrm{a}}$

2

$1.87^{\mathrm{b}}$

Same letters in the same columns indicate no statistically significant differences at $\mathrm{P}<0.10$.

Table 4H. Dry aggregate stability (GMD) LSD means comparison for enclosure (Date 3).

Overall dry aggregate (GMD) mean

\begin{tabular}{cc} 
& $\mathrm{mm}$ \\
\cline { 2 - 3 } Open & $2.34^{\mathrm{a}}$ \\
Closed & $2.02^{\mathrm{b}}$
\end{tabular}

Same letters in the same columns indicate no statistically significant differences at $\mathrm{P}<0.10$. 


\section{APPENDIX I \\ Experiment 2: Wet aggregate stability (GMD) analysis (not included in the main text)}

Table 1I. ANOVA table for wet aggregate diameter (GMD) at Date 1.

\begin{tabular}{lccccc}
\hline \hline Source & df & Sum of Squares & Mean Square & F & Pr $>$ F \\
\hline Treatment & 1 & 0.06 & 0.06 & 2.74 & 0.17 \\
Field & 2 & 0.14 & 0.07 & 3.37 & 0.14 \\
Treatment*Field & 2 & 0.28 & 0.14 & 6.52 & $0.06^{* *}$ \\
Enclosure & 1 & 0.10 & 0.10 & 4.87 & $0.09^{* *}$ \\
Treatment*Enclosure & 1 & 0.18 & 0.18 & 8.50 & $0.04^{* *}$
\end{tabular}

** $\mathrm{P}<0.10$.

The analysis of variance for wet aggregate stability (GMD) for Date 1 was presented in table 1I.

In the split-plot analysis, no significant effect of treatment on GMD was observed on Date 1.

However the single species grazing $(1.75 \pm 0.37 \mathrm{~mm})$ exhibited slightly larger wet aggregate size

than the mixed species grazing $(1.61 \pm 0.15 \mathrm{~mm})$ (Table 60 in main text). Although not

statistically significant, the wet aggregate stability data taken at Date 1 for the erosion plots did

not support the study's hypothesis: the single species grazing system will have a higher

environmental impact than the mixed species grazing.

The split-plot ANOVA of wet aggregate (GMD) size for Date 1 indicated no significant effect of field on the measured values. A significant effect of enclosure on wet aggregate stability was observed on Date 1 . The open erosion plots $(1.58 \pm 0.18 \mathrm{~mm})$ exhibited significantly smaller wet aggregate sizes than the closed erosion plots $(1.77 \pm 0.34 \mathrm{~mm})$ at Date 1 (Table 60 in main text). This observation supported the study's hypothesis: the open erosion plots will exhibit signs of a higher environmental impact than closed erosion plots. The interaction of enclosure by treatment was significant indicating that grazing treatment explained the variability of wet aggregate 
(GMD) size found between enclosures. Wet aggregate stability was only determined on Date 1 around the erosion plots due to insufficient samples on Date 3. 